Chemical Technology Division Chemical Technology Division Chemical Technology Division

\section{Yucca Mountain Project - Argonne National Laboratory Annual Progress Report, FY 1994}

by J. K. Bates, J. A. Fortner. P. A. Finn. D. J. Wronkiewicz, J. C. Hoh, J. W. Emery. E. C. Buck, and S. F. Wolf 
Argonne National Laboratory, with facilities in the states of Illinois and Idaho, is owned by the United States government, and operated by The University of Chicago under the provisions of a contract with the Department of Energy.

\section{DISCLAIMER}

This report was prepared as an account of work sponsored by an agency of the United States Government. Neither the United States Government nor any agency thereof, nor any of their employees, makes any warranty, express or implied, or assumes any legal liability or responsibility for the accuracy, completeness, or usefulness of any information, apparatus, product. or process disclosed, or represents that its use would not infringe privately owned rights. Reference herein to any specific commercial product, process, or service by trade name, trademark, manufacturer, or otherwise, does not necessarily constitute or imply its endorsement, recommendation, or favoring by the United States Government or any agency thereof. The views and opinions of authors expressed herein do not necessarily state or reflect those of the United States Government or any agency thereof.

Reproduced from the best available copy.

Available to DOE and DOE contractors from the

Office of Scientific and Technical Information

P.O. Box 62

Oak Ridge, TN 37831

Prices available from (615) $576-8401$

Available to the public from the

National Technical Information Service

U.S. Department of Commerce

5285 Port Ro,yal Road

Springfield, VA 22161 
Distribution Category:

High-Level Radioactive Waste Disposal in Tuff (UC-814)

ANL-94/42

\section{ARGONNE NATIONAL LABORATORY \\ 9700 South Cass Avenue \\ Argonne, Illinois 60439}

\section{YUCCA MOUNTAIN PROJECT - ARGONNE NATIONAL LABORATORY, ANNUAL PROGRESS REPORT, FY 1994 \\ by}

J. K. Bates, J. A. Fortner, P. A. Finn, D. J. Wronkiewicz, J. C. Hoh, J. W. Emery, E. C. Buck, and S. F. Wolf

Chemical Technology Division

February 1995 


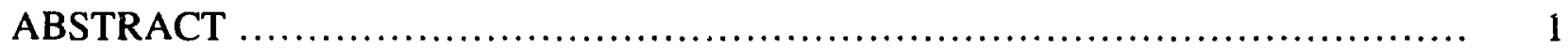

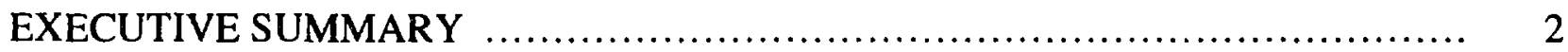

I. INTRODUCTION .................................................... 4

II. UNSATURATED TESTS WITH GLASS ................................. 5

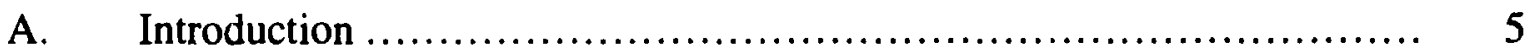

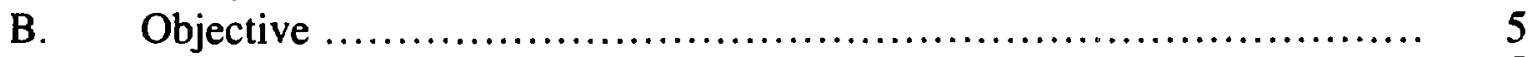

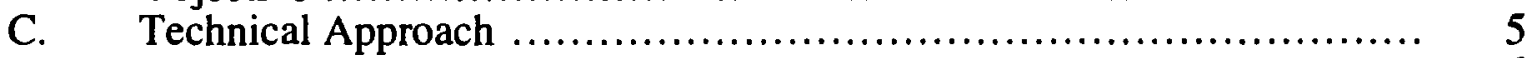

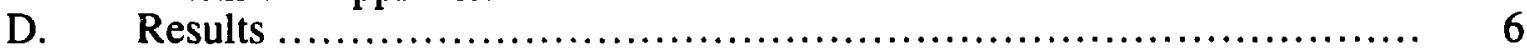

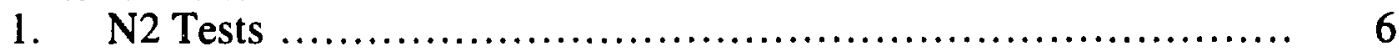

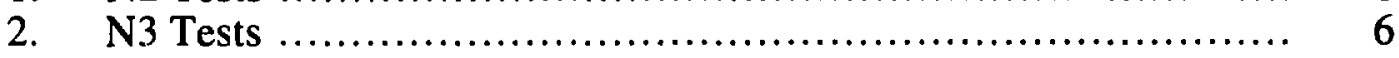

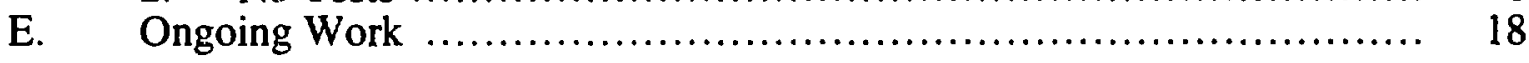

III. UNSATURATED TESTS WITH IRRADIATED SPENT FUEL ............. 20

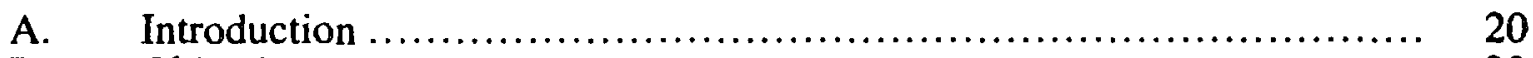

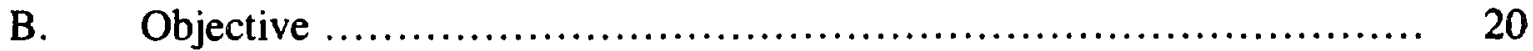

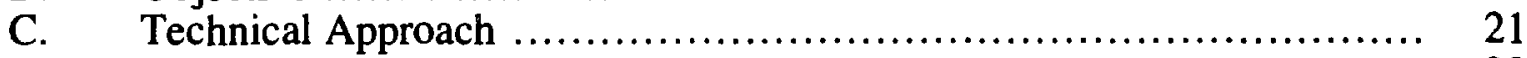

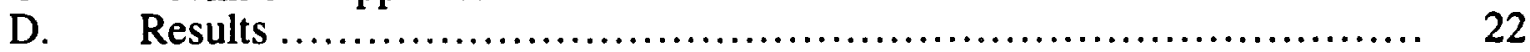

1. Solution Chemistry ......................................... 22

2. Radionuclide Release Rates for High Drip-Rate Tests ............. 22

3. Colloidal Composition ...................................... 25

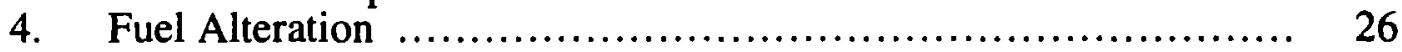

5. Low Drip-Rate and Vapor Tests ............................. 26

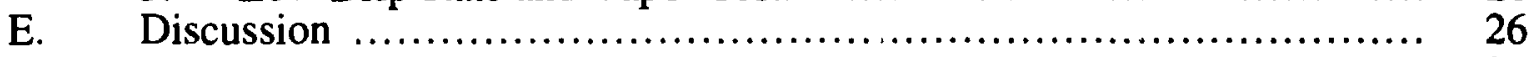

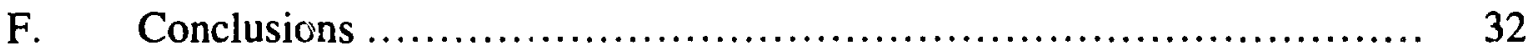

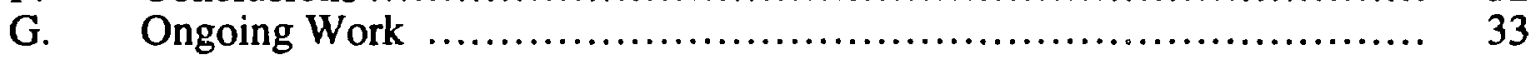

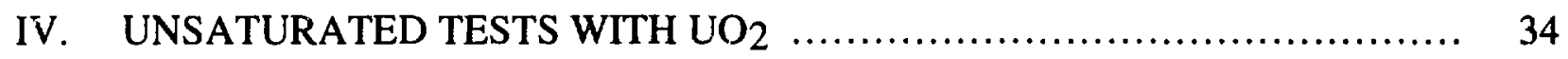

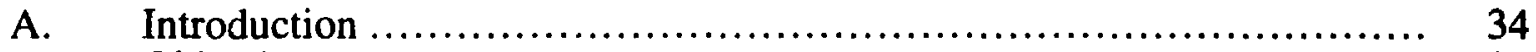

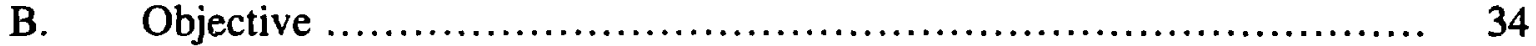

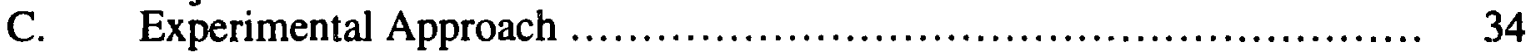

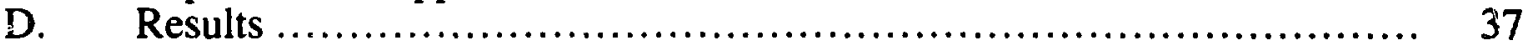

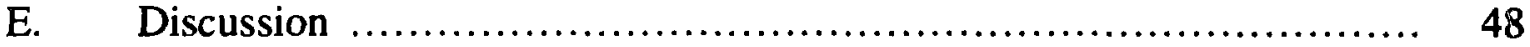

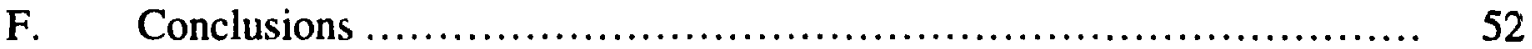

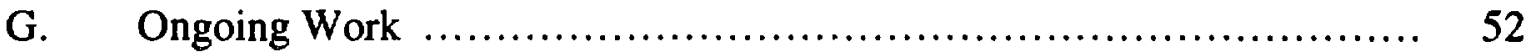

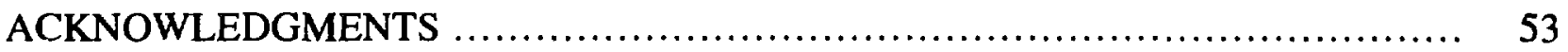

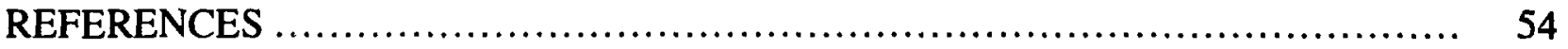




\section{LIST OF FIGURES}

No.

Title

Page

1. Cumulative Mass Release of Lithium, Boron, Magnesium, Manganese,

and Uranium frem the N3 Test Series through 340 Weeks

2. Cumulative Mass Release for Neptunium, Plutonium, and

Americium from the N3 Test Series

3. Cumulative Mass in Solution of Sodium, Silicon, Potassium, and

Calcium from the N3 Test Series through 340 Weeks

4. Cumulative Mass Release of Sodium, Silicon, Potassium, and

Calcium from the N3 Test Series, Corrected for EJ-13 Injection

Contributions, through 340 Weeks

5. Cumulative Mass in Solution of Iron and Nickel from the

N3 Test Series through 3,40 Weeks

6. Solution $\mathrm{pH}$ in $\mathrm{N} 3$ Test versus Time

7. EDS Spectra from Analytical Transmission Electron Microscopy

Study of N3 Series Colloids

8. Visual Appearance of ATM-106 Fuel in High Drip-Rate Test at

271 Days, 482 Days, and 581 Days

9. Visual Appearance of ATM-106 Trefoil at 581 Days

10. Visual Appearance of Zircaloy Filter from High Drip-Rate Test with ATM-106 Sample at 271 Days

11. Results from Analysis of ATM-106 after 581 Days of Testing

12. Schematic Diagram of Experimental Assembly Showing

Three-Pellet Sample Configuration

13. Cumulative Uranium Release in Milligrams as Measured after a

Ten-Minute Acid Strip of the Test Vessel Plus Contained Fluids

14. Fractional Release of Uranium for Eight- And Nine-Year Solutions from Test Number PMP8U-3

15. Suspended Fraction in Solution from Unsaturated Tests with $\mathrm{UO}_{2}$ after Eight Years

16. Leachate Concentrations Normalized to the Concentration of the Starting EJ-13 Leachant in Unsaturated Tests with $\mathrm{UO}_{2}$ Samples 


\section{LIST OF FIGURES (contd.)}

No.

$\underline{\text { Title }}$

Page

17. SEM Photomicrographs for the Top Surface of $\mathrm{UO}_{2}$ Pellet after Eight Years of Reaction

18. SEM Photomicrographs for the Bottom Surface of $\mathrm{UO}_{2}$ Pellet after Eight Years of Reaction 50

19. Paragenetic Sequence for Uranyl Minerals Formed under Oxidizing Conditions 


\section{LIST OF TABLES}

No.

Title

Page

1. SRL 165 Glass Composition Used in the N2 Test Series ..................... 6

2. ATM-10 Glass Composition Used in the N3 Test Series .................... 7

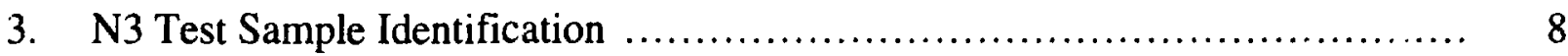

4. Release Rates for Selected Elements from the N3 Series through 340 Weeks

5. Strontium, Technetium, and Thorium in Solution after 174.5-Week Interval

6. Experimental Matrix for Spent Fuel Tests at $90^{\circ} \mathrm{C}$

7. Carbon Content and pH Results for Spent Fuel Leachate at $\sim 581$ Days .......... 22

8. Transuranic and Cesium Measured in High Drip-Rate Tests at 581 Days

9. Maximum Nuclide Fraction at Successive Time Intervals for High Drip-Rate Tests

10. Actinides in Leachate and Material on Filters Determined by Alpha Spectroscopy

11. Distribution of Cesium and Transuranics in Low Drip-Rate and Vapor Tests after $\sim 581$ Days

12. Average Unprecipitated Fractions for Unsaturated High DripRate versus Saturated Tests

13. Maximum Fraction for Unsaturated High Drip-Rate versus Saturated Tests

14. Total Uranium Release in Unsaturated Tests with $\mathrm{UO}_{2}$ Samples

15. Results for Eight Unsaturated Tests with $\mathrm{UO}_{2}$ Samples

16. Normalized Release Rate for $\mathrm{UO}_{2}$ Samples in Unsaturated Tests 


\title{
YUCCA MOUNTAIN PROJECT - ARGONNE NATIONAL LABORATORY, ANNUAL PROGRESS REPORT, FY 1994
}

\author{
J. K. Bates, J. A. Fortner, P. A. Finn, D. J. Wronkiewicz, \\ J. C. Hoh, J. W. Emery, E. C. Buck, and S. F. Wolf
}

\begin{abstract}
This document reports on the work done by the Nuclear Waste Management Section of the Chemical Technology Division (CMT), Argonne National Laboratory, in the period October 1993-September 1994. Studies have been performed to evaluate the performance of nuclear waste glass and spent fuel samples under unsaturated conditions (low volume water contact) that are likely to exist in the Yucca Mountain environment being considered as a potential site for a high-level waste repository. Tests with simulated waste glasses have been in progress for over eight years and demonstrate that actinides from initially fresh glass surfaces will be released as a result of the spallation of reacted glass layers from the surface, as the small volume of water passes over the waste form. The glass reaction appears to follow nearly linear reaction kinetics for the time period of testing and does not exhibit the decrease that is commonly observed during the intermediate stage of reaction in tests done with large volumes of water.

Studies are also underway to evaluate the performance of spent fuel samples and unirradiated $\mathrm{UO}_{2}$ in projecred repository conditions. Tests with $\mathrm{UO}_{2}$ have been ongoing for nine years and show that the oxidation of $\mathrm{UO}_{2}$ occurs rapidly, and the resulting paragenetic sequence of secondary phases that form on the sample surface is similar to that observed in natural analogues. The reaction of spent fuel samples under conditions similar to those used with $\mathrm{UO}_{2}$ have been in progress for nearly two years, and the results suggest that spent fuel follows the same reaction progress as $\mathrm{UO}_{2}$. The release of individual fission products and transuranic elements was not congruent, with the release being controlled by the formation of small particles or colloids that are suspended in solution and transported away from the waste form. The reaction progress depends on the composition of the spent fuel samples used and, likely, on the composition of the groundwater that contacts the waste form.
\end{abstract}




\section{EXECUTIVE SUMMARY}

The volcanic tuff beds at Yucca Mountain, Nevada, are being studicd as a potential site for the U.S. high-level nuclear waste repository. The potential site at Yucca Mountain lies severa! hundred meters above the local water table in a hydrologically unsaturated zone. Because only water vapor or small volumes of liquid water in the repository horizon are expected to contact the waste forms, we have designed test methods which represent the expected repository environment. We are using these methods to study the waste/repository interactions that may occur and to project the long-term behavior of emplaced waste (glass and spent fuel).

These tests are being performed to provide realistic bounding release input for performance assessment studies and model validation. It is often assumed that waste forms will react most rapidly when contacted with large volumes of water. However, our tests with low volumes of water resulted in more rapid alteration of the waste forms and a non-solubility-limited release of radionuclides from the waste form. That is, the reaction of waste under conditions of low volume water contact rapidly saturates the solution with released elements, accelerates secondary mineral phase formation, and results in a distribution of radionuclides in solution that is completely different from that observed in tests with large volumes of water. Long-term tests are underway with transuranic-doped glasses, spent fuel samples, and unirradiated $\mathrm{UO}_{2}$.

Tests are being performed with transuranic-doped glasses that represent versions of reference compositions which may be produced at the Defense Waste Processing Facility (DWPF) and the West Valley Demonstration Project (WVDP). The tests are being conducted with dripping $J-13$ groundwater that has been equilibrated with tuff at $90^{\circ} \mathrm{C}(\mathrm{EJ}-13$ water). This water is altered from the composition of $J-13$ water to provide a potentially more realistic reaction condition. These tests are being conducted with as-cast glass at $90^{\circ} \mathrm{C}$ and have been ongoing for periods of up to eight years.

The results with both DWPF and WVDP glasses are similar in that the reaction as measured ny the release of the soluble components of the glass (e.g., B, Li) is nearly linear as a function of time, but the release of individual elements differs depending on the reaction mechanism that controls the glass reaction and the formation of secondary reaction products. For both glasses, the release of transuranic elements is controlled by the rate at which the reacted layer that is formed by glass/water contact is rinsed away from the glass and spalls into solution. This spalled reaction layer retains the majority of transuranic elements, remains suspended in solution, and thus forms a means by which actinide elements can be transported through the engineered barrier system. For DWPF glass, the reacted layer is composed mainly of a smectite-type clay, which retains the transuranic elements, while the layer for the WVDP glass is made up of the mineral brockite surrounded by clay. The brockite forms very early in the reaction sequence and incorporates Am and $\mathrm{Pu}$ into its structure. The brockite is found both in the test solution as suspended particles or colloids and the reacted layer itself. Portions of the reacted layer are also found in solution.

Additional tests must be performed on prehydrated glass, or glass that has been exposed to water vapor prior to liquid water contact, so that the radionuclide release rate can be fully bounded. Additionally, the rate at which the glass reacts when exposed to water vapor must be determined as a function of glass composition, time, and temperature. This information is necessary to predict the extent of prehydration that will occur before liquid water contact. Preliminary assessments of glass reaction when compared to spent fuel have shown that the release from glass may be a significant contributor to the overall release of radionuclides from the engineered barrier system. Thorough knowledge of the reaction of glass under realistic conditions is essential to further refine this comparison and improve on the performance assessment calculations. 
Long-term tests at $90^{\circ} \mathrm{C}$ are also unclerway with EJ-13 well water and two types of spent fuel, ATM-103 and ATM-106. In tests up to 581 days, both the leachate and the physical appearance of the spent fuel have been visibly characterized. Colloids formed during spent fuel dissolution were characterized by analyzing the leachate. The major colloid phases present appear similar to the secondary phases that form on the spent fuel itself. These pnases are rich in fission products and transuranic elements and include schoepite and soddyite. Also, a smectite clay was found in severai of the tests.

The amount of Am and $\mathrm{Cm}$ released tivin the two fuels was one to two orders of magnitude greater than that released from spent fuel under saturated conditions. The cause of the difference in behavior has not been identified. However, it could be due to the presence of large amounts of colloids which contained actinides in the leachate of the unsaturated tests.

While spent fuel tests have been underway for a relatively short time, it is apparent that under conditions of low-volume water contact, such as will occur under unsaturated conditions, spent fuel undergoes alteration in a manner where the entire reaction process is accelerated compared to that observed under saturated conditions. That is, the conversion of the $\mathrm{UO}_{2}$ matrix to oxidized secondary phases occurs instantly in terms of repository time frames. This results in the individual fission products and actinide elements being released noncongruently, with release of most radionuclides being controlled by the formation of particulates in solution. These particulates may be colloidal analogues of the phases identified on the Zircaloy retainer or partially dissolved grains of spent fuel itself. The results also indicate that the spent fuel reaction and radionuclide release depend on the spent fuel type or composition. This suggests that developing an acceptable bounding release scenario by testing only a few fuel types may not be possible. Furthermore, extrapolation from the reaction progress time line indicates that the fuel reaction will be very dependent on the groundwater composition. As the fuel oxidizes, it transforms into secondary phases that depend on the cation content of the groundwater. It is possible that groundwaters more concentrated in specific cations (e.g., Si, Na, K) may promote the formation of secondary phases and accelerate the reaction of spent fuel. Finally, the rate at which the fuel oxidizes in the presence of small volumes of water and air is so rapid that prior oxidation of the fuel during storage in unlikely to affect total radionuclide release; however, dry oxidation that results in cladding rupture would expose a greater surface area of fuel to reaction. However if no credit can be given to the cladding as a barrier, even this prior oxidation becomes less important.

In addition to spent fuel studies, drip tests with $\mathrm{UO}_{2}$ pellets (nonirradiated) and EJ-13 well water have been ongoing for 7.5 to 8.8 years. Results from these tests show that oxidation $c$ : $\mathrm{UO}_{2}$ occurs rapidly and suggest that the sequence of altered phases (e.g., schoepite and soddyite) that form on the pellets is similar to that observed in natural analogues. This finding suggests that tests with low volume of water accurately simulate reaction processes that occur in nature and provide information essential for evaluating the performance of an unsaturated repository. 


\section{INTRODUCTION}

Ash-flow tuff beds at Yucca Mountain, Nevada, are currently being investigated as a potential site for the permanent disposal of high-level nuclear waste. The proposed repository horizon is to be located in an unsaturated environment, approximately 200 to $400 \mathrm{~m}$ above the present-day water table. Matrix flow is expected to be the dominant water transport mechanism, with only limited amounts of water being available to corrode the waste packages and transport the available radionuclides. In the event of eventual breaching of the waste containers, the nuclear waste forms are most likely to be exposed to humid air and limited amounts of flowing water, which may contact the waste by dripping onto the waste package or through wicking of water from the geologic media to the waste form through a bridge of solid materials that may have fallen or been emplaced in the waste package bore hole.

Because only water vapor or small volumes of liquid water in the repository horizon are expected to contact the waste forms, we have designed test methods which represent the expected repository environment. We are using these methods to study the waste/repository interactions that may occur and to project the long-term behavior of emplaced waste (glass and spent fuel). These tests are being performed to provide realistic bounding release input for performance assessment studies and model validation. 


\section{UNSATURATED TESTS WITH GLASS}

\section{A. Intrcduction}

The Unsaturated Glass Testing Program was upgraded to Quality Affecting in February 1986, when tests with a Defense Waste Processing Facility (DWPF) glass (SRL 165) were begun. These tests are still ongoing and are called the "N2 tests." The tests are performed in a batch mode, where tests are terminated at specific time periods up to one year, and a continuous mode, where tests continue but the leachate is sampled at intermittent intervals. A report [1] was issued after the batch tests were completed, and sampling in the continuous test has continued. This year data were analyzed and are reported for the continuous tests.

A second set of Unsaturated Tests began in July 1987 using a West Valley Demonstration Plant (WVDP) glass (ATM-10). These tests (eight batch mode, four continuous mode) are termed the "N3 tests," and up to this year no results of these tests have been reported, other than a description of some particulates found in the test solution [2]. This year the data from the last seven years have been cornpiled and are, in part, reported below.

\section{B. Objective}

The objective of this task is to use the Unsaturated Test procedure to determine the reaction progress of glass under conditions that are likely to exist at the potential Yucca Mountain repository site. These conditions are where as-cast glass is exposed to intermittent dripping water. During the tests the leachates are monitored for the release of glass components, such as $\mathrm{B}$ and $\mathrm{Li}$, and for radionuclides. The former provides an indication of the glass reaction, and the latter provides information regarding how the transuranic elements such as $\mathrm{Np}, \mathrm{Pu}$, and $\mathrm{Am}$ are released from the glass. Also examined are the interactions between the glass and the 304L type stainless steel which makes up the retainer that hoids the glass during the test.

\section{Technical Approach}

Both the N2 and N3 tests were performed according to the NNWSI Unsaturated Test Procedure (NNWSI-05-01 1, Rev. 1, see reference [1]), as specified in the approved Test Plans. The procedure has remained unchanged, except for additional analyses that can now be performed due to imcroved techniques. These techniques were developed to analyze the small volumes of water that are generated during the test periods and include the analysis of anions and particulate or colloidal material in solution. The colloidal analysis involves determining the size fraction distribution of raoionuclides as collected on filters of varying sizes and using analytical electron microscopy ( $A E M)$ to characterize solid particulates that have been collected on a "holey" (perforated) carbon grid through which test leachate has passed. Neither of these techniques provides a full charicterization of the colloidal properties of the particulates. The sequential filtering can be used to determine size fractions during test conditions and also, if required, the identity and radionuclide content of the particles. In the N2 and N3 test series, sequential filtering has been done, but the colloids trapped on the filters have not been studied. The filters have been retained for further examination if desired.

During the first sampling periods this year for both test series, there was sufficient water for additional water/material interaction tests because the tests had not been sampled for approximately three years. This water was retained in the original test vessels until these vessels were needed for the second sampling period. At that time, the leachate was removed from the original test vessel and stored in a glass vial, and the original test vessels were acid stripped to determine the amount of cations and transuranic elements that had sorbed to the vessel walls. These results have not been completely analyzed, so the updated results reported below do nor 
fully reflect the total reaction of the glass or release of radionuclides from the glass. The data reported below are those that have been compiled to date. Emphasis has been placed on the N3 series because no data from that test series have been reported previously.

D. Results

$$
\text { 1. N2 Tests }
$$

The N2 tests are being performed with SRL 165 glass that has been doped with the transuranic elements $\mathrm{Np}, \mathrm{Pu}$, and $\mathrm{Am}$ and with Tc. The composition of this glass is given in Table 1. The N2 tests were sampled on 12/21/93 after a period of 190 weeks without sampling. The results from the N2 tests were reported at the International High-Level Radioactive Waste Management Conference held in Las Vegas, May 16-22, 1994. The N2 results up to the 12/21/93 sampling period are presented there.

The second sampling of the $\mathrm{N} 2$ tests occurred on $6 / 20 / 94$, which was a period of 26 weeks since the previous sampling. The results from the 6/20/94 sampling period are not complete, and no additional data are reported. The tests are continuing with obvious interaction between the glass and the metal retainer sections. From our earlier results, we know that this results in the formation of iron silicate particles, which are released to solution. Also, the glass reacts in a manner such that the alteration layer that forms on the glass is not firmly attached to the glass. During the minor water flow that occurs during testing, sections of the reacted layer are released from the glass and enter the solution as colloidal suspensions. This released layer retains most of the Pu and Am in the glass, and thus these elements are released from the glass as particulates suspended in solution. The properties of these particles could be determined under a range of solution conditions ( $\mathrm{pH}$, ionic strength, etc.) if the information were required.

\section{2. $\quad$ N3 Tests}

The N3 test vessels have been samp - d periodically since test initiation, with the exception of a long interval between September 19, J and January 1994 when no guidance for sampling was given. Sampling was last done on 1/12/94 and 7/14/94. The composition of the actinide-doped ATM-10 glass used in the N3 tests is given in Table 2.

Table 1. SRL 165 Glass Composition (oxide wt \%) Used in the N2 Test Series

\begin{tabular}{lclll}
\hline Element & SRL 165 Glass & & Element & SRL 165 Glass \\
\cline { 1 - 2 } & 4.08 & & $\mathrm{Sr}$ & 0.11 \\
$\mathrm{~B}$ & 6.76 & & $\mathrm{Ti}$ & 0.14 \\
$\mathrm{Ba}$ & 0.06 & & $\mathrm{Zn}$ & 0.04 \\
$\mathrm{Ca}$ & 1.62 & & $\mathrm{Zr}$ & 0.66 \\
$\mathrm{Cr}$ & $<0.01$ & & $\mathrm{U}$ & 0.92 \\
$\mathrm{Fe}$ & 11.74 & & $\mathrm{Tc}$ & 0.02 \\
$\mathrm{~K}$ & 0.19 & & $237 \mathrm{~Np}$ & -01 \\
$\mathrm{Li}$ & 4.18 & & $238 \mathrm{Pu}$ & - \\
$\mathrm{Mg}$ & 0.70 & & $239 \mathrm{Pu}$ & 0.01 \\
$\mathrm{Mn}$ & 2.79 & & $241 \mathrm{Am}$ & 0.0004 \\
$\mathrm{Na}$ & 10.85 & & $244 \mathrm{Cm}$ & - \\
$\mathrm{Ni}$ & 0.85 & & $137 \mathrm{Cs}$ & - \\
$\mathrm{Si}$ & 52.86 & & \\
\hline
\end{tabular}


Table 2. ATM-10 Glass Composition ${ }^{\mathrm{a}}$ Used in the N3 Test Series

\begin{tabular}{|c|c|c|}
\hline Oxide & Mean wt $\%$ & wt\% Std. Dev. \\
\hline $\mathrm{Al}_{2} \mathrm{O}_{3}$ & 6.65 & 0.0209 \\
\hline $\mathrm{AmO}_{2}$ & 0.0064 & 0.000073 \\
\hline $\mathrm{B}_{2} \mathrm{O}_{3}$ & 9.17 & 0.082 \\
\hline $\mathrm{BaO}$ & 0.045 & 0.00131 \\
\hline $\mathrm{CaO}$ & 0.60 & 0.0354 \\
\hline $\mathrm{CeO}_{2}$ & 0.072 & 0.00127 \\
\hline $\mathrm{Cr}_{2} \mathrm{O}_{3}$ & 0.253 & 0.0107 \\
\hline $\mathrm{CsO}_{2}$ & 0.062 & 0.0015 \\
\hline $\mathrm{Fe}_{2} \mathrm{O}_{3}$ & 11.5 & 0.2065 \\
\hline $\mathrm{K}_{2} \mathrm{O}$ & 3.34 & 0.125 \\
\hline $\mathrm{La}_{2} \mathrm{O}_{3}$ & 0.025 & 0.0020 \\
\hline $\mathrm{Li}_{2} \mathrm{O}$ & 2.88 & 0.0281 \\
\hline $\mathrm{MgO}$ & 1.15 & 0.0296 \\
\hline $\mathrm{MnO}_{2}$ & 1.29 & 0.0219 \\
\hline $\mathrm{Na}_{2} \mathrm{O}$ & 10.5 & 0.150 \\
\hline $\mathrm{Nd}_{2} \mathrm{O}_{3}$ & 0.168 & 0.0023 \\
\hline $\mathrm{NiO}$ & 0.296 & 0.0135 \\
\hline $\mathrm{NpO}_{2}$ & 0.021 & 0.00041 \\
\hline $\mathrm{P}_{2} \mathrm{O}_{5}$ & 2.34 & 0.258 \\
\hline $\mathrm{PuO}_{2}$ & 0.0081 & 0.000527 \\
\hline $\mathrm{RhO}_{2}$ & 0.012 & 0.0018 \\
\hline $\mathrm{RuO}_{2}$ & 0.061 & 0.0108 \\
\hline $\mathrm{SO}_{3}$ & 0.31 & 0.090 \\
\hline $\mathrm{SiO}_{2}$ & 45.8 & 2.391 \\
\hline $\mathrm{SrO}$ & 0.025 & 0.00096 \\
\hline $\mathrm{Tc}_{2} \mathrm{O}_{7}$ & 0.0031 & 0.000083 \\
\hline $\mathrm{ThO}_{2}$ & 3.29 & 0.0336 \\
\hline $\mathrm{TiO}_{2}$ & 0.858 & 0.0245 \\
\hline $\mathrm{UO}_{2}$ & 0.527 & 0.0171 \\
\hline $\mathrm{Y}_{2} \mathrm{O}_{3}$ & 0.017 & 0.00082 \\
\hline $\mathrm{ZrO}_{2}$ & 0.247 & 0.00513 \\
\hline Total & 101.5 & \\
\hline
\end{tabular}

aFrom Maupin et al. (Ref. 3).

The N3 series consists of 12 tests, eight of which were terminated in pairs within the first year at roughly 13-week intervals. The remaining four, N3 \#9 through N3 \#12, have been running in continuous mode. One of these, $\mathrm{N} 3 \# 11$, is a blank test containing no glass or stainless steel waste form holder. Table 3 lists the tests, along with sampling dates and solution volume information, through the July 1994 sampling.

The liquid collected with each sampling was initially analyzed for cations by inductively coupled plasma-atomic emission spectroscopy (ICP-AES). After the 1990 samplings, the more sensitive technique of inductively coupled plasma-mass spectroscopy (ICP-MS) was us $2 d$ to determine elemental concentrations in solution. The concentrations of the transuranic elements 
Table 3. N3 Test Sample Identification

\begin{tabular}{|c|c|c|c|c|c|c|}
\hline Test \# & Description & $\begin{array}{c}\text { Date } \\
\text { Started }\end{array}$ & $\begin{array}{c}\text { Date } \\
\text { Sampled }\end{array}$ & $\begin{array}{c}\text { Cumulative } \\
\text { Test Period } \\
\text { (weeks) }\end{array}$ & $\begin{array}{c}\text { EJ-13 Water } \\
\text { Injected } \\
(\mathrm{mL})\end{array}$ & $\begin{array}{c}\text { Solution } \\
\text { Recovered } \\
(\mathrm{mL})\end{array}$ \\
\hline N3 \#1 & Batch & 07/06/87 & $10 / 01 / 87$ & 12.5 & 2.38 & \\
\hline N3\#2 & Batch & $07 / 06 / 87$ & $10 / 01 / 87$ & 12.5 & 2.38 & \\
\hline N3 \#3 & Batch & $07 / 06 / 87$ & $01 / 04 / 88$ & 26 & 4.40 & 2.58 \\
\hline N3 \#4 & Batch & $07 / 06 / 87$ & $01 / 04 / 88$ & 26 & 4.40 & 3.01 \\
\hline N3 \#5 & Batch & $07 / 06 / 87$ & $04 / 04 / 88$ & 39 & 6.35 & 3.64 \\
\hline N3 \#6 & Batch & $07 / 06 / 87$ & $04 / 04 / 88$ & 39 & 6.35 & 4.19 \\
\hline N3 \#7 & Batch & $07 / 06 / 87$ & $07 / 04 / 88$ & 52 & 8.3 & 5.64 \\
\hline N3 \#8 & Batch & $07 / 06 / 87$ & $07 / 04 / 88$ & 52 & 8.3 & 5.57 \\
\hline \multirow[t]{16}{*}{ N3 \#9 } & Continuous & $07 / 06 / 87$ & $08 / 24 / 87$ & 6.5 & 1.47 & 0.66 \\
\hline & Continuous & $08 / 02 / 87$ & $10 / 01 / 87$ & 12.5 & 1.47 & 0.73 \\
\hline & Continuous & $10 / 01 / 87$ & $11 / 19 / 87$ & 19.5 & 1.47 & 1.05 \\
\hline & Continuous & $11 / 19 / 87$ & $01 / 04 / 88$ & 26 & 1.47 & 0.95 \\
\hline & Continuous & 01/04/88 & $02 / 22 / 88$ & 33 & 1.47 & 1.01 \\
\hline & Continuous & $02 / 22 / 88$ & 04/04/88 & 39 & 1.47 & 0.88 \\
\hline & Continuous & 04/04/88 & $05 / 19 / 88$ & 45.5 & 1.47 & 1.07 \\
\hline & Continuous & $05 / 19 / 88$ & 07/05/88 & 52 & 1.47 & 1.32 \\
\hline & Continuous & $07 / 05 / 88$ & $10 / 03 / 88$ & 65 & 2.45 & 1.83 \\
\hline & Continuous & $10 / 03 / 88$ & $01 / 05 / 88$ & 78.5 & 2.52 & 1.14 \\
\hline & Continuous & $01 / 05 / 88$ & $04 / 03 / 89$ & 91 & 2.38 & 0.96 \\
\hline & Continuous & $04 / 03 / 89$ & 07/06/89 & 104.5 & 2.52 & 0.99 \\
\hline & Continuous & 07/06/89 & $01 / 08 / 90$ & 131 & 4.47 & 2.59 \\
\hline & Continuous & 01/08/90 & $09 / 10 / 90$ & 166 & 5.75 & 1.58 \\
\hline & Continuous & $09 / 10 / 90$ & $01 / 12 / 94$ & 340.5 & 26.67 & 7.99 \\
\hline & Continuous & $01 / 12 / 94$ & $07 / 14 / 94$ & 366.5 & 4.4 & 0.58 \\
\hline \multirow[t]{16}{*}{ N3 \#10 } & Centinuous & $07 / 06 / 87$ & $08 / 24 / 87$ & 6.5 & 1.47 & 1.01 \\
\hline & Continuous & $08 / 02 / 87$ & $10 / 01 / 87$ & 12.5 & 1.47 & 0.72 \\
\hline & Continuous & $10 / 01 / 87$ & $11 / 19 / 87$ & 19.5 & 1.47 & 1.15 \\
\hline & Continuous & $11 / 19 / 87$ & $01 / 04 / 88$ & 26 & 1.47 & 0.95 \\
\hline & Continuous & 01/04/88 & $02 / 22 / 88$ & 33 & 1.47 & 1.14 \\
\hline & Continuous & $02 / 22 / 88$ & $04 / 04 / 88$ & 39 & 1.47 & 1.05 \\
\hline & Continuous & $6+1 / 4 / 88$ & $05 / 19 / 88$ & 45.5 & 1.47 & 0.62 \\
\hline & Continuous & $05 / 19 / 88$ & 07/05/88 & 52 & 1.47 & 0.90 \\
\hline & Continuous & 07/05/88 & $10 / 03 / 88$ & 65 & 2.45 & 1.79 \\
\hline & Continuous & $10 / 03 / 88$ & $01 / 05 / 89$ & 78.5 & 2.52 & 1.69 \\
\hline & Continuous & $01 / 05 / 88$ & $04 / 03 / 89$ & 91 & 2.38 & 1.23 \\
\hline & Continuous & 04/03/89 & 07/06/89 & 104.5 & 2.52 & 1.37 \\
\hline & Continuous & 07/06/89 & 01/08/90 & 131 & 4.47 & 3.02 \\
\hline & Continuous & 01/08/90 & $09 / 10 / 90$ & 166 & 5.75 & 4.79 \\
\hline & Continuous & $09 / 10 / 90$ & $01 / 12 / 94$ & 340.5 & 26.67 & 13.16 \\
\hline & Continuous & $01 / 12 / 94$ & $07 / 14 / 94$ & 366.5 & 4.40 & 3.01 \\
\hline
\end{tabular}


Table 3 contd.

\begin{tabular}{|c|c|c|c|c|c|c|}
\hline Test \# & Description & $\begin{array}{c}\text { Date } \\
\text { Started } \\
\end{array}$ & $\begin{array}{c}\text { Date } \\
\text { Sampled }\end{array}$ & $\begin{array}{c}\text { Cumulative } \\
\text { Test Period } \\
\text { (weeks) }\end{array}$ & $\begin{array}{c}\text { EJ-13 Water } \\
\text { Injected } \\
\text { (mL) }\end{array}$ & $\begin{array}{c}\text { Solution } \\
\text { Recovered } \\
(\mathrm{mL})\end{array}$ \\
\hline $\begin{array}{l}\text { N3 \#11 } \\
\text { (Blank) }\end{array}$ & $\begin{array}{l}\text { Continuous } \\
\text { Continuous } \\
\text { Continuous } \\
\text { Continuous } \\
\text { Continuous } \\
\text { Continuous } \\
\text { Continuous } \\
\text { Continuous } \\
\text { Continuous } \\
\text { Continuous } \\
\text { Continuous } \\
\text { Continuous } \\
\text { Continuous } \\
\text { Continuous } \\
\text { Continuous } \\
\text { Continuous } \\
\text { Continuous }\end{array}$ & $\begin{array}{l}07 / 06 / 87 \\
08 / 02 / 87 \\
10 / 01 / 87 \\
11 / 19 / 87 \\
01 / 04 / 88 \\
02 / 22 / 88 \\
04 / 04 / 88 \\
05 / 19 / 88 \\
07 / 05 / 88 \\
08 / 25 / 88 \\
10 / 03 / 88 \\
01 / 05 / 88 \\
04 / 03 / 89 \\
07 / 06 / 89 \\
01 / 08 / 90 \\
09 / 10 / 90 \\
01 / 12 / 94\end{array}$ & $\begin{array}{l}08 / 24 / 87 \\
10 / 01 / 87 \\
11 / 19 / 87 \\
01 / 04 / 88 \\
02 / 22 / 88 \\
04 / 04 / 88 \\
05 / 19 / 88 \\
07 / 05 / 88 \\
08 / 25 / 88 \\
10 / 03 / 88 \\
01 / 05 / 88 \\
04 / 03 / 89 \\
07 / 06 / 89 \\
01 / 08 / 90 \\
09 / 10 / 90 \\
01 / 13 / 94 \\
07 / 14 / 94\end{array}$ & $\begin{array}{l}6.5 \\
12.5 \\
19.5 \\
26 \\
33 \\
39 \\
45.5 \\
52 \\
59 \\
65 \\
78.5 \\
91 \\
104.5 \\
131 \\
166 \\
340.5 \\
366.5\end{array}$ & $\begin{array}{r}1.47 \\
1.47 \\
1.47 \\
1.47 \\
1.47 \\
1.47 \\
1.47 \\
1.47 \\
1.62 \\
1.32 \\
2.52 \\
2.38 \\
2.52 \\
4.47 \\
5.75 \\
26.67 \\
4.40\end{array}$ & $\begin{array}{l}1.06 \\
0.82 \\
1.09 \\
1.04 \\
1.12 \\
1.08 \\
1.09 \\
1.20 \\
1.35 \\
1.01 \\
1.71 \\
1.55 \\
1.83 \\
3.08 \\
4.31 \\
8.39 \\
1.83\end{array}$ \\
\hline N3\#12 & $\begin{array}{l}\text { Continuous } \\
\text { Continuous } \\
\text { Continuous } \\
\text { Continuous } \\
\text { Continuous } \\
\text { Continuous } \\
\text { Continuous } \\
\text { Continuous } \\
\text { Continuous } \\
\text { Continuous } \\
\text { Continuous } \\
\text { Continuous } \\
\text { Continuous } \\
\text { Continuous } \\
\text { Continuous }\end{array}$ & $\begin{array}{l}10 / 06 / 87 \\
11 / 19 / 87 \\
01 / 04 / 88 \\
02 / 22 / 88 \\
04 / 04 / 88 \\
05 / 19 / 88 \\
07 / 05 / 88 \\
08 / 25 / 88 \\
10 / 03 / 88 \\
01 / 05 / 89 \\
04 / 03 / 89 \\
07 / 06 / 89 \\
01 / 08 / 90 \\
09 / 10 / 90 \\
01 / 12 / 94\end{array}$ & $\begin{array}{l}11 / 19 / 87 \\
01 / 04 / 88 \\
02 / 22 / 88 \\
04 / 04 / 88 \\
05 / 19 / 88 \\
07 / 05 / 88 \\
08 / 25 / 88 \\
10 / 03 / 88 \\
01 / 05 / 89 \\
04 / 03 / 89 \\
07 / 06 / 89 \\
01 / 08 / 90 \\
09 / 10 / 90 \\
01 / 13 / 94 \\
07 / 14 / 94\end{array}$ & $\begin{array}{l}6.5 \\
13 \\
20 \\
26 \\
32.5 \\
39 \\
46.5 \\
52 \\
65.5 \\
78 \\
91.5 \\
118 \\
153 \\
327.5 \\
353.3\end{array}$ & $\begin{array}{r}1.47 \\
1.47 \\
1.47 \\
1.47 \\
1.47 \\
1.47 \\
1.47 \\
1.47 \\
2.52 \\
2.38 \\
2.52 \\
4.47 \\
5.75 \\
26.67 \\
4.40\end{array}$ & $\begin{array}{l}1.04 \\
1.05 \\
1.16 \\
1.09 \\
1.12 \\
1.00 \\
1.13 \\
0.7 \\
1.27 \\
0.74 \\
1.2 \\
1.28 \\
3.8 \\
5.16 \\
2.20\end{array}$ \\
\hline
\end{tabular}


$\mathrm{Np}, \mathrm{Pu}$, and $\mathrm{Am}$ in solution were determined by alpha spectroscopy. The alpha spectroscopy procedure was modified prior to the January 1994 samplings to include electroplating of the solution, in addition to the usual evaporation method. Electroplating affords higher energy resolution (by reducing the inelastic scattering that plagues thick samples), but the results are somewhat more difficult to normalize because it is not clear whether all the elements of interest are plated onto the planchet. A combination of evaporated and electroplated alpha spectra allows use of peak areas from the former to be interpreted in light of relative peak heights from the latter. Note that the ICP-MS method also detects these transuranic elements, and the agreement is generally quite gcod, although Am and Pu concentrations are generally near ICP-MS detection limits.

The analytical data from the solutions are reported as a concentraticn in the submitted volume. Mass release of an element during the test period was calculated with a corrected solution volume, which accounts for any dilutions performed. Solution volume for determining total elemental mass release was determined by the formula

$$
\mathrm{V}=\mathrm{V}_{\mathrm{c}} \cdot \frac{\left(\mathrm{V}_{\mathrm{c}}-\mathrm{s}\right)+\mathrm{d}}{\left(\mathrm{V}_{\mathrm{c}}-\mathrm{s}\right)}
$$

where $V_{c}$ is the volume of solution collected, $s$ is the total volume of all samples removed prior to dilution (such as samples for $\mathrm{pH}$, carbon, colloid, and anion analyses), and $\mathrm{d}$ is the volume of dilutions (distilled water and, where applicable, dilute nitric acid). If more than one dilution was performed with additional sampling between dilutions, then Eq. 1 was applied recursively, i.e., V calculated for the first dilution was used as $V_{c}$ for the second dilution, etc.

The $\mathrm{pH}$ levels were measured periodically; however, the $\mathrm{pH}$ behavior was found to be correlated with the stainless steel test vessel where the solution was collected and did not correlate with any other measurements.

Starting with the January 1994 samplings, the solutions have also been tested for carbon (both organic and total carbon) and anion content. Also starting in January 1994, solutions have been sampled for colloidal material and analyzed by analytical transmission electron microscopy.

\section{a. Solution Analyses}

Masses of dissolved elements are shown in Figs. 1-5 for the continuous tests. The solution data can be roughly divided into three categories: (1) $M_{g} \gg M_{b}$ or $M_{E J-13 \text {, }}$ (2) $M_{g} \sim M_{b} \sim M_{E J-13}$, and (3) $M_{g} \sim M_{b} \gg M_{E J-13}$, where $M_{g}$ is the solution mass from the glass tests (N3 \#9, N3 \#10, and N3\#12), $M_{b}$ is the solution mass from the blank test (N3 \#11), and $\mathrm{M}_{\mathrm{EJ}-13}$ is the mass in the volume of injected EJ-13 water. Category (1) includes $\mathrm{Li}, \mathrm{B}, \mathrm{Mg}, \mathrm{Mn}$, $\mathrm{U}, \mathrm{Np}, \mathrm{Pu}$, and $\mathrm{Am}$, and the data clearly indicate elemental release trends from the glass. The data from Category (2), which includes $\mathrm{Na}, \mathrm{Si}, \mathrm{K}$, and $\mathrm{Ca}$, are more difficult to interpret, and the observed trends are presumably due to competing effects of sorption, reaction, and spallation or redissolution. Category (3) includes Fe and $\mathrm{Ni}$. These elements appear from the stainless steel test vessel in which the solution resides for extended periods, and their release into solution poses difficulty in evaluating the glass performance.

In Fig. 1, the cumulative solution mass of $\mathrm{Li}, \mathrm{B}, \mathrm{Mg}, \mathrm{Mn}$, and $\mathrm{U}$ is plotted as a function of elapsed time through the January 1994 samplings. The release for N3 \#10 during the gap in sampling between September 1990 and January 1994 is systematically higher than for N3 \#9 and N3 \#12, except for Mg and Mn, which are components of stainless steel; these appear 

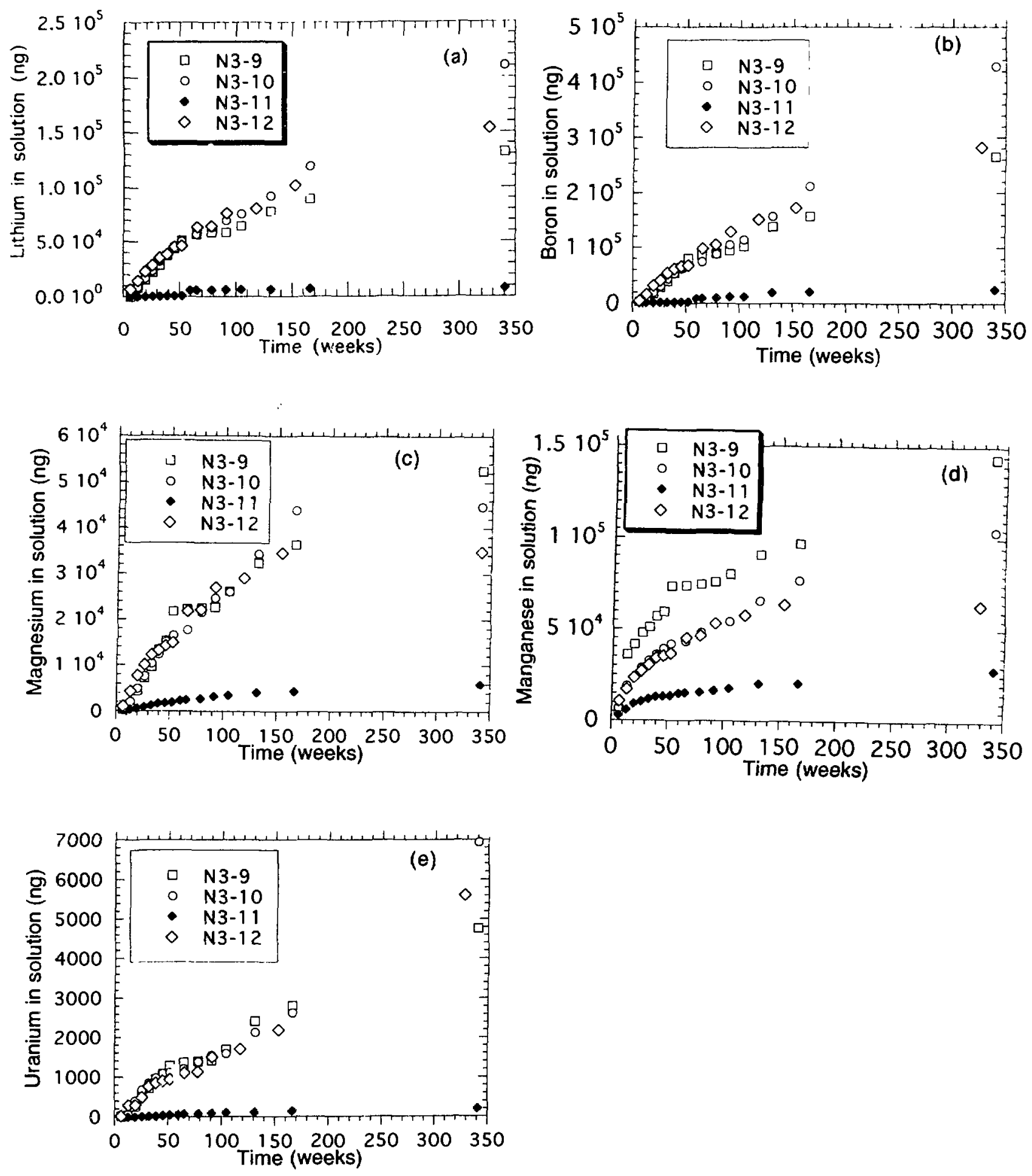

Fig. 1. Cumulative Mass Release of (a) Lithium, (b) Boron, (c) Magnesium, (d) Manganese, and (e) Uranium from the N3 Test Series through 340 Weeks 

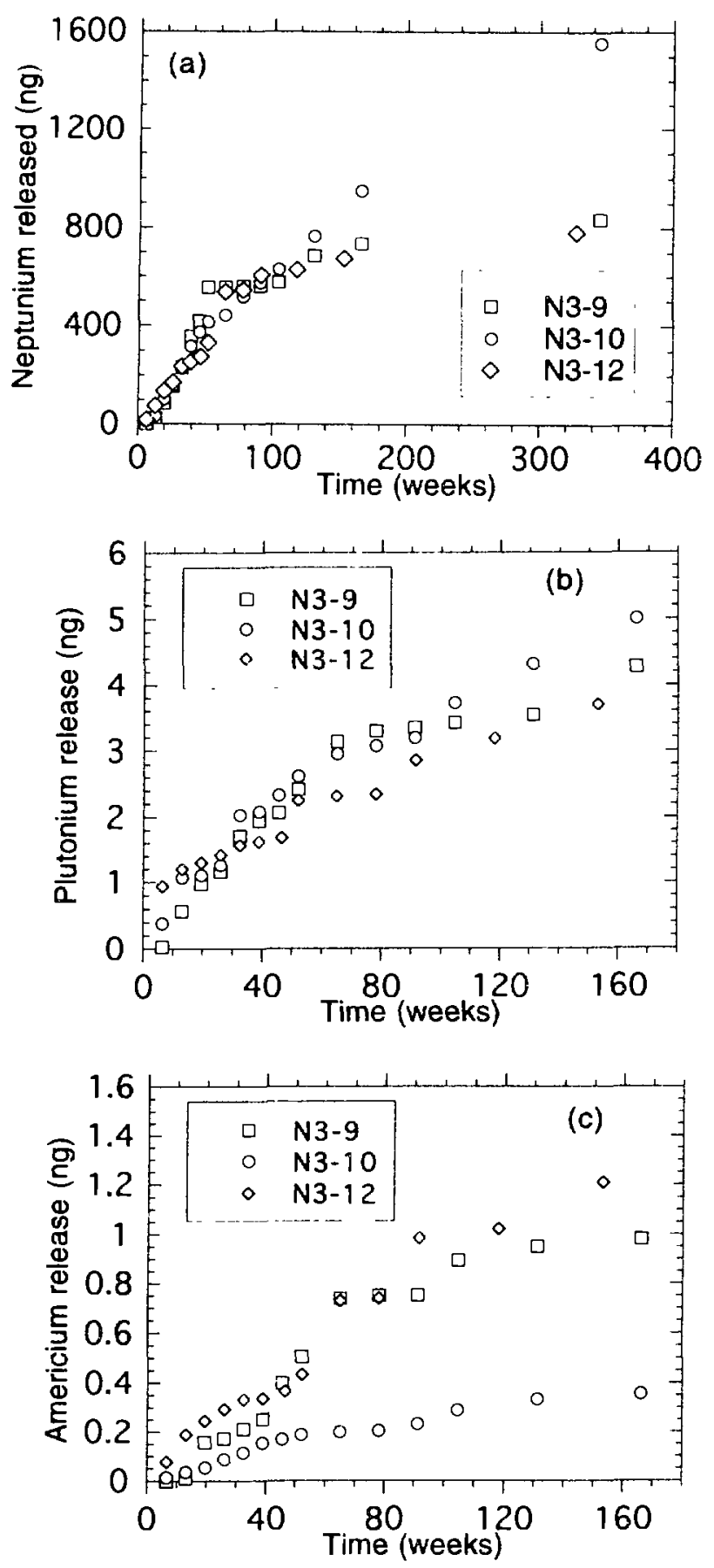

Fig. 2. Cumulative Mass Release for (a) Neptunium, (b) Plutonium, and (c) Americium from the N3 Test Series. The plutonium and americium plots are a sum of solution plus acid wash results, and are only available through 166 weeks. 

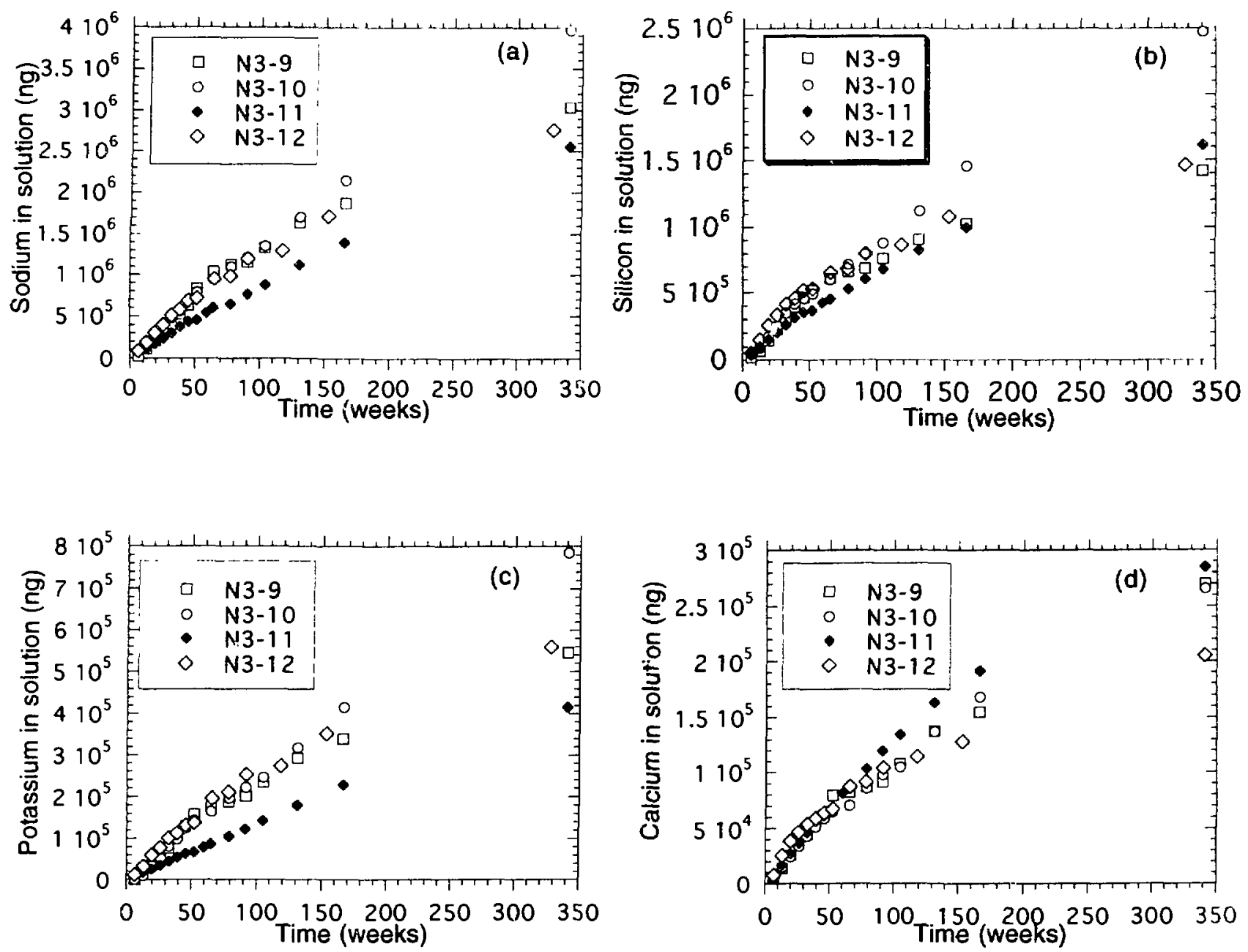

Fig. 3. Cumulative Mass in Solution of (a) Sodium, (b) Silicon, (c) Potassium, and (d) Calcium from the N3 Test Series through 340 Weeks 

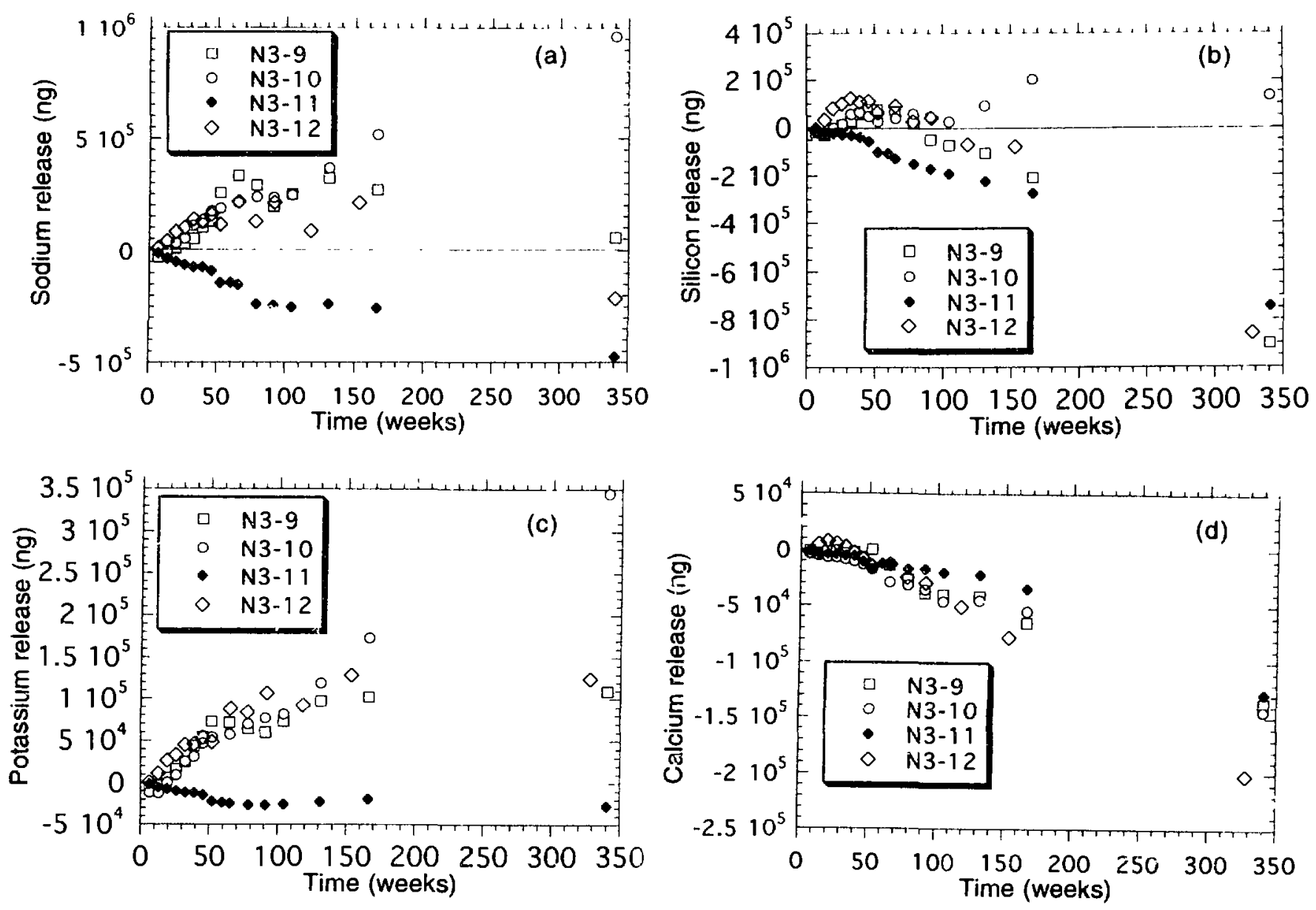

Fig. 4. Cumulative Mass Release of (a) Sodium, (b) Silicon, (c) Potassium, and (d) Calcium from the N3 Test Series, Corrected for EJ-13 Injection Contributions, through 340 Weeks
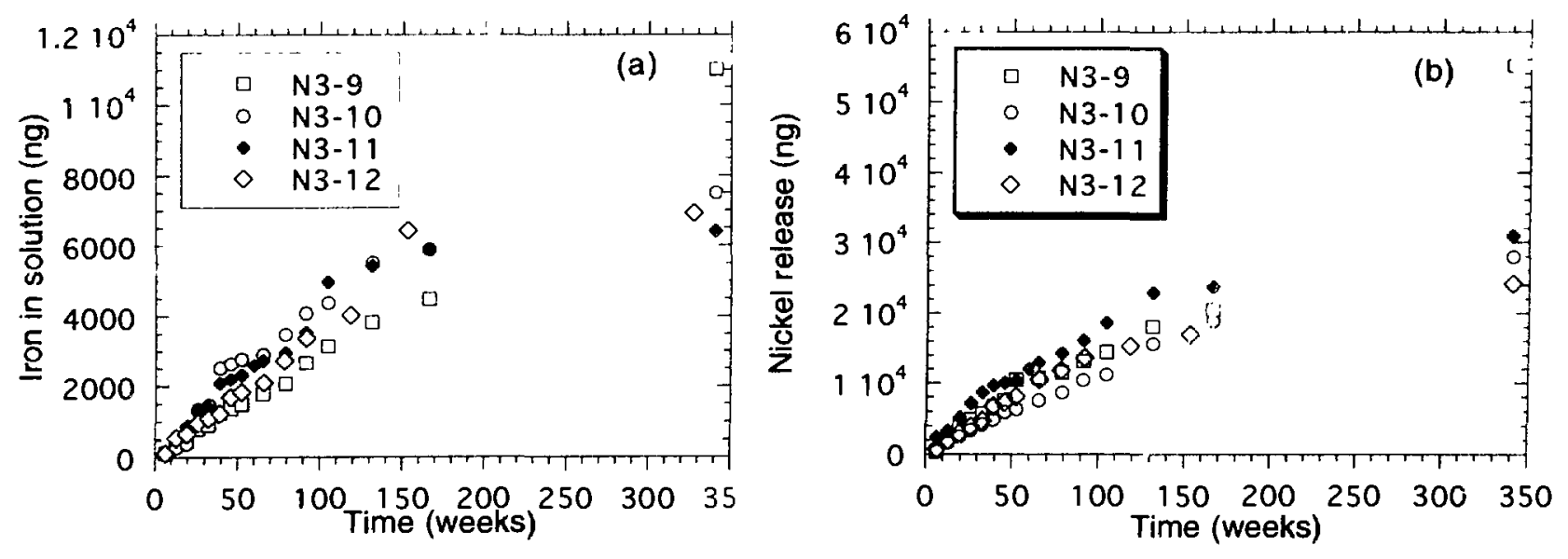

Fig. 5. Cumulative Mass in Solution of (a) Iron and (b) Nickel from the N3 Test Series through 340 Weeks 
to be released more rapidly from the $\mathrm{N} 3 \# 9$ test, where more severe reaction with the stainless steel waste form holder was observed. A few further comments on the $\mathrm{Mg}$ and $\mathrm{Mn}$ data are in order: the magnesium in the $\mathrm{N} 3$ \#11 (biank) test solution is well above detecion limits and mitches very closely with the amount expected simply from injection (labeled EJ-13 in the legend). The manganese in solution from the N3 \#11 test is well above that from the EJ-13 water, where this element was below detection limits.

In Fig. 2, the cumulative solution mass of the transuranic elements $\mathrm{Np}, \mathrm{Pu}$, and Am is plotted for the glass tests through the January 1994 samplings. At oresent, acid-strip results are available only through the September 1990 samplings. Neptunium was not observed above background in the acid strip solutions, suggesting that it does not form irsoluble phases.

Table 4 lists average release rates, $\Delta \mathrm{M}_{\mathrm{i}} / \Delta \mathrm{t}$, through 340 weeks for $\mathrm{Li}, \mathrm{B}, \mathrm{U}$, $\mathrm{Np}, \mathrm{Pu}$, and $\mathrm{Am}$, plus a concentration-corrected or fractional release rate, $R_{i}=\frac{\Delta M_{i}}{\Delta t}$, where $\Delta \mathrm{M}_{\mathrm{i}}$ is the mass loss over time $\Delta t$, and $\mathrm{M}_{\mathrm{i}}$ is the total mass of element $\mathrm{i}$ in the glass (from Table 2 and an average glass sample weight of $10.4 \mathrm{~g}$ ). These data allow comparison of releases by elements present in the glass in widely varying concentrations. The data have not yet been normalized to the surface area of the glass.

Boron release is useful as a benchmark of glass corrosion, as it is not expected to form secondary phases. As can be seen from the rates $R$, the fractional releases of $B$ and $\mathrm{Li}$ are the greatest, followed closely by $\mathrm{Np}$. Uranium, plutonium, and americium have fractional releases an order of magnitude (or more) lower, strongly suggesting incorporation into secondary phases or sorption onto the glass or stainless steel waste form holder. Formation of uranium phases was previously observed in several test series [4]. The transuranics may be incorporated into any number of phases, a likely candidate being brockite, a calcium-thoriumphosphate phase. Unfortunately, thorium, which is present in this glass at 3.29 oxide wt \%, was not reported in solution by ICP-AES, and data were thus not available prior to the January 1994 samplings.

Table 4. Release Rates for Selected Elements from the N3 Series through 340 Weeks

\begin{tabular}{|c|c|c|c|c|c|c|}
\hline \multirow[b]{2}{*}{ Test } & \multicolumn{2}{|c|}{$\mathrm{Li}$} & \multicolumn{2}{|c|}{ B } & \multicolumn{2}{|c|}{$\overline{\mathbf{U}}$} \\
\hline & $\begin{array}{c}\text { Release } \\
\text { Rate } \\
\text { (ng/day) }\end{array}$ & $\begin{array}{c}\mathbf{R} \\
\left(\text { day }^{-1}\right)\end{array}$ & $\begin{array}{c}\text { Release } \\
\text { Rate } \\
\text { (ng/day) }\end{array}$ & $\begin{array}{c}R \\
\left(\text { day }^{-1}\right)\end{array}$ & $\begin{array}{c}\text { Release } \\
\text { Rate } \\
\text { (ng/day) }\end{array}$ & $\begin{array}{c}\mathrm{R} \\
\left(\text { day }^{-1}\right)\end{array}$ \\
\hline N3 \#9 & 75 & $5.4 \times 10^{-7}$ & 120 & $4 \times 10^{-7}$ & 2.5 & $5 \times 10^{-8}$ \\
\hline N3 \#10 & 100 & $7.2 \times 10^{-7}$ & 180 & $6 \times 10^{-7}$ & 3 & $6 \times 10^{-8}$ \\
\hline \multirow[t]{3}{*}{ N3 \#12 } & 75 & $5.4 \times 10^{-7}$ & 120 & $4 \times 10^{-7}$ & 2.5 & $5 \times 10^{-8}$ \\
\hline & \multicolumn{2}{|c|}{$\mathrm{Np}$} & \multicolumn{2}{|c|}{$\mathrm{Pu}^{\mathrm{a}}$} & \multicolumn{2}{|c|}{$\mathrm{Am}^{\mathrm{a}}$} \\
\hline & $\begin{array}{c}\text { Release } \\
\text { Rate } \\
\text { (ng/day) }\end{array}$ & $\begin{array}{c}\mathbf{R} \\
\left(\text { day }^{-1}\right)\end{array}$ & $\begin{array}{c}\text { Release } \\
\text { Rate } \\
\text { (ng/day) }\end{array}$ & $\begin{array}{c}\mathbf{R} \\
\left(\text { day }^{-1}\right)\end{array}$ & $\begin{array}{c}\text { Release } \\
\text { Rate } \\
\text { (ng/day) }\end{array}$ & $\begin{array}{c}R \\
\left(\text { day }^{-1}\right)\end{array}$ \\
\hline N3\#9 & 0.35 & $1.9 \times 10^{-7}$ & $3.6 \times 10^{-3}$ & $4.8 \times 10^{-9}$ & $1 \times 10^{-3}$ & $1.7 \times 10^{-9}$ \\
\hline N3 \#10 & 0.65 & $3.5 \times 10^{-7}$ & $3.9 \times 10^{-3}$ & $5.2 \times 10^{-9}$ & $3 \times 10^{-4}$ & $5.1 \times 10^{-10}$ \\
\hline N3 \#12 & 0.33 & $1.8 \times 10^{-7}$ & $2.6 \times 10^{-3}$ & $2.5 \times 10^{-9}$ & $1.2 \times 10^{-3}$ & $2 \times 10^{-9}$ \\
\hline
\end{tabular}

aCalculated for total (solution plus acid strip) through 166 weeks only. 
In Fig. 3, the cumulative solution mass of the category (2) elen sents ( $\mathrm{Na}$, $\mathrm{Si}, \mathrm{K}$, and $\mathrm{Ca}$ ) is plotted as a function of elapsed time through the January 1994 samplings. Note that the blank N3 \#1 1 test has cumulative solution mass values comparable to those of the glasscontaining tests. This suggests that more complex processes are taking place.

Figure 4 plots the same elements as in Fig. 3, but with the total mass due to the injected EJ-13 water subtracted. By comparing Figs. 3 and 4, we determined that the alkali ions $\mathrm{Na}$ and $\mathrm{K}$ are released at a level of about $10 \%$ of the total concentration in the solution. The negative release of these elements observed for the blank $\mathrm{N} 3$ \#11 is probably real, indicating their sorption onto the stainless steel test vessel. Note that $\mathrm{Na}$ and $\mathrm{K}$ are released at much greater le vels between the 166- and 340-week samplings for $\mathrm{N} 3 \# 10$, as was observed for $\mathrm{B}, \mathrm{Li}, \mathrm{U}, \mathrm{Np}, \mathrm{Pu}$, and Am.

Calcium is sorbed or incorporated by reaction into solid phases attached to the waste package assemblage (WPA) for all the tests, the blank test sorbing somewhat less (suggesting interaction of calcium with the glass). For the first 50 weeks or so, a slight positive release of calcium is indicated for the WPA-bearing tests.

Silicon shows an initial release from the WPA-bearing tests for the first 100 weeks, followed by sorption (except for the N3 \#10 test). The blank test shows continuous, strong sorption; note that the amount of silicon sorbed after 340 weeks is comparable to the total silicon in solution, i.e., about one-third of the injected silicon is sorbed or unaccounted for in N3 \# 11 .

Figure 5 shows cumulative $\mathrm{Fe}$ and $\mathrm{Ni}$ release in solution for the continuous tests. As mentioned above, the mass in solution far exceeds that injected with the EJ-13 water. The blank test behaving virtually the same as the WPA-bearing tests indicates that the observed masses are caused by the test vessel and are not of great use in evaluating the giass. However, there was more rust-colored material, indicating stainless steel corrosion, visible on the waste form holder of the N3 \#9 test than on the holders of the N3 \#10 and N3 \#12 tests during the January and July 1994 samplings. This qualitative observation appears to be reflected by the data in Fig. 5 .

As mentioned above, data for thorium were not reported prior to the use of the ICP-MS in the procedure. Reports since January 1994 have included thorium, as well as the previously unreported (or undetected) elements Tc and Sr. These data are presented in Table 5. Trends in their release cannot be inferred at this time but will be reported at a later time as more data are collected.

Figure 6 is a plot of measured solution $\mathrm{pH}$ versus total elapsed time. The arrow indicates the $\mathrm{pH}$ of the EJ-13 water that has been injected recently. Over the term of the test, the starting $\mathrm{pH}$ of the EJ-13 water has varied between $\sim 8$ and 9 . Attempts to finc a correlation between $\mathrm{pH}$ and element releases proved unsuccessful; it is probable that the $\mathrm{pH}$ is affected by interaction with the test vessel and does not completely reflect glass behavior in these tests.

\section{b. Analysis of Colloidal Particles in Solution}

For the sample periods ending in January and July 1994, specimens of colloidal material from the solutions were prepared for AEM analysis. Samples were prepared by wicking between 5 and $15 \mu \mathrm{L}$ of solution from the test vessel through "holey" carbon TEM grids. These were then submitted for analysis by the standard procedure. The material that is trapped on the grid represents the colloids present in only a small volume of solution, and does not provide a complete representation of colloids that may be in solution. 
Table 5. Strontium, Technetium, and Thorium in Solution after 174.5-Week Interval

\begin{tabular}{lrrr}
\hline & \multicolumn{3}{c}{ Element in Solution (ng) } \\
\cline { 2 - 4 } Test & Sr & Tc & Th \\
\hline N3 \#9 & 733 & 3 & 10 \\
N3 \#10 & 1144 & 87 & 1 \\
N3 \#11 & 525 & 0 & 0 \\
N3\#12 & 654 & 10 & 8 \\
\hline
\end{tabular}

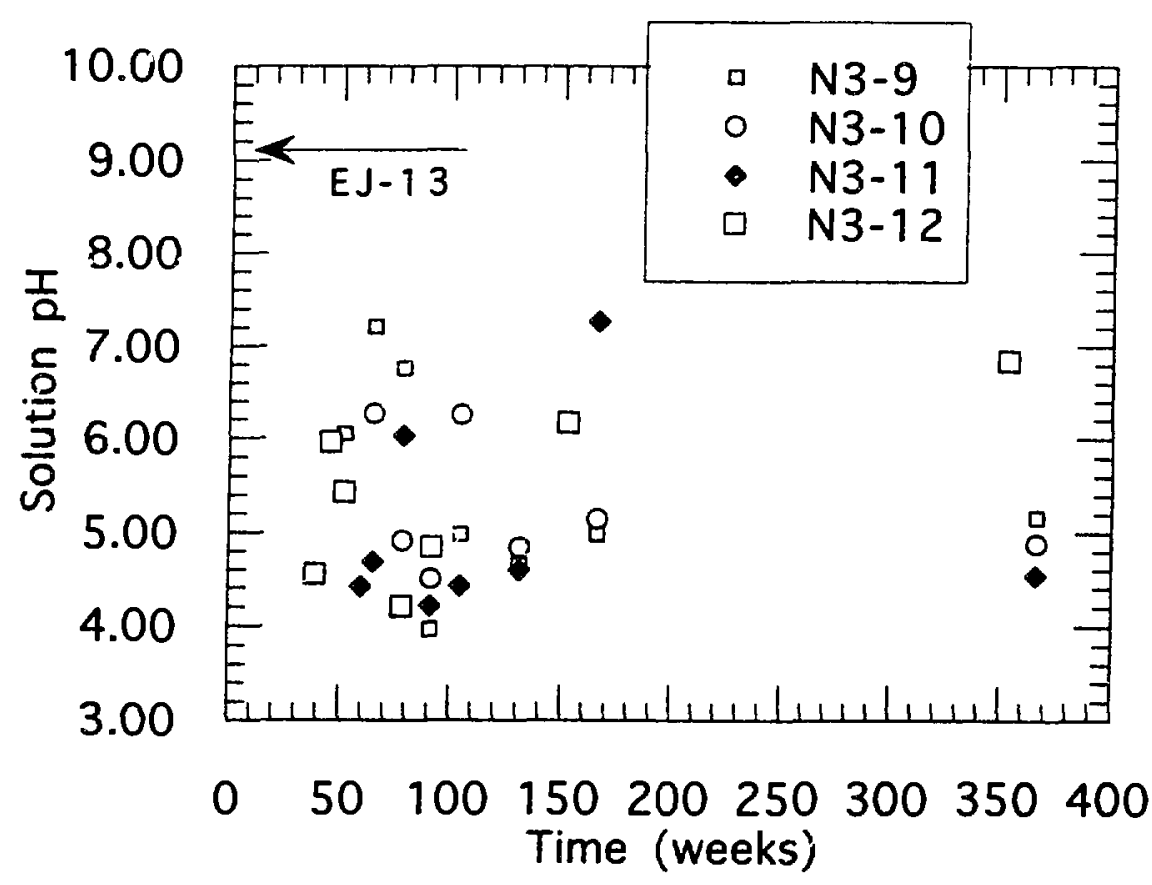

Fig. 6. Solution $\mathrm{pH}$ in N3 Test versus Time 
The colloid material was found to be mostly smectite-type clay particles of 1-10 $\mu \mathrm{m}$ diameter (Fig. 7). The clay particles frequently incorporated a variety of elements or presipitated phases, including a calcium-thorium phosphate, calcium silicates, iron oxide, uranium oxicles, and occasional $\mathrm{Pb}, \mathrm{Zn}, \mathrm{Sn}$, or $\mathrm{Ba}$. A complete description of the phases will be given later, and a partial description of the phases found in the 1990 sampling has been reported by Bates [2].

\section{E. Ongoing Work}

The N2 and N3 tests are continuing. They represent the longest term tests in progress which provide quality approved input to the Yucca Mountain Project. The data are required to validate modeling codes and to determine the form by which radionuclides are released to solution. Since the volume of solution that is collected can be varied, depending on the sampling interval, leachate can be collected and used in further studies of colloidal material released from the waste form and in integrated tists involving the effects of other engineered materials. The tests will be continued in FY 1995, and the data from both test series compiled and published in refereed journals.

It is important to recognize that prior to the contact of glass with liquid water in an unsaturated environment, glass will first be exposed to water vapor, creating a pre-aged glass. In the repository the main release scenario will occur because of reaction between liquid water and pre-aged glass. Preliminary performance assessment studies [5] that compare the release of radionuclides for glass and spent fuel have concluded that glass can provide a significant proportion of the radionuclide release for the overall repository. To refine this assessment and to provide a bounding limit to radionuclide release, further testing of pre-aged glass must be performed. Two issues are paramount: (1) what is the rate at which the glass will react with water vapor as a function of glass composition, time, and temperature? and (2) when the pre-aged glass contacts liquid water, what will be the manner and rate by which radionuclides are released to solution? Without this information, a credible performance assessment of release from the engineered barrier system cannot be done. 

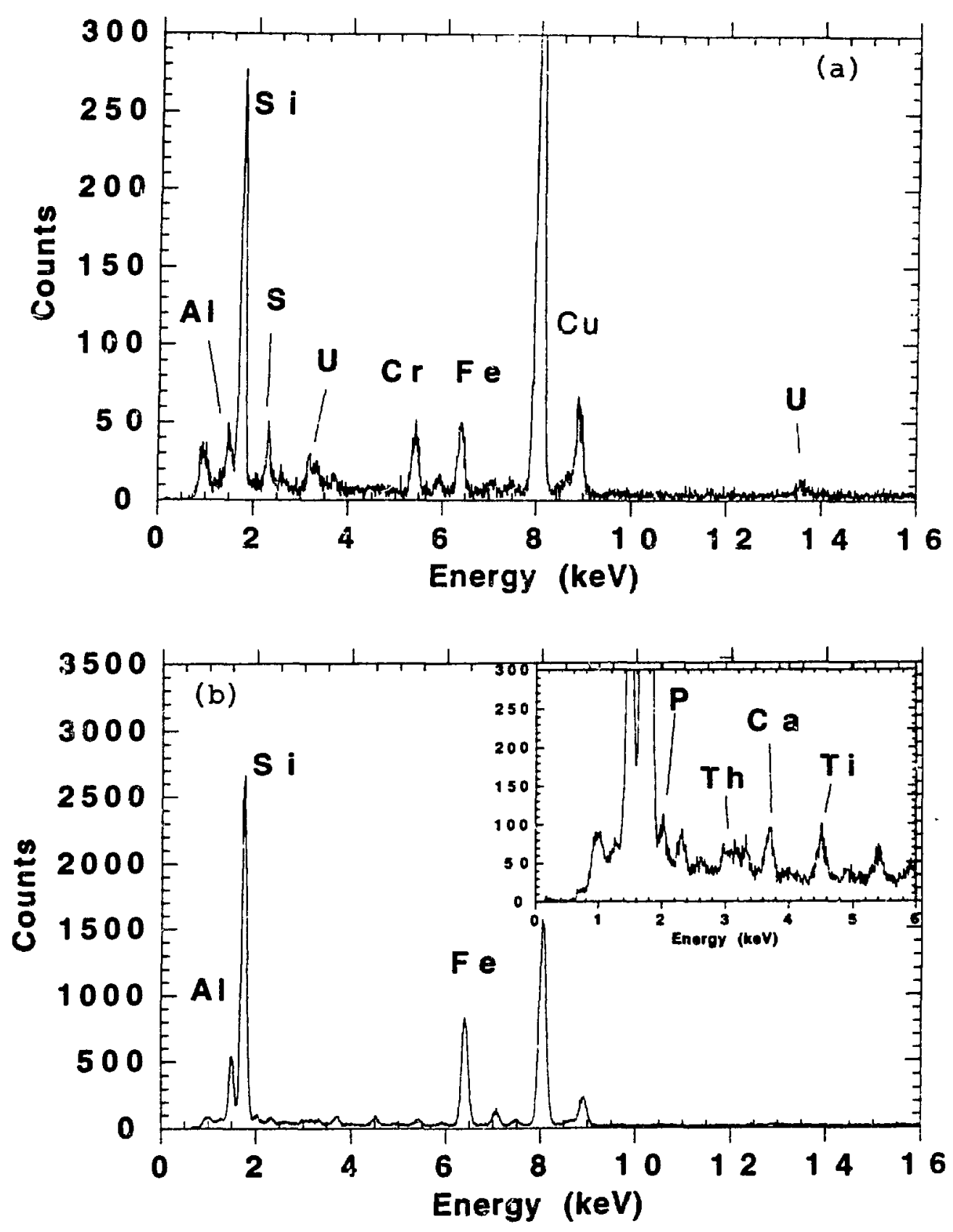

Fig. 7. EDS Spectra from Analytical Transmission Electron Microscopy Study of N3 Series Colloids: (a) Clay Material with Evidence of Uranium Silicate Formation and (b) Clay Material with Evidence of Brockite (a Ca-Th-P Bearing Mineral) Formation (inset) 


\section{UNSATURATED TESTS WITH IRRADIATED SPENT FUEL}

\section{A. Introduction}

The Unsaturated Spent Fuel Testing Program in CMT provides technical support to DOE's Yucca Mountain Site Characterization Project (YMP), which is investigating the tuff beds of Yucca Mountain as a potential location for a high-level radioactive waste repository. As part of the waste package development portion of this project, which is directed by Lawrence Livermore National Laboratory, this program was initiated in 1994 to evaluate factors likely to affect spent fuel reaction in an unsaturated environment. The data resulting from this program will provide a firm basis for the Yucca Mountain modeling and performance assessment programs, accounting for important physical parameters which affect spent fuel dissolution in an unsaturated environment and relating the mechanistic basis of spent fuel reaction to conditions which will exist in an unsaturated environment. Without this information, it will not be possible to validate spent fuel reaction models generated to predict long-term performance. Results from the program will also be used to validate models generated to predict long-term performance.

The tasks of the Unsaturated Spent Fuel Testing Program are to (1) develop and perform a test to measure spent fuel behavior in unsaturated conditions, (2) characterize both the leachate and the spent fuel surfaces during these tests, (3) perform testing to quantify the effects of variables deemed important in spent fuel performance, and (4) characterize spent fuel performance under a range of bounding repository conditions. The information provided by these tasks, when combined with data generated by the YMP, will form the basis of a well-founded program that will qualify the spent fuel waste packages for repository disposal.

Under the geologically unsaturated conditions expected at the proposed Yucca Mountain repository, the most likely scenario for water contact on buried spent fuel is that thin films of water could condense on the fuel. The limited quantities of solution expected to condense would preclude volumetric dilution of the radiolytic and fuel dissolution products. Rapid increases in the concentrations of fuel dissolution products would result in the leachate becoming saturated with certain secondary alteration minerals, accelerating the precipitation of secondary phases. This may or may not promote additional dissolution of the spent fuel and/or preferential release of some of the radionuclides within the spent fuel.

This section reports on our tests of the release behavior of radionuclides from spent fuel under unsaturated conditions. The emphasis is on recent results, with some discussion of release under unsaturated versus saturated conditions. The topics addressed are the released fraction of cesium and actinides; the amount, size distribution, and observed phases of colloids in the leachate; the ionic fraction in the leachate; and the appearance of the fuel.

\section{B. Objective}

The objective of this task is to use unsaturated tests to measure the reactivity of spent fuel under a range of potential repository conditions. Data from the tests will yield information of the (1) chemistry of the solutions after contact with the spent fuel as a function of time, (2) the dissolution rate of the spent fuel matrix, (3) the form of the released radionuclides, (4) the release rate of the radionuclides, and (5) the type of alteration products formed as a function of total reaction time. 


\section{Technical Approach}

The leach/dissolution behavior of two types of irradiated fuels, ATM-103 and ATM-106, is being determined in two tests with a saturated water vapor atmosphere, two with a drip rate of $0.075 \mathrm{~mL} / 3.5 \mathrm{~d}$, and two with a drip rate of $0.75 \mathrm{~mL} / 3.5 \mathrm{~d}$. A control test without fuel but with a drip rate of $0.075 \mathrm{~mL} / 3.5 \mathrm{~d}$ is also included.

The experimental configuration and initial results for these tests have been reported elsewhere [6,7]. The two fuels are well-characterized $[8,9]$ and came from the pressurized water reactor at Calvert Cliffs. The ATM-103 has a burnup of $30 \mathrm{MW}-\mathrm{d} / \mathrm{kg} \mathrm{U}$ and a grain size of 9-19 $\mu \mathrm{m}$. The ATM-106 has a burnup of $43 \mathrm{MW}-\mathrm{d} / \mathrm{kg} \mathrm{U}$ and a grain size of 6-14 $\mu \mathrm{m}$. Fragments of the spent fuel were placed inside a Zircaloy holder with a $20-\mu \mathrm{m}$-thick base drilled with $\sim 10 \mu \mathrm{m}$ holes. The base, which retains the fuel but releases the leached water, is designated as the "retainer." The groundwater came from well J-13 near Yucc: Mountain, which has a chemistry representative of the saturated zone. The water was equilibrat ed at $90^{\circ} \mathrm{C}$ for 80 days with crushed core samples of Topopah Spring tuff and is designated EJ-13 This water is more concentrated in $\mathrm{Si}$ and $\mathrm{Na}$ than $\mathrm{J}-13$ and is a surrogate for water that may cositact spent fuel in a repository environment. After reaction times of $120,275,482$, and 581 days, the tests were interrupted to collect accumulated fluid, acid strip the stainless steel test vessel, and restart each test in a new vessel. (The fuel transfer is accomplished in approximately two hours.) After an acid strip, an acid wash was done on each test vessel. Total time each fuel sample was reacted under unsaturated conditions was 581 days. The last two intervals ( 275 to 482 days and 482 days to 581 days) occurred this fiscal year.

The spent fuel test matrix is shown in Table 6. The test vessels of the two tests at high drip rate were sampled at the end of the third ( 482 days) and the fourth interval ( 581 days); the other five unsaturated tests were only sampled at 120,275, and 581 days (three intervals). The spent fuel was visually examined by using a camera with $10 \mathrm{X}$ magnification; video records were kept. The dry appearance of the fuel after the third interval (482 days) differed from that previously observed and may indicate that the injection of water had been partially reduced during this interval. In addition, only two-thirds of the expected fluid was present in the test vessels.

Aliquots of the leachate taken at each interval were characterized with regard to $\mathrm{pH}$, carbon content, anion content, radionuclide content as dissolved and suspended material, total radionuclide content, and elemental release. At 581 days, aliquots from the high drip-rate tests were passed sequentially through 1000,100 , and $50 \mathrm{~nm}$ filters to determine the distribution of the colloidal material. The filters were saved for future autoradiographic and AEM analysis of the colloids [10]. The fluid was analyzed by gamma spectroscopy and ICP-MS; filters were analyzed by alpha spectroscopy.

Table 6. Experimental Matrix for Spent Fuel Tests at $90^{\circ} \mathrm{C}$

\begin{tabular}{lccc}
\hline Test Number & Fuel & Water Form & Vol. EJ-13/3.5 d \\
\hline S3-1J1 & ATM-103 & Inject & $0.075 \mathrm{~mL}$ \\
S6-1J1 & ATM-106 & Inject & $0.075 \mathrm{~mL}$ \\
S3-2J1 & ATM-103 & Inject & $0.75 \mathrm{~mL}$ \\
S6-2J1 & ATM-106 & Inject & $0.75 \mathrm{~mL}$ \\
S3-V1 & ATM-103 & Vapor &.-- \\
S6-V1 & ATM-106 & Vapor & --- \\
CC-1J1 & None & Inject & $0.075 \mathrm{~mL}$ \\
\hline
\end{tabular}




\section{Results}

\section{Solution Chemistry}

The $\mathrm{pH}$ and carbon analyses for all seven tests at the end of the fourth interval are shown in Table 7. The two vapor tests have the lowest pH's of all the tests, 6.1 and 6.7. The pH was 6.9 for the high drip-rate tests and 7.1 for the low drip-rate tests, while during the fourth interval the $\mathrm{pH}$ of the EJ-13 leachant ranged between 8.4 and 7.3. An acidic solution was present in the control test $(\mathrm{pH}=3.2$ ), but this may represent the effect of the $\mathrm{pH}$ of the EJ-13, which had been used for 16 months. In general, radiolysis and the formation of nitrogen-based acids appear to be responsible for the change in $\mathrm{pH}$, especially that in the leachant $[6,7]$.

For the high drip-rate tests at 581 days, the organic and inorganic carbon contents had decreased compared to the starting EJ-13 water to $\sim 3 \mathrm{ppm}$ each (Table 7). For the two vapor and the two low drip-rate tests, the organic carbon had increased to 11-26 ppm, and the inorganic carbon had decreased to $\sim 3 \mathrm{ppm}$. The increase in organic carbon was also observed in the control test.

\section{Radionuclide Release Rates for High Drip-Rate Tests}

The amount of transuranics and cesium measured in the two high drip-rate tests at 581 days is shown in Table 8 . Also reported are the unprecipitated fraction and the maximum fraction of each radionuclide. The unprecipitated fraction is the ratio of the material not deposited on the vessel walls (both dissolved and suspended material) to the total amount of material

Table 7. Carbon Content and $\mathrm{pH}$ Results for Spent Fuel Leachate, at $\sim 581$ Days

\begin{tabular}{|c|c|c|c|c|c|}
\hline \multirow[b]{2}{*}{ Test } & \multirow[b]{2}{*}{$\mathrm{pH}$} & \multicolumn{3}{|c|}{ Content, $\mathrm{ppm}^{\mathrm{a}}$} & \multirow[b]{2}{*}{ Test Condition } \\
\hline & & Organic & Inorganic & Total & \\
\hline S6-V1-574 & 6.7 & 26 & 3 & 30 & Vapor \\
\hline S3-V1-580 & 6.1 & 11 & 4 & 15 & Vapor \\
\hline$S 3-2 J 1-581^{b}$ & 6.9 & 3 & 3 & 6 & High Drip Rate \\
\hline$S 6-2 J 1-581^{b}$ & 6.9 & 3 & 2 & 6 & High Drip Rate \\
\hline$S 3-1 J 1-568 \mathrm{C}$ & 7.1 & 12 & 4 & 16 & Low Drip Rate \\
\hline S6-1J1-569c & 7.1 & 11 & 2 & 13 & Low Drip Rate \\
\hline CC- $1 \mathrm{~J} 1-569 \mathrm{c}, \mathrm{d}$ & 3.2 & 39 & 13 & 52 & Control \\
\hline$E J-13(0)^{e}$ & 8.4 & 5 & 20 & 26 & -- \\
\hline$E J-13(+3)^{f}$ & 7.3 & 7 & 22 & 28 & --- \\
\hline
\end{tabular}

aAt concentrations $\leqq 5 \mathrm{ppm}$, the carbon analysis has a $\pm 50 \%$ precision.

bThese tests were interrupted at 482 days, the leachate removed, and the test restarted. A new bottle of EJ-13 was introduced.

cTwo different bottles of EJ-13 were used.

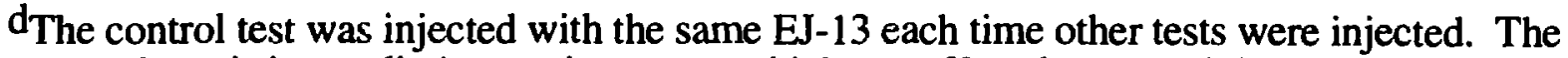
control test is in a radiation environment, which can affect the $\mathrm{pH}$ and the carbon content of the fluid.

eNew bottle of EJ-13 at month 0 .

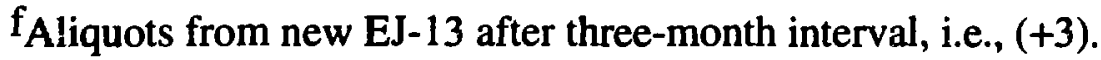


Table 8. Transuranic ${ }^{a}$ and Cesium Measured in High Drip-Rate Tests at 581 Days

\begin{tabular}{|c|c|c|c|c|c|c|}
\hline \multirow[b]{2}{*}{ Isotope } & \multicolumn{4}{|c|}{ Mass (g) } & \multirow{2}{*}{$\begin{array}{l}\text { Unprecip. } \\
\text { Frac. (\%) }\end{array}$} & \multirow{2}{*}{$\begin{array}{l}\text { Maximum } \\
\text { Frac. (\%) }\end{array}$} \\
\hline & Leachate & Strip & Wash & Total & & \\
\hline \multicolumn{7}{|c|}{ ATM-106 } \\
\hline$A m-241^{b}$ & $3(-11)$ & $2(-9)^{c}$ & $1(-10)$ & $2(-9)$ & 2 & $4(-5)$ \\
\hline Am-243 & $\ldots d$ & $6(-10)$ & -- & $6(-10)$ & --- & $4(-5)$ \\
\hline $\mathrm{Cm}-244$ & $5(-12)$ & $4(-10)$ & $7(-12)$ & $4(-10)$ & 1 & $1(-4)$ \\
\hline Np-237 & $5(-9)$ & $2(-8)$ & --- & $2(-8)$ & 25 & $7(-4)$ \\
\hline Pu-239 & $8(-11)$ & $4(-9)$ & $1(-9)$ & $5(-9)$ & 2 & $1(-5)$ \\
\hline Cs-137 & $1(-6)$ & $7(-8)$ & -- & $1(-6)$ & 94 & $2(-2)^{e}$ \\
\hline \multicolumn{7}{|c|}{ ATM-103 } \\
\hline$A m-241^{b}$ & $5(-10)$ & $6(-8)^{\mathrm{c}}$ & $3(-10)$ & $6(-8)$ & $<1$ & $1(-3)$ \\
\hline Am-243 & --- & $1(-8)$ & --- & $1(-8)$ & -- & $2(-3)$ \\
\hline $\mathrm{Cm}-244$ & $1(-10)$ & $4(-9)$ & $3(-11)$ & $4(-9)$ & 2 & $4(-3)$ \\
\hline Np-237 & $2(-7)$ & $6(-7)$ & $6(-10)$ & $8(-7)$ & 25 & $3(-2)$ \\
\hline Pu-239 & $2(-8)$ & $1(-8)$ & $4(-9)$ & $3(-8)$ & 59 & $9(-5)$ \\
\hline Cs- 137 & $1(-6)$ & $5(-8)$ & -- & $1(-6)$ & 96 & $2(-2)^{e}$ \\
\hline
\end{tabular}

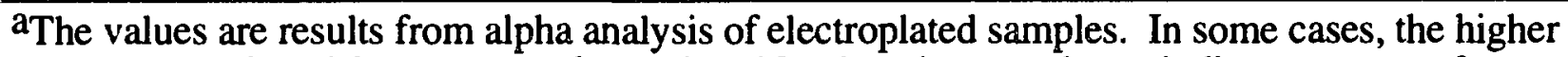
counts were found for evaporated samples. Numbers in parentheses indicate powers of ten.

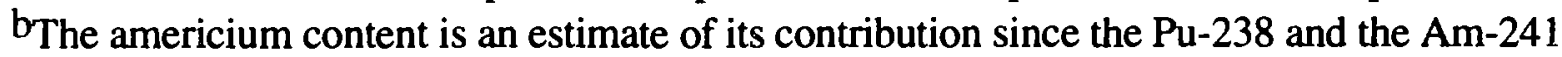
peaks from alpha spectroscopy cannot be separated. A measurement of Am-241 can be obtained from the gamma spectroscopy results.

cThis is the Am-241 measured value.

$\mathrm{d}$ Dashes indicate non-detection of this isotope.

eValue is equivalent to $10^{-6}$ fraction/day during the fourth interval.

measured as released from the spent fuel. Note that the measured amount of material released from the spent fuel includes all material that is no longer directly associated with the spent fuel and includes material in solution and material sorbed to the stainless steel vessels. The total release should also include the material that has accumulated on the Zircaloy retainer or alteration products on the spent fuel fragments. However, to date, we have not quantitatively measured the material associated with the Zircaloy retainer or alteration products on the spent fuel. The maximum fraction is the ratio between the total measured amount of isotope released in a given test interval and the expected amount of the isotope in the fuel under test. Similar data sets were collected for all tests at each test interval.

From the data in Table 8, the relative release characteristics of the two different fuels can be compared. In the ATM-106 test, most of the transuranics had precipitated except for neptunium. Most of the cesium was in solution. The order of the maximum fraction for the transuranics was $\mathrm{Np} \sim \mathrm{Cm}>\mathrm{Am}>\mathrm{Pu}$. The cesium maximum fraction was two to three orders of magnitude greater than the actinide fractions and corresponds to approximately $10^{-6}$ fraction/day during the fourth interval. This value is comparable to that found in Swedish leaching experiments [11]. Because we did not consider any additional material associated with secondary phases on the Zircaloy retainer or the spent fuel fragments, this comparison must be viewed cautiously. 
In the ATM-103 sample, a large fraction of the plutonium had not precipitated. The order of the maximum fractions was $\mathrm{Np}>\mathrm{Cm} \sim \mathrm{Am} \gg \mathrm{Pu}$. The cesium fraction was nearly the same as the neptunium fraction. Since the measured cesium fraction was the same for ATM-103 and ATM-106, the release of the actinides to the leachate appears to be significantly faster from ATM-103 than ATM-106. (This observation may be modified if a greater fraction of the cesium is incorporated in secondary phases associated with either the Zircaloy retainer or the spent fuel.)

The maximum fractions for the transuranics and cesium measured in the two high drip-rate tests are shown in Table 9 for the four time intervals. For the ATM-106 fuel, the measured amount of cesium released increased with time, while the amount of the transuranics released did not appear to increase. There was a spread of two orders of magnitude in the maximum fractions for the transuranics, with plutonium being the species with the minimal release. For the ATM-103 fuel, the amount of cesium released increased substantially in the fourth interval, as did all the actinide releases. There was greater than two orders of magnitude range in the maximum fractions for all the actinides. In addition, the plutonium fraction was an order of magnitude greater for ATM-103 than ATM-106.

The results for the high drip-rate tests indicate that the radionuclides that accumulate in the test vessel as a result of corrosion of the fuel fragments release at a consistent rate during the first year and a half of continuous testing. Also, the solutions analyzed in the test vessel have a higher proporiion of $\mathrm{Am}$ and $\mathrm{Cm}$ compared with $\mathrm{Pu}$.

Table 9. Maximum Nuclide Fraction at Successive Time Intervals for High Drip-Rate Tests ${ }^{a}$

\begin{tabular}{|c|c|c|c|c|}
\hline & \multicolumn{4}{|c|}{ ATM-106 Nuclide Fraction } \\
\hline & $113 \mathrm{~d}$ & $271 \mathrm{~d}$ & $482 \mathrm{~d}$ & $581 \mathrm{~d}$ \\
\hline $\begin{array}{l}\text { Am-241 } \\
\text { Am-243 } \\
\text { Cm-244 } \\
\text { Np-237 }\end{array}$ & $\begin{array}{c}2(-5) \\
2(-5) \\
2(-5) \\
\text { N.A.b }\end{array}$ & $\begin{array}{l}7(-5) \\
1(-4) \\
2(-4) \\
\text { N.A. }\end{array}$ & $\begin{array}{l}6(-5) \\
7(-5) \\
1(-4) \\
2(-3)\end{array}$ & $\begin{array}{l}4(-5) \\
4(-5) \\
1(-4) \\
7(-4)\end{array}$ \\
\hline \multirow[t]{3}{*}{$\begin{array}{l}\text { Pu-239 } \\
\text { U-238 } \\
\text { Cs- } 137 \\
\end{array}$} & $\begin{array}{l}8(-6) \\
7(-6) \\
1(-4)\end{array}$ & $\begin{array}{l}2(-5) \\
4(-5) \\
1(-3)\end{array}$ & $\begin{array}{c}5(-5) \\
\text { N.A. } \\
9(-3)\end{array}$ & $\begin{array}{l}1(-5) \\
\text { N.A. } \\
2(-2)\end{array}$ \\
\hline & \multicolumn{4}{|c|}{ ATM-103 Nuclide Fraction } \\
\hline & $120 \mathrm{~d}$ & $275 \mathrm{~d}$ & $432 \mathrm{~d}$ & $581 \mathrm{~d}$ \\
\hline $\begin{array}{l}\text { Am-241 } \\
\text { Am-243 } \\
\mathrm{Cm}-244 \\
\mathrm{~Np}-237 \\
\mathrm{Pu}-239 \\
\mathrm{U}-238 \\
\mathrm{Cs}-137\end{array}$ & $\begin{array}{c}6(-4) \\
1(-3) \\
8(-3) \\
\text { N.A. } \\
1(-6) \\
1(-5) \\
5(-4)\end{array}$ & $\begin{array}{c}2(-6) \\
1(-5) \\
2(-5) \\
\text { N.A. } \\
2(-7) \\
1(-6) \\
1(-4)\end{array}$ & $\begin{array}{c}7(-6) \\
1(-5) \\
2(-5) \\
7(-4) \\
8(-7) \\
\text { N.A. } \\
8(-4)\end{array}$ & $\begin{array}{c}1(-3) \\
2(-3) \\
4(-3) \\
3(-2) \\
9(-5) \\
\text { N.A. } \\
2(-2)\end{array}$ \\
\hline
\end{tabular}

The radionuclide content associated with the Zircaloy retainer is not included.

$b_{N}$.A. indicates not available. 


\section{Colloidal Composition}

For the first two intervals, the americium release was not congruent with the uranium release. From earlier data [6,7], much of the americium was determined to be in a colloidal form within the leachate. The presence of large quantities of colloidal material has potential significant consequences for transport of radionuclide material under long-term storage conditions. Since results from these tests can be applied to the conditions expected for long-term storage of DOE spent nuclear fuel, we performed a limited study of the actinide content of the colloids formed in our tests.

Aliquots of the leachate from the two high drip-rate tests at 581 days were sequentially passed through 1000,100 , and $50 \mathrm{~nm}$ filters to determine the composition of the colloidal material. Cesium passed through all three filters. The filtration behavior of the actinides for ATM-103 and ATM-106 exhibited two similarities: (1) a bimodal distribution for curium, with $50 \%$ of the content being $\geq 1000 \mu \mathrm{m}$ and $50 \%$ being $<50 \mathrm{~nm}$, and (2) neptunium species $<100 \mathrm{~nm}$. The difference was that the Am and Pu species were $<100 \mathrm{~nm}$ for ATM-103 but $>100 \mathrm{~nm}$ for ATM-106 fuel. Also, the distribution of the actinides in the colloidal fraction appears to be unique for each actinide, as shown in Table 10.

Also shown in Table 10 is the calculated concentration of each actinide in the final filtered solution. These values can be compared to the expected ionic concentrations at $\mathrm{pH}=6.9$. The expected concentrations (in units of $\mathrm{mol} / \mathrm{L}$ ) for $\mathrm{Pu}, \mathrm{Np}$, and $\mathrm{Am}$ are $9 \times 10^{-9}[11], 5 \times 10^{-8}$ [11], and $1 \times 10^{-7}$ [12], respectively. The values in Table 10 are comparable to the reported values for $\mathrm{Pu}$ and $\mathrm{Np}$ but are orders of magnitude lower than the americium concentration. The latter observation may indicate that americium forms colloidal species under unsaturated conditions.

Table 10. Actinides in Leachate ${ }^{a}$ and Material on Filters Determined by Alpha Spectroscopy

\begin{tabular}{|c|c|c|c|c|c|c|}
\hline \multirow[b]{2}{*}{ Isotope } & \multicolumn{4}{|c|}{ Mass (g) } & \multicolumn{2}{|c|}{ Final Filt. Sln. ${ }^{b}$} \\
\hline & Unfil. SIn. & $1000 \mathrm{~nm}$ & $100 \mathrm{~nm}$ & $50 \mathrm{~nm}$ & $\mathrm{~g}$ & $\mathrm{~mol} / \mathrm{L}$ \\
\hline \multicolumn{7}{|c|}{ ATM-106 } \\
\hline$A m-241^{c}$ & $3(-11)$ & $1(-11)$ & $8(-12)$ & $1(-12)$ & $8(-12)$ & $3(-11)$ \\
\hline $\begin{array}{l}\text { Crii-244 } \\
\text { Np-237 }\end{array}$ & $\begin{array}{l}5(-12) \\
5(-9)\end{array}$ & $\begin{array}{l}2(-12) \\
--d d\end{array}$ & $\begin{array}{l}6(-13) \\
2(-9)\end{array}$ & $\begin{array}{l}3(-14) \\
1(-9)\end{array}$ & $\begin{array}{l}3(-12) \\
2(-9)\end{array}$ & $\begin{array}{l}1(-11) \\
8(-9)\end{array}$ \\
\hline $\mathrm{Pu}-239$ & $3(-10)^{e}$ & $2(-10)$ & $1(-10)$ & $2(-11)$ & $3(-11)$ & $1(-10)$ \\
\hline \multicolumn{7}{|c|}{ ATM-103 } \\
\hline Am-241c & $5(-10)$ & --- & $<8(-10)$ & -- & -- & --- \\
\hline $\mathrm{Cm}-244$ & $1(-10)$ & $4(-12)$ & $3(-11)$ & $5(-12)$ & $6(-11)$ & $2(-10)$ \\
\hline Np-237 & $2(-7)$ & -- & $3(-7)$ & $2(-7)$ & -- & -- \\
\hline Pu-239 & $2(-8)$ & $1(-9)$ & $1(-8)$ & $6(-9)$ & $3(-9)$ & $9(-9)$ \\
\hline
\end{tabular}

aThe pH's of the two leachates for ATM-106 and ATM-103 were both 6.9.

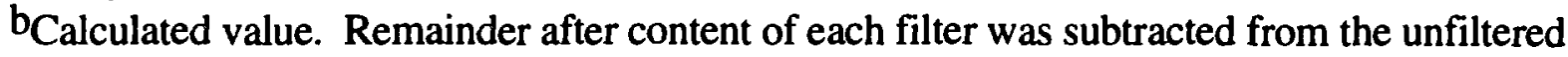
solution.

correction for $\mathrm{Pu}-238$ content.

dDashes indicate non-detection of this isotope.

eThis value is that for an evaporated sample that was analyzed by alpha spectroscopy. 


\section{Fuel Alteration}

The surface appearance of the ATM-106 fuel at 271, 482, and 581 days of testing is shown in Fig. 8. The lighter colored areas may indicate the formation of alteration products on the surface. A trefoil shape is readily apparent at 581 days (see Figs. 8 and 9). Its appearance can be noted as early as 271 days. This change at the fuel surface may be evidence of the rate of material removal.

The visual appearance of the material on the Zircaloy retainer at 271 days is shown in Fig. 10. This retainer was examined after it was dry. The findings were the following.

An optical microscopic examination of the alteration minerals on the Zircaloy retainer revealed an abundance of yellow alteration minerals with minor amounts of small black particles. The yellow crystals display a crystal morphology and EDS composition that are consistent with the presence of uranyl oxide hydrates (Figs. $11 \mathrm{a}$ and 11b). These mineral types were also prevalent during the early alteration of $\mathrm{UO}_{2}$ pellets, as discussed in $\mathrm{Sec}$. IV. The uranyl oxide hydrates also have incorporated radioactive $\mathrm{Cs}$ and, to a lesser extent, $\mathrm{Ba}$ and $\mathrm{Mo}$ from the dissolving spent nuclear fuel (Fig. 11c). The black particles observed during the optical examinations display a surface morphology that is reminiscent of spalled $\mathrm{UO}_{2}$ granules from the $\mathrm{UO}_{2}$ drip tests (Sec. IV). The SEM/EDS and AEM/EDS spectra from these samples reveal a uranium-dominated composition, with lesser Cs and Mo, as well as trace amounts of light rare earth elements (Figs. 11b-11e). These particulates may represent fines produced from mechanically damaged spent fuel particles. More likely, they may represent granules that have been loosened and dislodged from the spent fuel particles as the intergrain boundary regions have corroded.

\section{Low Drip-Rate and Vapor Tests}

The release behavior of cesium and the transuranics in the four other fuel tests and the control test is reported in Table 11. The values for the isotopes in the control tests are used as base values to eliminate any influence of cross-contamination from hot cell equipment.

The leachate in the low drip-rate and the vapor tests contained four orders of magnitude less cesium than that in the high drip-rate tests, and the transuranic release rate for the low drip-rate tests was two orders of magnitude lower. For the low drip-rate tests, the maximum fraction of Am and Cm released in the ATM-103 test was an order of magnitude greater than that in the ATM-106 test. This difference was also noted in the high drip-rate tests, but its cause has not been found.

For the vapor test with ATM-103, no release of cesium and the transuranics appears to have occurred if the results are compared to those from the control test. For the vapor test with ATM-106 fuel, the fraction of transuranics found in the vessel strip was an order of magnitude greater than that found in any of the three other tests. A possible reason may be that this vessel had not been acid stripped for 441 days.

\section{E. Discussion}

Tables 12 and 13 present the unprecipitated and maximum fractions, respectively, for cesium and the actinides for the following cases: the sum of the first two test intervals (120 and 275 days) for the high drip-rate tests with ATM-103 and ATM-106, the fourth test interval for these same tests, and saturated tests conducted by Wilson [13]. The total test time for Wilson was 540 days, versus 275 days at our second test sampling and 581 days (100-day interval) at our fourth sampling. The test temperatures are similar. The ratio of fuel weight to total volume of 
(a)

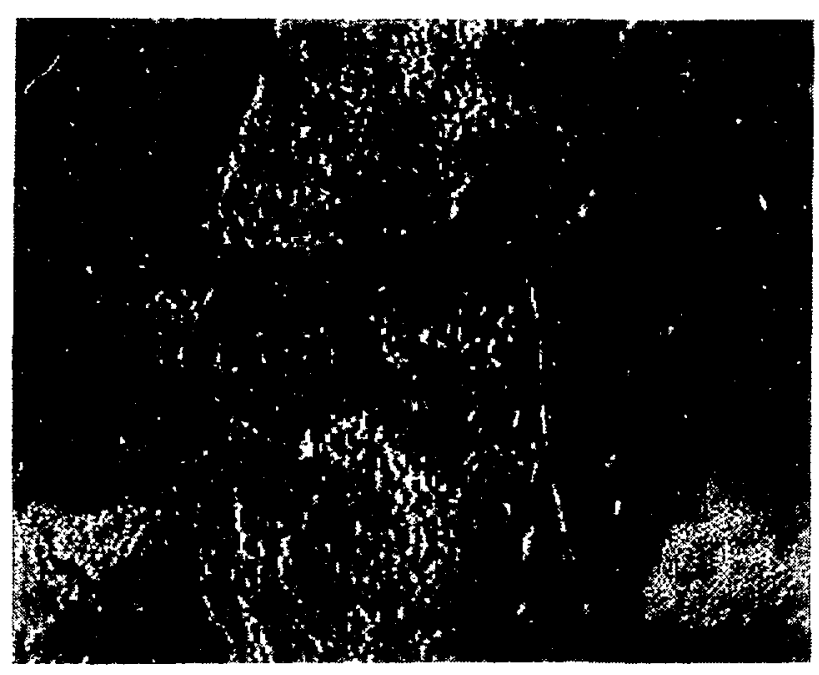

(b)

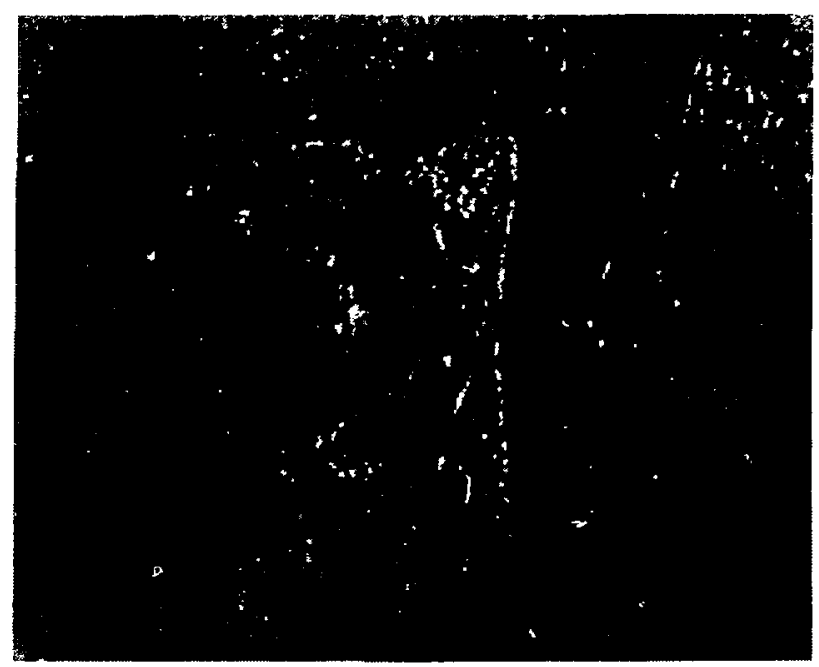

(c)

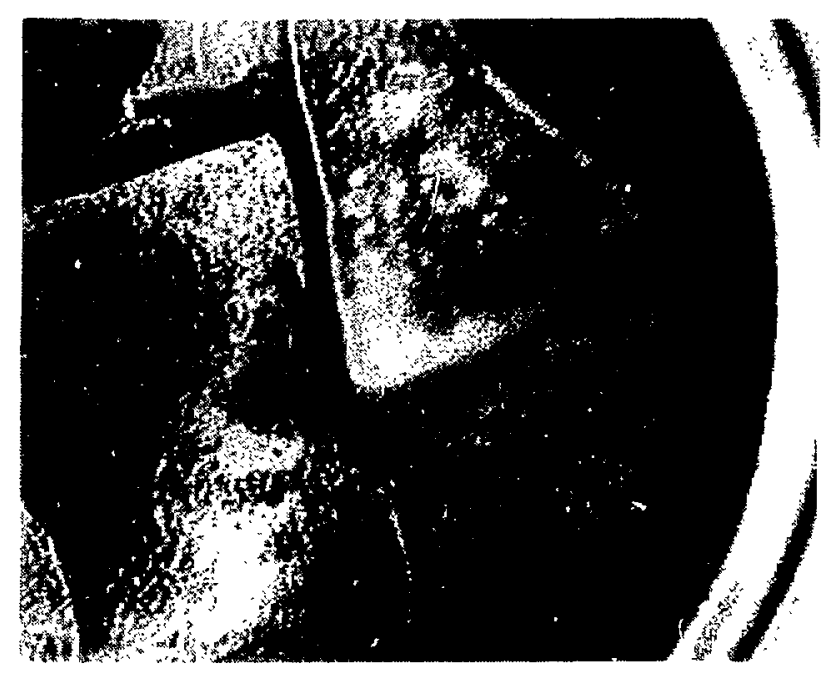

Fig. 8. Visual Appearance of ATM-106 Fuel in High Drip-Rate Test (10X Magnification) at (a) 271 Days, (b) 482 Days, and (c) 581 Days. Note light-colored areas at 581 days and pronounced shape of trefoil at lower left. 


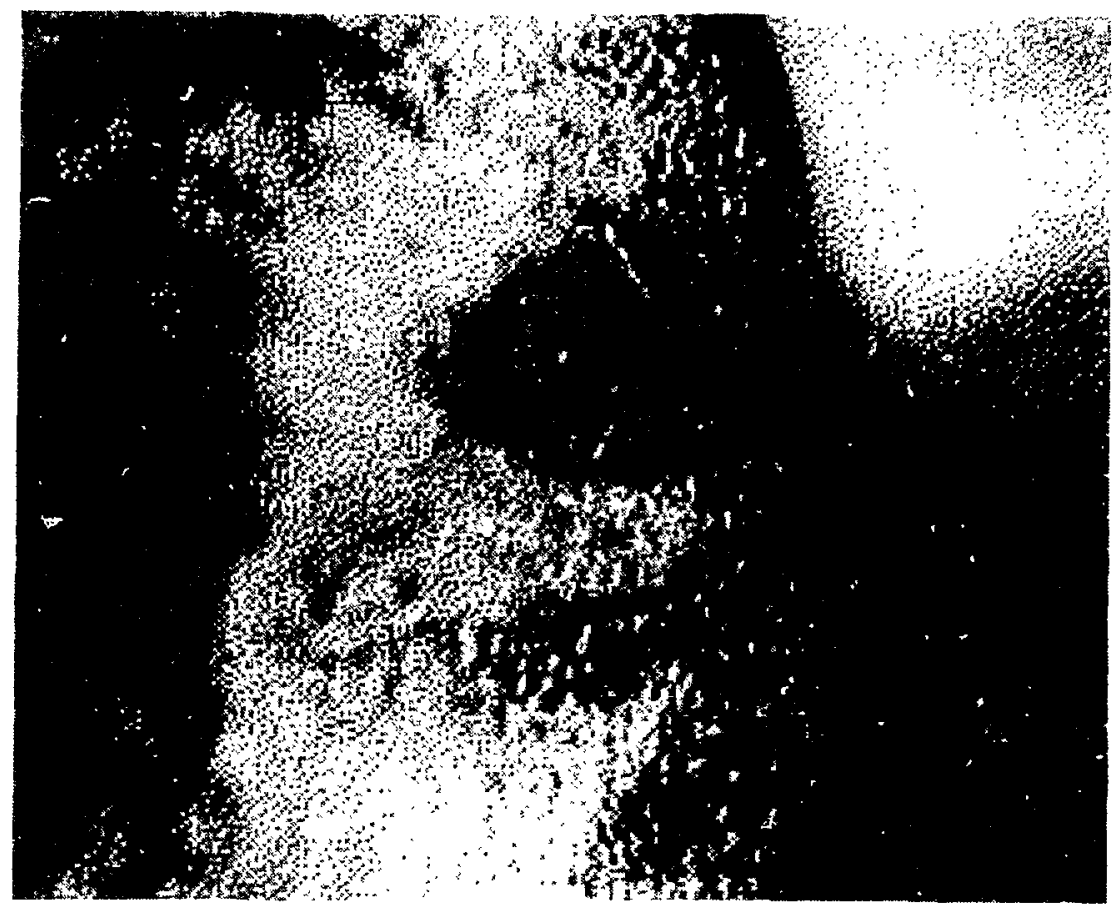

Fig. 9. Visual Appearance of ATM-106 Trefoil at 581 Days (20X Magnification). Light-colored areas are more pronounced and may be alteration products.

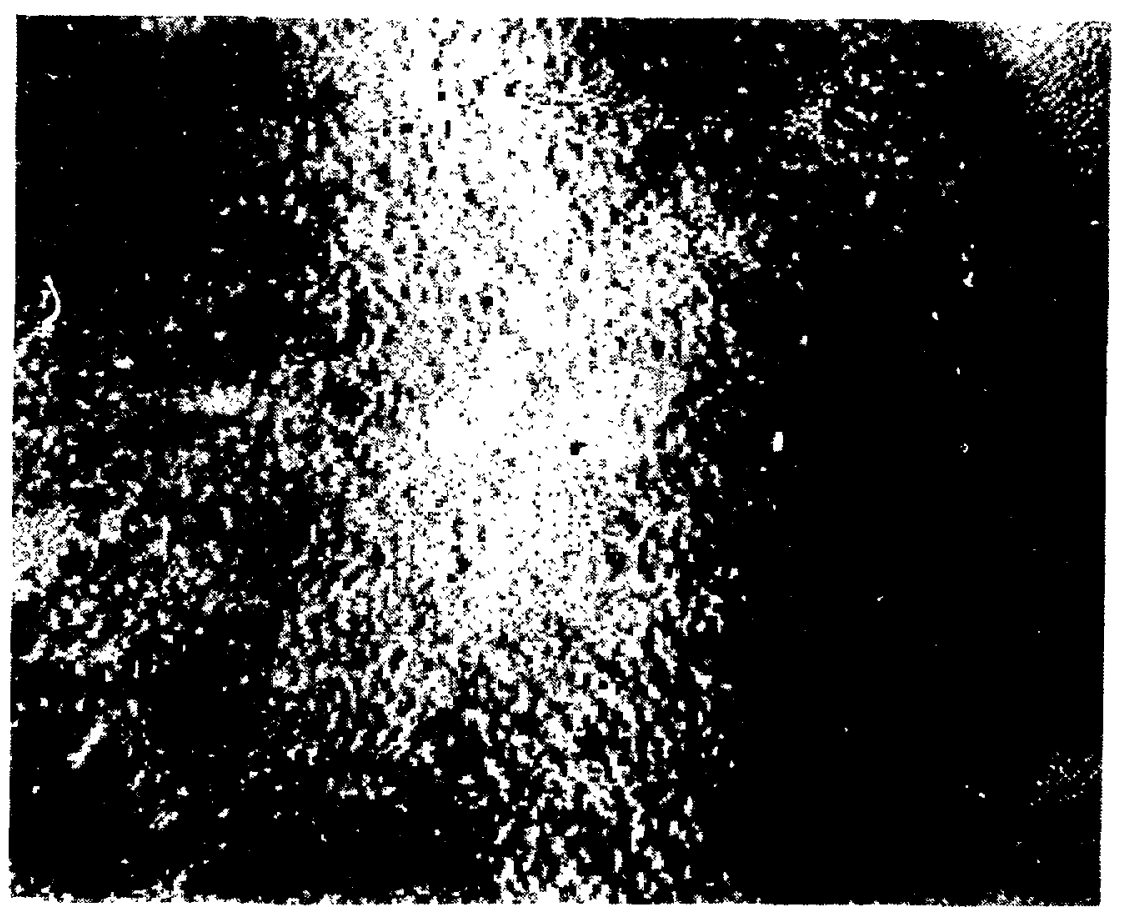

Fig. 10. Visual Appearance of Zircaloy Filter from High Drip-Rate Test with ATM-106 Sample at 271 Days. The light-colored regions were identified from SEM and TEM as possibly billietite, a barium-containing member of the becquerelite group. 

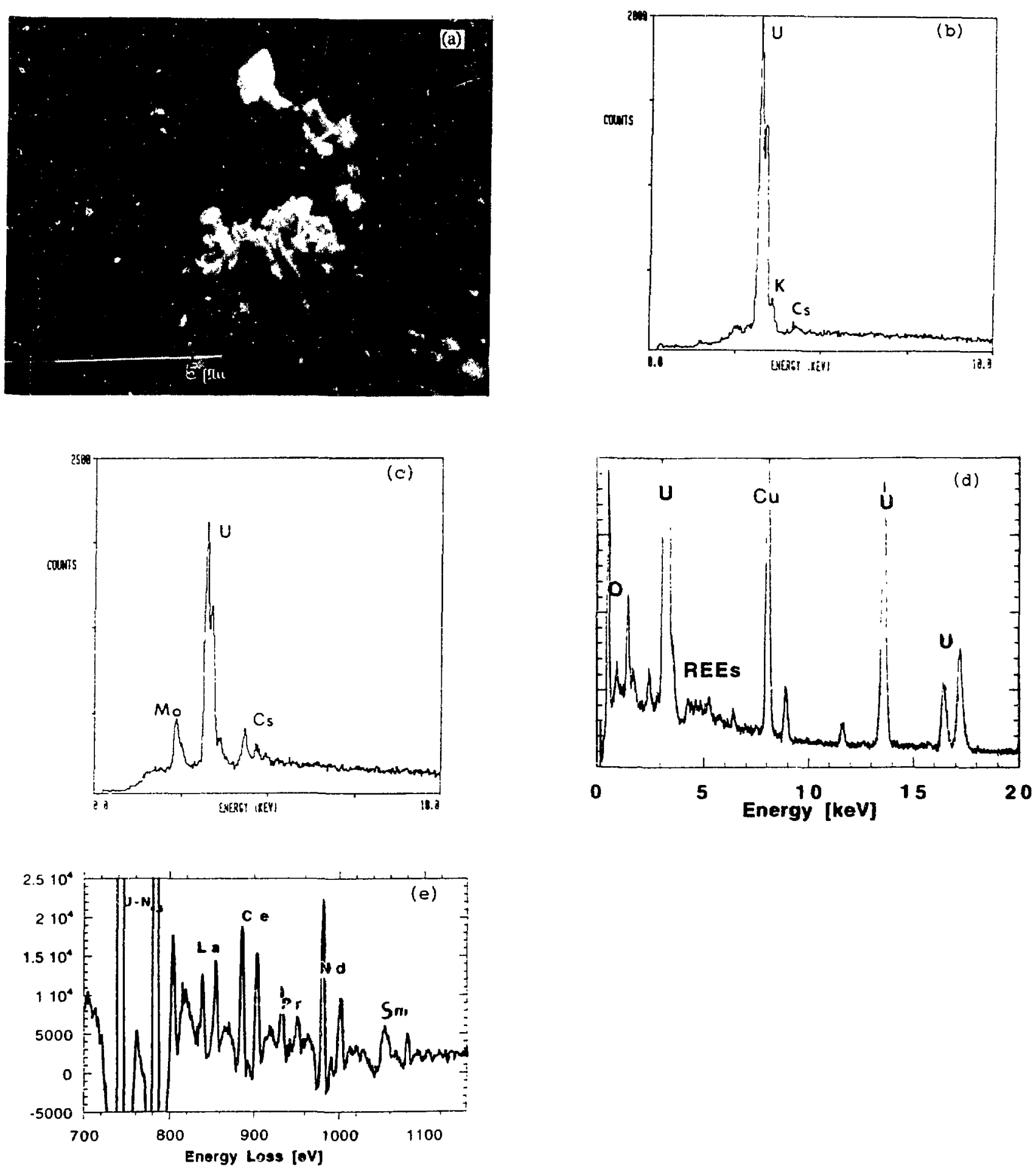

Fig. 11. Results from Analysis of ATM-106 after 581 Days of Testing: (a) SEM Image, (b and c) EDS Spectra of Uranyl Oxide Hydrates and Spent Fuel Particles, (d) AEM Characterization of Uranium Oxide Particles Found in Spent Fuel Test, and (e) EDS Analysis of Uranium Oxide Fuel 
Table 11. Distribution of Cesiur and Transuranics in Low Drip-Rate and Vapor Tests after $\sim 581$ Days

\begin{tabular}{|c|c|c|c|c|c|c|}
\hline & \multicolumn{4}{|c|}{ Mass (g) } & \multirow{2}{*}{$\begin{array}{l}\text { Unprecip. } \\
\text { Frac. (\%) }\end{array}$} & \multirow{2}{*}{$\begin{array}{l}\text { Maximum } \\
\text { Frac. (\%) }\end{array}$} \\
\hline & Leachate & Strip & Wash $^{\mathrm{a}}$ & Total & & \\
\hline \multicolumn{7}{|c|}{ ATM-106 - Low Drip Rate } \\
\hline$A m-241^{b}$ & $1(-11)$ & $1(-10)$ & $1(-11)$ & $1(-10)$ & 8 & $2(-6)$ \\
\hline $\mathrm{Cm}-244$ & $4(-13)$ & $2(-11)$ & $5(-13)$ & $2(-11)$ & 2 & $5(-6)$ \\
\hline$N p-237$ & $2(-10)$ & $4(-8)$ & $3(-8)$ & $7(-8)$ & $<1$ & $2(-3)$ \\
\hline Pu-239 & $2(-11)$ & $9(-10)$ & $4(-10)$ & $1(-9)$ & 2 & $3(-6)$ \\
\hline Cs- 137 & $7(-10)$ & $3(-9)$ & -- & $4(-9)$ & 20 & $6(-5)$ \\
\hline \multicolumn{7}{|c|}{ ATM-106 - Vaporc } \\
\hline$A m-241^{b}$ & $1(-12)$ & $2(-9)$ & $5(-10)$ & $3(-9)$ & $<1$ & $4(-5)$ \\
\hline $\mathrm{Am}-243$ & --- & $3(-10)$ & $2(-10)$ & $5(-10)$ & $<1$ & $3(-5)$ \\
\hline $\mathrm{Cm}-244$ & $4(-14)$ & $1(-10)$ & $3(-11)$ & $1(-10)$ & $<1$ & $2(-5)$ \\
\hline Np-237 & $1(-9)$ & $2(-8)$ & $3(-8)$ & $5(-8)$ & 2 & $2(-3)$ \\
\hline Pu-239 & $3(-11)$ & $1(-8)$ & $5(-9)$ & $2(-8)$ & $<1$ & $7(-5)$ \\
\hline Cs-137 & $1(-10)$ & $1(-8)$ & $\cdots$ & $1(-8)$ & 1 & $2(-4)$ \\
\hline \multicolumn{7}{|c|}{ ATM-103 - Low Drip Rate } \\
\hline$A m-241^{b}$ & $5(-12)$ & $7(-10)$ & $6(-11)$ & $8(-10)$ & $<1$ & $2(-5)$ \\
\hline $\mathrm{Am}-243$ & -- & $3(-10)$ & - & $3(-10)$ & $<1$ & $5(-5)$ \\
\hline $\mathrm{Cm}-244$ & $8(-14)$ & $5(-11)$ & $3(-12)$ & $5(-11)$ & $<1$ & $4(-5)$ \\
\hline Np-237 & $2(-9)$ & $2(-8)$ & $7(-9)$ & $3(-8)$ & 7 & $1(-3)$ \\
\hline $\mathrm{Pu}-239$ & $1(-11)$ & $7(-10)$ & $6(-10)$ & $1(-9)$ & 1 & $3(-6)$ \\
\hline Cs-137 & $3(-10)$ & $2(-9)$ & -- & $2(-9)$ & 13 & $3(-5)$ \\
\hline \multicolumn{7}{|c|}{ ATM-103 - Vapor } \\
\hline$A m-241^{b}$ & $3(-12)$ & $9(-11)$ & $6(-11)$ & $2(-10)$ & 2 & $5(-6)$ \\
\hline $\mathrm{Cm}-244$ & $1(-14)$ & $1(-12)$ & $6(-13)$ & $2(-12)$ & $<1$ & $2(-6)$ \\
\hline Np-237 & $3(-10)$ & $7(-9)$ & -- & $7(-9)$ & 4 & $2(-4)$ \\
\hline $\mathrm{Pu}-239$ & $2(-11)$ & $3(-10)$ & $1(-10)$ & $4(-10)$ & 5 & $9(-7)$ \\
\hline Cs- 137 & $3(-10)$ & $6(-11)$ & -- & $4(-10)$ & 83 & $7(-6)$ \\
\hline \multicolumn{7}{|c|}{ Control - Low Drip Rate } \\
\hline$A m-241^{b}$ & $2(-12)$ & $4(-11)$ & $6(-11)$ & $1(-10)$ & $\overline{2}$ & $\cdots$ \\
\hline $\mathrm{Cm}-244$ & $6(-14)$ & $1(-12)$ & $4(-12)$ & $5(-12)$ & 1 & --- \\
\hline $\mathrm{Np}-237$ & $3(-9)$ & $5(-9)$ & $5(-9)$ & $1(-8)$ & 23 & --- \\
\hline Pu-239 & $6(-11)$ & $2(-10)$ & $2(-10)$ & $5(-10)$ & 12 & --- \\
\hline Cs- 137 & $4(-13)$ & $5(-10)$ & -.- & $5(-10)$ & $<1$ & --- \\
\hline
\end{tabular}

aThe acid wash contributed $40-60 \%$ of the total plutonium and up to $30 \%$ of the total Am, Np, and $\mathrm{Cm}$.

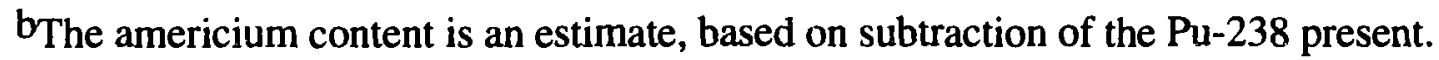

cThe test vessel had not been stripped for 441 days. Therefore, the values for the strip and the wash are elevated compared to those for the other test vessels. 
Table 12. Average Unprecipitated Fractions (\%) for Unsaturated High Drip-Rate versus Saturated Tests

\begin{tabular}{lcrrrr}
\hline & $\mathrm{U}$ & Pu & Am & Cm & Cs \\
\hline ATM-103 $(275 \mathrm{~d})^{\mathrm{a}}$ & 50 & 40 & 50 & 70 & 98 \\
ATM-103 $(100 \mathrm{~d})^{\mathrm{b}}$ & N.A.c & 59 & $<1$ & 2 & 96 \\
${\text { ATM-106 }(275 \mathrm{~d})^{\mathrm{a}}}^{\mathrm{a}}$ & 20 & 50 & 10 & 30 & 60 \\
${\text { ATM-106 }(100 \mathrm{~d})^{\mathrm{b}}}$ & N.A. & 2 & 2 & 1 & 94 \\
Wilson $(540 \mathrm{~d})^{\mathrm{d}}$ & 10 & 5 & 3 & 3 & 85 \\
\hline
\end{tabular}

aThis is total time for first two test intervals.

bFourth test interval.

$\mathrm{c}_{\mathrm{N}} . \mathrm{A} .=$ not yet available.

dReference 12; bare fuel for three test periods at $85^{\circ} \mathrm{C}$.

Table 13. Maximum Fraction (\%) for Unsaturated High Drip-Rate versus Saturated Tests

\begin{tabular}{|c|c|c|c|c|c|}
\hline & $\mathrm{U}$ & $\mathrm{Pu}$ & $\mathrm{Am}$ & $\mathrm{Cm}$ & Cs \\
\hline ATM-103 $(275 d)^{\mathrm{a}}$ & $1(-5)$ & $1(-6)$ & $6(-4)$ & $7(-3)$ & $6(-4)$ \\
\hline $\operatorname{ATM}-103(100 \mathrm{~d})^{\mathrm{b}}$ & N.A. & $9(-5)$ & $1(-3)$ & $4(-3)$ & $2(-2)$ \\
\hline ATM-106 (275 d)a & $5(-5)$ & $3(-5)$ & $9(-5)$ & $2(-4)$ & $1(-3)$ \\
\hline ATM-106 (100d) $)^{b}$ & N.A. & $1(-5)$ & $4(-5)$ & $1(-4)$ & $2(-2)$ \\
\hline Wilson $(540 \mathrm{~d})^{\mathrm{c}}$ & $1(-4)$ & $1(-4)$ & $2(-4)$ & $4(-5)$ & $1(-2)$ \\
\hline Werme $^{d}$ & $1(-4)$ & -- & -- & $\cdots$ & $8(-3)$ \\
\hline
\end{tabular}

aThis is total time and total fractions for first two test intervals.

bFourth test interval.

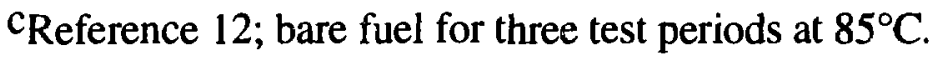

dReference 10. 
fluid in contact with the fuel was slightly greater for the unsaturated tests at the end of the second interval. Therefore, we assumed that fluid was in contact with the fuel either as a film of water or as a pool of liquid in the fuel holder during our tests.

By comparing our 275-day data to those of Wilson, we noted three major differences. These noted differences do not reflect the material released from the spent fuel but retained by the Zircaloy. First, a much larger fraction of the material was unprecipitated in the unsaturated tests. The one exception was cesium in the ATM-106 test. The low cesium release is confirmed by incorporation of cesium into the uranyl hydrate phase described previously (Sec. III.D.4) and is consistent with cesium uranate phases that have been reported in the literature $[11,14]$. Second, the maximum fraction of $\mathrm{Cs}, \mathrm{U}$, and $\mathrm{Pu}$ released for the unsaturated tests is approximately an order of magnitude less than that in the saturated tests. Third, the maximum fraction of $\mathrm{Cm}$ and Am released in the unsaturated tests is about an order of magnitude greater than that in the saturated tests. These differences appear to be linked to the higher unprecipitated fraction in the unsaturated tests.

By comparing our 100-day data to that of Wilson, we found that the fraction of cesium released is comparable for all three fuels. However, for the ATM-103 fuel, the fraction of Am and $\mathrm{Cm}$ released is one and two orders of magnitude greater, respectively, than that observed in Wilson's test. The plutonium release is comparable. For the ATM-106 fuel, the curium release is an order of magnitude greater than Wilson's, and the Am and Pu release is an order of magnitude less.

The amount of Am and $\mathrm{Cm}$ released from the two fuels was one to two orders of magnitude greater than that released from spent fuel under saturated conditions. The cause of these differences has not been identified. However, uranium may form insoluble alteration products in which transuranics are not incorporated. The transuranics could then be carried by the fluid, either as soluble species or as colloids, away from the site of the uranium alteration products. This mechanism suggests the existence of different transport routes for uranium and for the transuranics. This potential difference would have to be considered in any modeling efforts.

\section{F. Conclusions}

In the high drip-rate tests, actinides appeared to have been released from the fuel fragments at a consistent rate during 581 days of testing. The leachates contained a higher proportion of Am and $\mathrm{Cm}$ than $\mathrm{Pu}$. The distribution of the actinides in the colloidal fraction appears to differ for each actinide and for each fuel type. The leachates for both ATM-103 and ATM-106 had a bimodal distribution for curium, with $50 \%$ of the content being $\geq 1000 \mu \mathrm{m}$ and $50 \%$ being $<50 \mathrm{~nm}$, and the neptunium species were $<100 \mathrm{~nm}$. The Am and Pu species were $<100 \mathrm{~nm}$ for ATM-103 but $>100 \mathrm{~nm}$ for ATM-106.

The leachate in the low drip-rate and the vapor tests had four orders of magnitude less cesium than that in the high drip-rate tests. The actinide release rate for the low drip-rate tests was two orders of magnitude lower than that in the high drip-rate tests. For the low drip-rate tests, the maximum fraction of Am and Cm released in the ATM-103 test was an order of magnitude greater than that in the ATM-106 test. This difference in release behavior for the two fuels was also noted in the high drip-rate tests, but its cause has not been elucidated.

The amount of Am and $\mathrm{Cm}$ released from the two fuels under unsaturated conditions was one to two orders of magnitude greater than that released from spent fuel under saturated conditions. The cause of the difference has not been identified. However, uranium may form insoluble alteration products in which transuranics are not incorporated. This could result in different transport routes for uranium and for the transuranics. 
Uranyl oxide hydrate minerais containing $\mathrm{Cs}$ and lesser amounts of $\mathrm{Mo}$ and $\mathrm{Ba}$ were found on the Zircaloy retainer used for the first 270 days in the high-drip rate test with ATM-106. The occurrence of uranyl oxide hydrates is similar to patterns observed during initial stages of $\mathrm{UO}_{2}$ alteration in unsaturated tests, as well as initial stages of alteration of naturally occurring uraninite. These phases may retard the migration of fission pruducts during the corrosion of spent nuclear fuel. Small $(\sim 5 \mu \mathrm{m})$ particles of spent fuel interspersed within the uranyl oxide hydrate crystals were also observed. The genesis of these particles is not known.

\section{G. Ongoing Work}

All of the unsaturated tests remain in progress. Detailed analysis of the leachates will continue in the next year to determine if there is a diminution in the leach rate and a change in the composition, form, and quantity of the radionuclides. The full suite of radionuclides and fission products released during the tests will be reported (see below).

Limited studies by AEM on the formation and characterization of colloids in the leachate will continue, with emphasis on the impact of colloids on fuel dissolution. Colloids in solution could also be examined by using more detailed techniques to determine the actinide content of individual colloidal species, as well as the composition of the colloids in solution, as a function of ionic strength and $\mathrm{pH}$, but this information requires an addirional commitment from the Yucca Mountain Project.

Data collected on leachate samples with ICP-MS have not yet been analyzed due to the need for data on the non-natural isotopic distributions for the spent fuel. Work has begun on acquiring the needed data and will continue.

Samples of alteration phases produced in these tests will continue to be monitored with reference to mineral paragenetic trends and retardation mechanisms foi spent fuel corrosion products. A more detailed Test Plan will be written to address new issues that have been identified during the above-described testing of spent fuel under low water volume conditions. This Test Plan will use a fuller range of spent fuel samples and reaction conditions than used in our initial tests, and the results from the newly planned tests should be directly interpretable in terms of information needed to conduct realistic performance assessment of engineered barrier performance. 


\section{UNSATURATED TESTS WITH UO2}

\section{A. Introduction}

The present tests with $\mathrm{UO}_{2}$ are being conducted to examine the feasibility of using the unsaturated drip test method on spent nuclear fuel (see Sec. III). Because direct testing of spent fuel is difficult due to its high level of radioactivity, unirradiated $\mathrm{UO}_{2}$ is being used as a surrogate for spent fuel. While these experiments are not completely analogous to spent fuel behavior, the reaction processes occurring during the corrosion of spent fuel and $\mathrm{UO}_{2}$ may be similar since spent fuel contains $>95 \% \mathrm{UO}_{2}$. Therefore, the gross processes observed in the $\mathrm{UO}_{2}$ experiments should be relevant to spent fuel behavior, especially with respect to the identification of secondary alteration products and modes of waste form degradation.

\section{B. Objective}

The objective of this project is to evaluate the reaction of $\mathrm{UO}_{2}$ after exposure to dripping EJ-13 water at $90^{\circ} \mathrm{C}$ (Unsaturated Test Method). These tests will thus examine the alteration behavior of $\mathrm{UO}_{2}$ under a potential unsaturated repository scenario, where limited amounts of groundwater contact and migrate across the waste material. More specifically, these tests are designed to examine the dissolution behavior of the $\mathrm{UO}_{2}$ pellets, identify long-term alteration mineral paragenetic trends, describe parameters that control the release of uranium from the $\mathrm{UO}_{2}$ pellets, and serve as a pilot study for similar tests with spent nuclear fuel.

\section{Experimental Approach}

The experimental procedure for these tests is described in detail by Wronkiewicz et al. [15] and will be summarized here. Sample pellets were fabricated from pressed and sintered $\mathrm{UO}_{2}$ granules with a natural isotopic composition. Trace element abundances are minor: the $\mathrm{B}, \mathrm{Si}, \mathrm{Ca}$, $\mathrm{Ni}, \mathrm{Cu}$, and $\mathrm{Al}$ concentrations are between 1 and $5 \mathrm{ppm}$ and the $\mathrm{Cl}, \mathrm{Th}$, and $\mathrm{Fe}$ concentrations are 10,15 , and $20 \mathrm{ppm}$, respectively. All other trace constituents were $<1 \mathrm{ppm}$ each. The overall oxygen/metal ratio was determined to be $2.000 \pm 0.002$ by measuring the weight difference of a sample both before and after open-air heating to $850^{\circ} \mathrm{C}$. The effect of variable sample surface area on the dissolution rate has been examined by preparing several different sample pellet, disk, and granule configurations (bottom of Table 14). All sample assemblies were encased in a sleeve of Zircaloy -4 tubing with the assembled $\mathrm{UO}_{2}$ surfaces exposed on the tops and bottoms to allow fluids to flow across the samples. The Zircaloy tube bottoms were pinched to keep the $\mathrm{UO}_{2}$ assembly from coming in direct contact with the vessel support plate.

The experiments were conducted in stain'ess steel (304L) vessels that provided a stable atmosphere for the containment and collection of the leachate and support of the specimen assembly (Fig. 12). Tests were conducted at $90 \pm 2{ }^{\circ} \mathrm{C}$. The leachant for the tests is equilibrated J-13 groundwater (EJ-13), which was prepared in the same manner as described in Sec. III.C. The EJ-13 leachant was periodically dripped onto the tops of the $\mathrm{UO}_{2}$ samples via a stainless steel/Teflon injection line. Water contact occurred on the top sample surfaces, with the fluids then flowing along the sides of the samples and dripping from the bottom $\mathrm{UO}_{2}$ surface into the test vessel chamber, where the leachate was collected. Two water injection rates were employed for the samples: $0.075 \mathrm{~mL} / 3.5$ days (six tests) and $0.0375 \mathrm{~mL} / 7$ days (two tests). Of the eight tests, five have been terminated at various time intervals to allow for a detailed examination of the reacted solid surfaces, and the remaining three tests have been continuously in operation for over nine years. 
Table 14. Total Uranium Release in Unsaturated Tests with $\mathrm{UO}_{2}$ Samples ${ }^{\mathrm{a}}$

\begin{tabular}{|c|c|c|c|c|c|c|c|c|c|c|c|c|}
\hline \multirow[b]{2}{*}{$\begin{array}{l}\text { Elapsed } \\
\text { Time } \\
\text { (wks) }\end{array}$} & \multicolumn{3}{|c|}{ Sample \#1 } & \multicolumn{3}{|c|}{ Sample \#2 } & \multicolumn{3}{|c|}{ Sample \#3 } & \multicolumn{3}{|c|}{ Sample \#4 } \\
\hline & $\begin{array}{l}\text { Sol. } \\
\text { Vol. } \\
\text { (mL) }\end{array}$ & $\begin{array}{c}\mathrm{U} \\
\text { Release } \\
(\mu \mathrm{g})\end{array}$ & $\begin{array}{c}\text { Cum. U } \\
\text { Release } \\
(\mu \mathrm{g})\end{array}$ & $\begin{array}{l}\text { Sol. } \\
\text { Vol. } \\
\text { (mL) }\end{array}$ & $\begin{array}{c}\mathrm{U} \\
\text { Release } \\
(\mu g)\end{array}$ & $\begin{array}{c}\text { Cum. U } \\
\text { Release } \\
(\mu g)\end{array}$ & $\begin{array}{l}\text { Sol. } \\
\text { Vol. } \\
\text { (mL) }\end{array}$ & $\begin{array}{c}\mathrm{U} \\
\text { Release } \\
(\mu \mathrm{g})\end{array}$ & $\begin{array}{c}\text { Cum. U } \\
\text { Release } \\
(\mu \mathrm{g})\end{array}$ & $\begin{array}{l}\text { Sol. } \\
\text { Vol. } \\
\text { (mL) }\end{array}$ & $\begin{array}{c}\text { U } \\
\text { Release } \\
(\mu \mathrm{g})\end{array}$ & $\begin{array}{c}\text { Cum. U } \\
\text { Release } \\
\text { ( } \mu \mathrm{g})\end{array}$ \\
\hline 8.0 & 0.84 & 26.2 & 26.2 & 0.81 & 11 & 11 & 0.78 & 0.28 & 0.28 & 0.81 & 2.7 & 2.7 \\
\hline 13.0 & 0.19 & 21.6 & 47.8 & 0.64 & 25.7 & 36.7 & 0.58 & 5.88 & 6.16 & 0.64 & 7.7 & 10.4 \\
\hline 19.6 & 0.77 & 449 & 497 & 1.01 & 388 & 425 & 0.79 & 71.3 & 77.5 & 0.83 & 9.2 & 19.6 \\
\hline 26.0 & 0.78 & 264 & 761 & 0.93 & 201 & 626 & 0.78 & 126 & 204 & 0.81 & 9.7 & 29.3 \\
\hline 32.6 & 0.67 & 129 & 890 & 0.81 & 56.2 & 682 & 0.75 & 88.8 & 293 & 0.75 & 193 & 222 \\
\hline 39.0 & 0.64 & 74.5 & 965 & 0.83 & 38.3 & 721 & 0.82 & 31.1 & 324 & 0.81 & 113 & 336 \\
\hline 45.6 & 0.66 & 1001 & 1966 & 0.66 & 46.9 & 768 & 0.85 & 195 & 518 & 0.63 & 624 & 959 \\
\hline 52.0 & 0.74 & 2159 & 4125 & 0.80 & 1446 & 2214 & 0.83 & 131 & 649 & 0.25 & 967 & 1927 \\
\hline $\begin{array}{l}78.0 \\
105\end{array}$ & $\begin{array}{l}3.21 \\
3.03\end{array}$ & $\begin{array}{l}274 \\
168\end{array}$ & $\begin{array}{l}4398 \\
4566\end{array}$ & $\begin{array}{l}2.63 \\
3.40\end{array}$ & $\begin{array}{r}1494 \\
105\end{array}$ & $\begin{array}{l}3708 \\
3812\end{array}$ & $\begin{array}{l}3.42 \\
3.31\end{array}$ & $\begin{array}{l}266 \\
139\end{array}$ & $\begin{array}{r}915 \\
1053\end{array}$ & 1.57 & 1401 & 3328 \\
\hline $\begin{array}{l}134 \\
157\end{array}$ & $\begin{array}{l}3.29 \\
2.58\end{array}$ & $\begin{array}{l}145 \\
124\end{array}$ & $\begin{array}{l}4711 \\
4836\end{array}$ & $\begin{array}{l}3.65 \\
3.22\end{array}$ & $\begin{array}{l}69.6 \\
174\end{array}$ & $\begin{array}{l}3882 \\
4056\end{array}$ & $\begin{array}{l}3.52 \\
3.06\end{array}$ & $\begin{array}{l}50.8 \\
287\end{array}$ & $\begin{array}{l}1104 \\
1391\end{array}$ & \multicolumn{3}{|c|}{$\begin{array}{l}\text { Terminated after } \\
78 \text { weeks }\end{array}$} \\
\hline $\begin{array}{l}183 \\
211 \\
\end{array}$ & 2.77 & 164 & 4999 & $\begin{array}{l}3.41 \\
2.09 \\
\end{array}$ & $\begin{array}{l}73.9 \\
193 \\
\end{array}$ & $\begin{array}{l}4130 \\
4323 \\
\end{array}$ & $\begin{array}{r}3.26 \\
3.32 \\
\end{array}$ & $\begin{array}{l}172 \\
250 \\
\end{array}$ & $\begin{array}{l}1563 \\
1813 \\
\end{array}$ & & & \\
\hline $\begin{array}{l}238 \\
291\end{array}$ & \multicolumn{3}{|c|}{$\begin{array}{l}\text { Terminated after } \\
183 \text { weeks }\end{array}$} & $\begin{array}{l}1.87 \\
5.43\end{array}$ & $\begin{array}{l}71.6 \\
38.1\end{array}$ & $\begin{array}{l}4394 \\
4432 \\
\end{array}$ & $\begin{array}{l}2.38 \\
6.14\end{array}$ & $\begin{array}{l}97.7 \\
106\end{array}$ & $\begin{array}{l}1911 \\
2017\end{array}$ & & & \\
\hline 358 & & & & 6.70 & 266 & 4698 & 8.15 & 424 & 2441 & & & \\
\hline 417 & & & & 4.47 & 325 & 5023 & 5.88 & 301 & 2742 & & & \\
\hline 469 & & & & & & & 4.24 & 298 & 3040 & & & \\
\hline \multicolumn{13}{|c|}{$\begin{array}{l}\text { Terminated after } \\
417 \text { weeks }\end{array}$} \\
\hline $\begin{array}{l}\text { Drip Ra } \\
\text { Configu }\end{array}$ & & \multicolumn{2}{|c|}{$\begin{array}{l}0.075 \mathrm{~mL} / 3.5 \text { days } \\
11 \text { disks }\end{array}$} & \multicolumn{3}{|c|}{$\begin{array}{l}0.075 \mathrm{~mL} / 3.5 \text { days } \\
11 \text { disks }\end{array}$} & \multicolumn{3}{|c|}{$\begin{array}{l}0.075 \mathrm{~mL} / 3.5 \text { days } \\
\text { Crushed } \mathrm{UO}_{2}\end{array}$} & & \multicolumn{2}{|c|}{$\begin{array}{l}0.075 \mathrm{~mL} / 3.5 \text { days } \\
\text { Crushed } \mathrm{UO}_{2}\end{array}$} \\
\hline $\begin{array}{l}\text { Sample } \\
\text { Sample }\end{array}$ & $\begin{array}{l}\text { g) } \\
\left.m^{2}\right)\end{array}$ & \multicolumn{2}{|c|}{$\begin{array}{l}29.52 \\
40.7\end{array}$} & \multicolumn{3}{|c|}{$\begin{array}{l}29.17 \\
40.6\end{array}$} & \multicolumn{3}{|c|}{$\begin{array}{l}19.86 \\
486\end{array}$} & \multicolumn{3}{|c|}{$\begin{array}{l}18.26 \\
467\end{array}$} \\
\hline Sample & $\left(m^{3}\right)$ & \multicolumn{2}{|l|}{2.83} & \multicolumn{3}{|c|}{2.80} & \multicolumn{3}{|c|}{2.21} & \multicolumn{3}{|c|}{2.14} \\
\hline
\end{tabular}


Table 14 (contd.)

\begin{tabular}{|c|c|c|c|c|c|c|c|c|c|c|c|c|}
\hline \multirow[b]{2}{*}{$\begin{array}{l}\text { Elapsed } \\
\text { Time } \\
\text { (wks) }\end{array}$} & \multicolumn{3}{|c|}{ Sample \#5 } & \multicolumn{3}{|c|}{ Sample \#6 } & \multicolumn{3}{|c|}{ Sample \#7 } & \multicolumn{3}{|c|}{ Sample \#8 } \\
\hline & $\begin{array}{l}\text { Sol. } \\
\text { Vol. } \\
\text { (mL) }\end{array}$ & $\begin{array}{c}\mathrm{U} \\
\text { Release } \\
(\mu \mathrm{g})\end{array}$ & 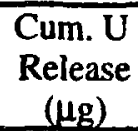 & $\begin{array}{l}\text { Sol. } \\
\text { Vol. } \\
\text { (mL) }\end{array}$ & $\begin{array}{c}\mathrm{U} \\
\text { Release } \\
(\mu \mathrm{g})\end{array}$ & $\begin{array}{c}\text { Cum. U } \\
\text { Release } \\
(\mu g)\end{array}$ & $\begin{array}{l}\text { Sol. } \\
\text { Vol. } \\
\text { (mL) }\end{array}$ & $\begin{array}{c}\text { U } \\
\text { Release } \\
(\mu g)\end{array}$ & $\begin{array}{c}\text { Cum. U } \\
\text { Release } \\
(\mu \mathrm{g})\end{array}$ & $\begin{array}{l}\text { Sol. } \\
\text { Vol. } \\
\text { (mL) }\end{array}$ & $\begin{array}{c}\mathrm{U} \\
\text { Release } \\
(\mu \mathrm{g})\end{array}$ & $\begin{array}{c}\text { Cum. U } \\
\text { Release } \\
\text { (ug) }\end{array}$ \\
\hline 8.0 & 0.75 & 2.85 & 2.85 & 0.87 & 2.61 & 2.61 & & & & & & \\
\hline 13.0 & 0.58 & 1.22 & 4.07 & 0.66 & 2.95 & 5.56 & 0.30 & 1.06 & 1.06 & 0.35 & 0.88 & 0.88 \\
\hline 19.6 & 0.85 & 109 & 113 & 0.78 & 30.4 & 36.0 & & & & & & \\
\hline 26.0 & 0.76 & 36.1 & 150 & 0.77 & 41.9 & 77.9 & 0.67 & 302 & 303 & 0.51 & 525 & 526 \\
\hline 32.6 & 0.77 & 33.8 & 183 & 0.70 & 799 & 876 & & & & & & \\
\hline 39.0 & 0.77 & 19.4 & 203 & 0.76 & 1391 & 2267 & & 95.3 & 398 & 0.34 & 247 & 772 \\
\hline 45.6 & 1.07 & 322 & 524 & 0.43 & 55.7 & 2323 & & & & & & \\
\hline 52.0 & 0.92 & 72.7 & 597 & 0.22 & 593 & 2916 & 0.39 & 565 & 1063 & 0.63 & 264 & 1036 \\
\hline 78.0 & 3.62 & 103 & 700 & 2.95 & 3710 & 6626 & 0.72 & 1075 & 2138 & 0.78 & 5948 & 6984 \\
\hline 105 & 3.41 & 47.8 & 748 & 3.14 & 389 & 7015 & 0.52 & 225 & 2363 & 0.37 & 2107 & 9091 \\
\hline 134 & 3.35 & 69.3 & 817 & & & & 0.13 & 79.3 & 2442 & 0.51 & 10324 & 19415 \\
\hline 157 & 1.54 & 58.2 & 876 & 6.52 & 450 & 7465 & 0.64 & 113 & 2555 & & & \\
\hline $\begin{array}{l}183 \\
211\end{array}$ & 1.24 & 31.1 & 907 & $\begin{array}{l}3.48 \\
1.16\end{array}$ & $\begin{array}{l}85.0 \\
424\end{array}$ & $\begin{array}{l}7550 \\
7974\end{array}$ & $\begin{array}{l}1.05 \\
2.53\end{array}$ & $\begin{array}{l}106 \\
110\end{array}$ & $\begin{array}{l}2661 \\
2771\end{array}$ & \multicolumn{3}{|c|}{$\begin{array}{c}\text { Terminated after } \\
117 \text { Weeks }\end{array}$} \\
\hline 238 & \multirow{2}{*}{\multicolumn{3}{|c|}{$\begin{array}{c}\text { Terminated after } \\
183 \text { weeks }\end{array}$}} & 2.37 & 56.0 & 8030 & 0.61 & 11.9 & 2783 & & & \\
\hline 291 & & & & 6.09 & 76.2 & 8106 & 1.50 & 14.4 & 2797 & & & \\
\hline 358 & & & & 7.79 & 97.0 & 8203 & 2.28 & 42.8 & 2840 & & & \\
\hline 417 & & & & 5.98 & 162.0 & 8365 & 1.88 & 56.8 & 2897 & & & \\
\hline 469 & & & & 4.80 & 198.0 & 8562 & 1.58 & 159.0 & 3056 & & & \\
\hline \multirow{3}{*}{\multicolumn{2}{|c|}{$\begin{array}{l}\text { Drip Rate } \\
\text { Configuration } \\
\text { Sample Wt (g) }\end{array}$}} & \multicolumn{2}{|c|}{$0.075 \mathrm{~mL} / 3.5$ days } & & \multicolumn{2}{|c|}{$0.075 \mathrm{~mL} / 3.5$ days } & & \multicolumn{2}{|c|}{$0.0375 \mathrm{~mL} / 7$ days } & & \multicolumn{2}{|c|}{$0.0375 \mathrm{~mL} / 7$ days } \\
\hline & & 3 Pellets & & & \multirow{2}{*}{\multicolumn{2}{|c|}{$\begin{array}{l}3 \text { Pellets } \\
48.36\end{array}$}} & & \multicolumn{2}{|c|}{3 Pellets } & \multicolumn{3}{|c|}{3 Pellets } \\
\hline & & \multicolumn{2}{|l|}{47.96} & & & & & \multicolumn{2}{|l|}{47.60} & \multicolumn{3}{|c|}{47.77} \\
\hline \multicolumn{2}{|c|}{ Sample SA $\left(\mathrm{m}^{2}\right)$} & \multicolumn{2}{|l|}{22.1} & & \multicolumn{2}{|l|}{22.2} & & \multicolumn{2}{|l|}{21.9} & \multicolumn{2}{|r|}{22.1} & \\
\hline \multicolumn{2}{|c|}{ Sample Vol. $\left(\mathrm{m}^{3}\right)$} & \multicolumn{2}{|l|}{4.54} & & \multicolumn{2}{|l|}{4.58} & & \multicolumn{2}{|l|}{4.48} & \multicolumn{3}{|c|}{4.54} \\
\hline
\end{tabular}

${ }^{a}$ Values represent total uranium released from sample, excluding portion that reprecipitates on the $\mathrm{UO}_{2}-\mathrm{Zircaloy}_{\text {assembly. Solution }}$ volumes determined by weight differences measured between the beginning and end of each cycle. Terminated tests are indicated, while remaining experiments are continuing. Blanks indicate no analysis performed. Horizontal bars separate per annum intervals. Water injection schedule and sample configuration explained in the text. All experiments were conducted at $90^{\circ} \mathrm{C}$. Determinations made from collected acid strip solution of the test vessels. 


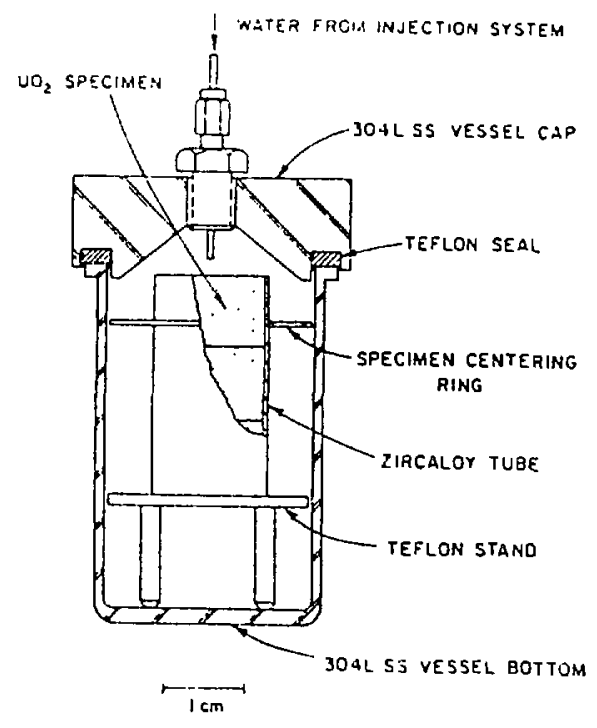

Fig. 12. Schematic Diagram of Experimental Assembly Showing Three-Pellet Sample Configuration

Solution samples have been periodically collected from these tests by opening the test vessels and collecting the accumulated leachate solution. Leachate aliquots have been analyzed for cations, anions, carbon, and $\mathrm{pH}$. Uranium concentrations have been determined for several different solution aliquots, including an acid strip of the test vessel plus accumulated fluid, an unfiltered solution, and a 5-nm filtered solution.

\section{Results}

Results for cumulative release of uranium from samples for periods up to nine years are summarized in Table 14, as are the details of the individual sample periods (Table 15). Figure 13 depicts the cumulative release of uranium from the samples, as recovered during a 10-min nitric acid strip of the test vessel components. All samples display a rapid increase in the rate of uranium released in the first 1-2 years. Uranium release rates during this interval ranged up to $14 \mathrm{mg}^{-2} \mathrm{~m}^{-2} \mathrm{~d}^{-1}$ (Table 16), with most of this release being attributed to the spallation of $\mathrm{UO}_{2}$ granules from the sample surface [14]. The value of $14 \mathrm{mg}^{\circ} \mathrm{m}^{-2} \cdot \mathrm{d}^{-1}$ is probably a minimum because the 10-min acid strip would not have completely dissolved the released grains. The final analysis for sample PMP8U-8 indicates a normalized release of $56 \mathrm{mg} \cdot \mathrm{m}^{-2} \bullet \mathrm{d}-1$. This higher value is believed to arise from a more complete dissolution of secondary uranyl minerals during the final overnight acid strip of the test vessel components. Analytical results that received between 2 and 9 years of testing indicate a decrease in the rate of uranium release from the samples relative to earlier periods (Fig. 13). Subsequent to the rapid release period, release rates for most tests decreased to an average of approximately 0.10 to $0.30 \mathrm{mg}^{\circ} \mathrm{m}^{-2} \cdot \mathrm{d}^{-1}$. This level of release has remained relatively constant throughout the remaining tests. Sample PMP8U-3 is an exception to the overall trend, with normalized uranium release rates remaining below $0.10 \mathrm{mg} \bullet \mathrm{m}^{-2} \bullet \mathrm{d}-1$ throughout the tests. 
Table 15. Results for Eight Unsaturated Tests with $\mathrm{UO}_{2}$ Samples (DIW = deionized water)

\begin{tabular}{|c|c|c|c|c|c|c|c|c|c|c|c|c|c|c|}
\hline $\begin{array}{l}\text { Exp. } \\
\text { No. }\end{array}$ & $\begin{array}{c}\text { Date } \\
\text { Started }\end{array}$ & $\begin{array}{c}\text { Date } \\
\text { Stopped/ } \\
\text { Sampled }\end{array}$ & $\begin{array}{c}\text { Sampling } \\
\text { Period } \\
\text { (weeks) }\end{array}$ & $\begin{array}{c}\text { Elapsed } \\
\text { Time } \\
\text { (weeks) }\end{array}$ & $\begin{array}{l}\text { Vessel } \\
\text { In }(g)\end{array}$ & $\begin{array}{l}\text { Vessel } \\
\text { Out (g) }\end{array}$ & $\begin{array}{c}\text { Vessel } \\
\text { Delta } \\
(\mathrm{g}) \\
\end{array}$ & $\begin{array}{c}\text { Portion } \\
\text { Removed } \\
\text { (mL) }\end{array}$ & $\begin{array}{c}\text { Acidified } \\
\text { Volume } \\
\text { (mL) }\end{array}$ & $\begin{array}{c}\text { DIW } \\
\text { Added } \\
\text { (mL) }\end{array}$ & $\begin{array}{c}\text { Sample } \\
\text { Number } \\
\end{array}$ & $\begin{array}{l}\text { U Conc. } \\
\text { Reported } \\
(\mu \mathrm{g} / \mathrm{mL})\end{array}$ & $\begin{array}{c}\text { Uranium } \\
\text { Release } \\
(\mu \mathrm{g})\end{array}$ & $\begin{array}{c}\text { Total } \\
\text { Release } \\
(\mu \mathrm{g})\end{array}$ \\
\hline \multirow[t]{13}{*}{1} & $04 / 25 / 85$ & $06 / 20 / 85$ & 8.0 & 8.0 & 355.13 & 355.97 & 0.84 & 0.00 & 11.93 & 030 & TF-174 & 2.2 & 26.246 & 26.246 \\
\hline & $06 / 20 / 85$ & $07 / 25 / 85$ & 5.0 & 13.0 & 355.41 & 356.16 & 0.75 & 0.00 & 14.22 & 0.00 & TF-189 & 1.516 & 21.557 & 47.803 \\
\hline & $07 / 25 / 85$ & $09 / 09 / 85$ & 6.6 & 19.6 & 355.49 & 356.26 & 0.77 & 0.00 & 9.94 & 0.00 & TF-214 & 45.2 & 449.288 & 497.090 \\
\hline & $09 / 09 / 85$ & $10 / 24 / 85$ & 6.4 & 26.0 & 355.36 & 356.14 & 0.78 & 0.00 & 16.48 & 0.00 & TF-229 & 16 & 263.680 & 760.770 \\
\hline & $10 / 24 / 85$ & $12 / 09 / 85$ & 6.6 & 32.6 & 356.27 & 356.94 & 0.67 & 0.00 & 10.05 & 10.00 & TF-245 & 6.45 & 129.322 & 890.092 \\
\hline & $12 / 09 / 85$ & $01 / 23 / 86$ & 6.4 & 39.0 & 356.17 & 356.81 & 0.64 & 0.00 & 11.39 & 0.00 & TF-260 & 6.54 & 74.490 & 964.582 \\
\hline & $01 / 23 / 86$ & $03 / 10 / 86$ & 6.6 & 45.6 & 356.18 & 356.84 & 0.66 & 0.00 & 14.12 & 0.00 & TF-276 & 70.9 & 1001.108 & 1965.689 \\
\hline & $03 / 10 / 86$ & $04 / 24 / 86$ & 6.4 & 52.0 & 356.18 & 356.92 & 0.74 & 0.00 & 16.74 & 0.00 & TF-294 & 129 & 2159.460 & 4125.149 \\
\hline & $04 / 24 / 86$ & $10 / 23 / 86$ & 26.0 & 78.0 & 356.25 & 359.46 & 3.21 & 0.00 & 11.95 & 0.00 & TF-356 & 22.9 & 273.655 & 4398.803 \\
\hline & $10 / 23 / 86$ & $04 / 28 / 87$ & 26.7 & 104.7 & 356.39 & 359.42 & 3.03 & 0.00 & 8.34 & 5.00 & $T F-432$ & 12.6 & $168 . \cup ั 84$ & 4566.887 \\
\hline & $04 / 28 / 87$ & $11 / 16 / 87$ & 28.9 & 133.6 & 356.36 & 359.65 & 3.29 & 0.00 & 9.97 & 10.00 & TF-518 & 7.26 & 144.982 & 4711.869 \\
\hline & $11 / 16 / 87$ & $04 / 25 / 88$ & 23.0 & 156.6 & 356.25 & 358.83 & 2.58 & 1.00 & 8.86 & 10.00 & TF-596 & 4.03 & 124.110 & 4835.979 \\
\hline & $04 / 25 / 88$ & $10 / 24 / 88$ & 26.0 & 182.6 & 356.04 & 358.81 & 2.77 & 1.20 & 8.37 & 10.00 & TF-700 & 5.05 & 163.674 & 4999.653 \\
\hline \multicolumn{15}{|c|}{ Terminated on $10 / 24 / 88$} \\
\hline \multirow[t]{18}{*}{2} & $04 / 25 / 85$ & $06 / 20 / 85$ & 8.0 & 8.0 & 355.34 & 356.15 & 0.81 & 0.00 & 15.68 & 0.00 & TF- 175 & 0.703 & 11.023 & 11.023 \\
\hline & $06 / 20 / 85$ & $07 / 25 / 85$ & 5.0 & 13.0 & 355.47 & 356.11 & 0.64 & 0.00 & 12.35 & 0.00 & TF-190 & 2.083 & 25.725 & 36.747 \\
\hline & $07 / 25 / 85$ & $09 / 09 / 85$ & 6.6 & 19.6 & 355.60 & 356.61 & 1.01 & 0.00 & 10.49 & 0.00 & TF-215 & 37 & 388.130 & 424.877 \\
\hline & 09/09/85 & $10 / 24 / 85$ & 6.4 & 26.0 & 355.64 & 356.57 & 0.93 & 0.00 & 15.25 & 0.00 & TF-230 & 13.2 & 201.300 & 626.176 \\
\hline & $10 / 24 / 85$ & $12 / 09 / 85$ & 6.6 & 32.6 & 356.08 & 356.89 & 0.81 & 0.00 & 9.10 & 10.00 & TF-246 & 2.94 & 56.154 & 682.330 \\
\hline & $12 / 09 / 85$ & $01 / 23 / 86$ & 6.4 & 39.0 & 355.73 & 356.56 & 0.83 & 0.00 & 12.98 & 0.00 & TF-261 & 2.95 & 38.291 & 720.620 \\
\hline & $01 / 23 / 86$ & $03 / 10 / 86$ & 6.6 & 45.6 & 355.72 & 356.38 & 0.66 & 0.00 & 13.56 & 0.00 & TF-277 & 3.46 & 46.917 & 767.537 \\
\hline & 03/10/86 & $04 / 24 / 86$ & 6.4 & 52.0 & 355.74 & 356.54 & 0.80 & 0.00 & 15.63 & 0.00 & TF-295 & 92.5 & 1445.775 & 2213.312 \\
\hline & $04 / 24 / 86$ & $10 / 23 / 86$ & 26.0 & 78.0 & 355.70 & 358.33 & 2.63 & 0.00 & 11.49 & 0.00 & TF-357 & 130 & 1493.700 & 3707.011 \\
\hline & $10 / 23 / 86$ & $04 / 28 / 87$ & 26.7 & 104.7 & 355.67 & 359.07 & 3.40 & 0.00 & 8.59 & 5.00 & TF-433 & 7.71 & 104.778 & 3811.790 \\
\hline & $04 / 28 / 87$ & $11 / 16 / 87$ & 28.9 & 133.6 & 355.53 & 359.18 & 3.65 & 0.00 & 8.12 & 10.00 & TF-519 & 3.84 & 69.580 & 3881.370 \\
\hline & $11 / 16 / 87$ & $04 / 25 / 88$ & 23.0 & 156.6 & 355.55 & 358.77 & 3.22 & 1.00 & 7.85 & 10.00 & TF-597 & 6.72 & 173.984 & 4055.354 \\
\hline & $04 / 25 / 88$ & $10 / 24 / 88$ & 26.0 & 182.6 & 355.43 & 359.01 & 3.41 & 1.20 & 7.17 & 10.00 & TF-701 & 2.79 & 73.915 & 4129.269 \\
\hline & $10 / 24 / 88$ & 05/08/89 & 28.0 & 210.6 & 355.39 & 357.41 & 2.09 & 0.80 & 7.79 & 4.00 & TF-797 & 10.1 & 192.926 & 4322.195 \\
\hline & $05 / 08 / 89$ & $11 / 13 / 89$ & 27.0 & 237.6 & 355.90 & 357.56 & 1.87 & 0.30 & 10.18 & 5.00 & DW-9 & 3.96 & 71.599 & 4393.794 \\
\hline & $11 / 13 / 89$ & $11 / 19 / 90$ & 53.0 & 290.6 & 346.47 & 360.41 & 5.43 & 0.70 & 9.61 & 7.00 & DW-58 & 2 & 38.136 & 4431.930 \\
\hline & $11 / 19 / 90$ & $03 / 05 / 92$ & 67.3 & 357.9 & 180.49 & 187.19 & 6.70 & 2.76 & 7.91 & 0.00 & DW-72a & 19.78 & 266.061 & 4697.990 \\
\hline & $\begin{array}{l}03 / 05 / 92 \\
\text { linated on }\end{array}$ & $\begin{array}{c}04 / 26 / 93 \\
1 / 26 / 93\end{array}$ & 59.4 & 417.3 & 180.64 & 185.11 & 4.47 & 1.74 & 8.59 & 0.00 & DW-82 & 23.119 & 325.167 & 5023.157 \\
\hline
\end{tabular}


Table 15 (contd.)

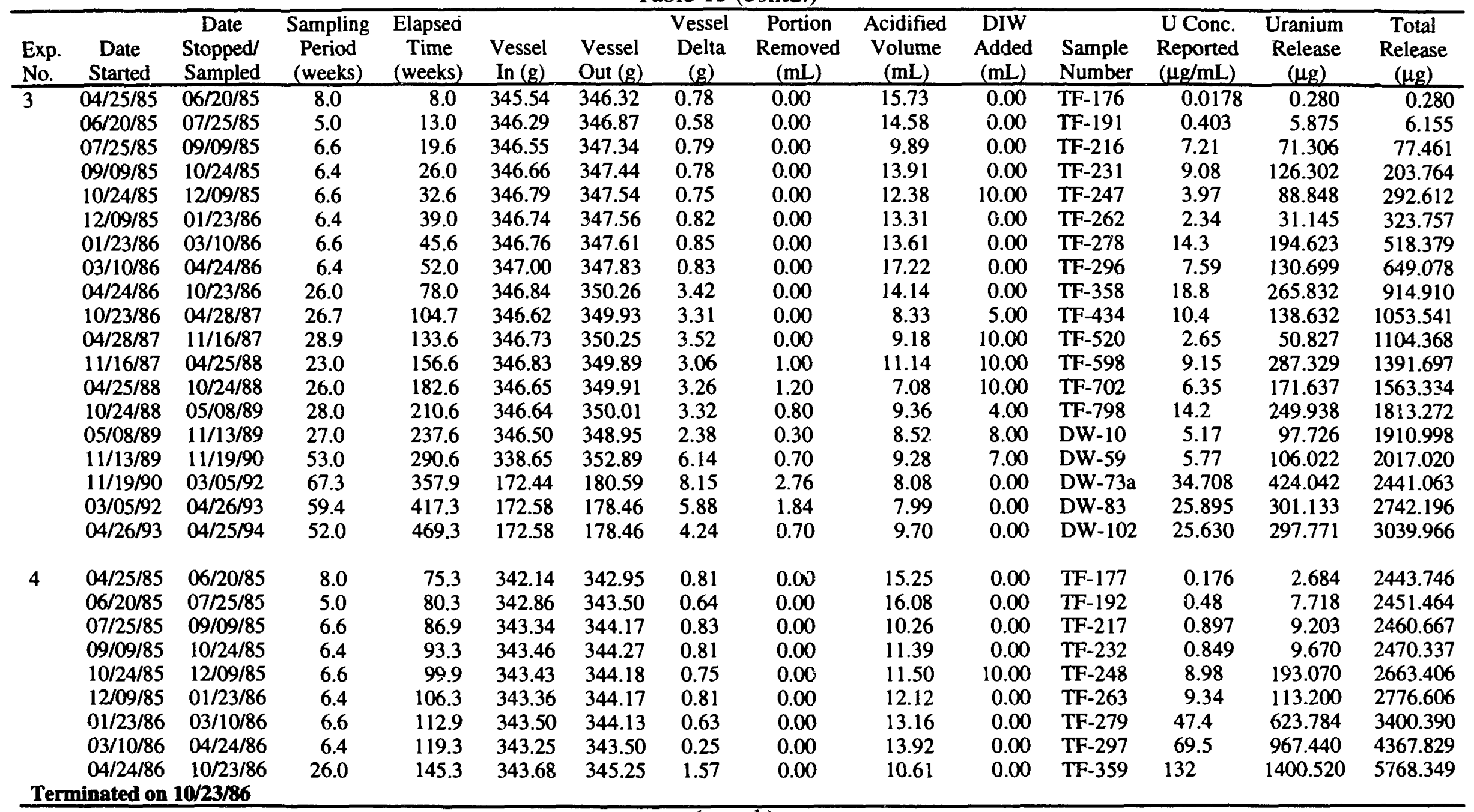


Table 15 (contd.)

\begin{tabular}{|c|c|c|c|c|c|c|c|c|c|c|c|c|c|c|}
\hline $\begin{array}{l}\text { Exp. } \\
\text { No. }\end{array}$ & $\begin{array}{c}\text { Date } \\
\text { Started }\end{array}$ & $\begin{array}{c}\text { Date } \\
\text { Stopped/ } \\
\text { Sampled }\end{array}$ & $\begin{array}{l}\text { Sampling } \\
\text { Period } \\
\text { (weeks) }\end{array}$ & $\begin{array}{c}\text { Elapsed } \\
\text { Time } \\
\text { (weeks) }\end{array}$ & $\begin{array}{l}\text { Vessel } \\
\text { In (g) }\end{array}$ & $\begin{array}{l}\text { Vessel } \\
\text { Out (g) }\end{array}$ & $\begin{array}{c}\text { Vessel } \\
\text { Delta } \\
(\mathrm{g})\end{array}$ & $\begin{array}{c}\text { Portion } \\
\text { Removed } \\
\text { (mL) }\end{array}$ & $\begin{array}{l}\text { Acidified } \\
\text { Volume } \\
\text { (mL) }\end{array}$ & $\begin{array}{c}\text { DIW } \\
\text { Added } \\
\text { (mL) }\end{array}$ & $\begin{array}{l}\text { Sample } \\
\text { Number }\end{array}$ & $\begin{array}{l}\text { U Conc. } \\
\text { Reported } \\
(\mu \mathrm{g} / \mathrm{mL})\end{array}$ & $\begin{array}{c}\text { Uranium } \\
\text { Release } \\
(\mu \mathrm{g})\end{array}$ & $\begin{array}{l}\text { Total } \\
\text { Release } \\
(\mu \mathrm{g})\end{array}$ \\
\hline \multirow[t]{13}{*}{5} & $04 / 25 / 85$ & $06 / 20 / 85$ & 8.0 & 8.0 & 368.47 & 369.22 & 0.75 & 0.00 & 18.02 & 0.00 & TF-178 & 0.158 & 2.847 & 2.847 \\
\hline & $06 / 20 / 85$ & $07 / 25 / 85$ & 5.0 & 13.0 & 368.67 & 369.25 & 0.58 & 0.00 & 14.14 & 0.00 & TF-193 & 0.0864 & 1.221 & 4.068 \\
\hline & $07 / 25 / 85$ & $09 / 09 / 85$ & 6.6 & 19.6 & 368.76 & 369.61 & 0.85 & 0.00 & 12.83 & 0.00 & TF-218 & 8.53 & 109.439 & 113.507 \\
\hline & $09 / 09 / 85$ & $10 / 24 / 85$ & 6.4 & 26.0 & 368.88 & 369.64 & 0.76 & 0.00 & 13.93 & 0.00 & TF-233 & 2.59 & 36.078 & 149.586 \\
\hline & $10 / 24 / 85$ & $12 / 09 / 85$ & 6.6 & 32.6 & 368.97 & 369.74 & 0.77 & 0.00 & 10.72 & 0.00 & TF-249 & 3.15 & 33.768 & 183.353 \\
\hline & $12 / 09 / 85$ & $01 / 23 / 86$ & 6.4 & 39.0 & 368.75 & 369.52 & 0.77 & 0.00 & 11.68 & 0.00 & TF-264 & 1.66 & 19.388 & 202.741 \\
\hline & $01 / 23 / 86$ & $03 / 10 / 86$ & 6.6 & 45.6 & 368.85 & 369.92 & 1.07 & 0.00 & 11.17 & 0.00 & TF-280 & 28.8 & 321.696 & 524.437 \\
\hline & $03 / 10 / 86$ & $04 / 24 / 86$ & 6.4 & 52.0 & 368.97 & 369.89 & 0.92 & 0.00 & 14.48 & 0.00 & TF-298 & 5.02 & 72.689 & 597.126 \\
\hline & $04 / 24 / 86$ & $10 / 23 / 86$ & 26.0 & 78.0 & 369.02 & 372.64 & 3.62 & 0.00 & 9.82 & 0.00 & TF-360 & 10.5 & 103.110 & 700.236 \\
\hline & $10 / 23 / 86$ & $04 / 28 / 87$ & 26.7 & 104.7 & 368.82 & 372.23 & 3.41 & 0.00 & 8.47 & 5.00 & $T F-435$ & 3.55 & 47.818 & 748.054 \\
\hline & $04 / 28 / 87$ & $11 / 16 / 87$ & 28.9 & 133.6 & 368.95 & 372.30 & 3.35 & 0.00 & 8.37 & 10.00 & TF-521 & 3.77 & 69.254 & 817.308 \\
\hline & $11 / 16 / 8 i$ & $v / 25 / 88$ & 23.0 & 156.6 & 368.81 & 370.35 & 1.54 & 1.00 & 8.23 & 10.00 & TF-599 & 1.12 & 58.227 & 875.535 \\
\hline & $04 / 25 / 88$ & $10 / 24 / 88$ & 26.0 & 182.6 & 368.77 & 370.01 & 1.24 & 0.40 & 7.72 & 10.00 & TF-703 & 1.19 & 31.128 & 906.663 \\
\hline \multicolumn{15}{|c|}{ Terminated on 10/24/88 } \\
\hline \multirow[t]{18}{*}{6} & $04 / 25 / 85$ & $06 / 20 / 85$ & 8.0 & 8.0 & 375.45 & 376.32 & 0.87 & 0.00 & 14.65 & 0.00 & TF-179 & 0.178 & 2.607 & 2.607 \\
\hline & $06 / 20 / 85$ & $07 / 25 / 85$ & 5.0 & 13.0 & 375.81 & 376.47 & 0.66 & 0.00 & 17.65 & 0.00 & TF- 194 & 0.167 & 2.947 & 5.554 \\
\hline & $07 / 25 / 85$ & $09 / 09 / 85$ & 6.6 & 19.6 & 375.88 & 376.66 & 0.78 & 0.00 & 11.40 & 0.00 & TF-219 & 2.67 & 30.438 & 35.992 \\
\hline & $09 / 09 / 85$ & $10 / 24 / 85$ & 6.4 & 26.0 & 375.88 & 376.65 & 0.77 & 0.00 & 11.95 & 0.00 & TF-234 & 3.51 & 41.944 & 77.936 \\
\hline & $10 / 24 / 85$ & $12 / 09 / 85$ & 6.6 & 32.6 & 376.00 & 376.70 & 0.70 & 0.00 & 10.85 & 0.00 & TF-250 & 73.6 & 798.560 & 876.495 \\
\hline & $12 / 09 / 85$ & $01 / 23 / 86$ & 6.4 & 39.0 & 375.73 & $3^{\prime \prime} / 6.49$ & 0.76 & 0.00 & 14.25 & 0.00 & TF-265 & 97.6 & 1390.800 & 2267.295 \\
\hline & $01 / 23 / 86$ & $03 / 10 / 86$ & 6.6 & 45.6 & 375.84 & 376.27 & 0.43 & 0.00 & 15.66 & 0.00 & TF-281 & 3.56 & 55.749 & 2323.044 \\
\hline & $03 / 10 / 86$ & $04 / 24 / 86$ & 6.4 & 52.0 & 375.93 & 376.15 & 0.22 & 0.00 & 13.76 & 0.00 & TF-299 & 43.1 & 593.056 & 2916.100 \\
\hline & $04 / 24 / 86$ & $10 / 23 / 86$ & 26.0 & 78.0 & 376.01 & 378.96 & 2.95 & 0.00 & 11.45 & 0.00 & TF-361 & 324 & 3709.800 & 6625.899 \\
\hline & $10 / 23 / 86$ & $04 / 28 / 87$ & 26.7 & 104.7 & 375.61 & 378.75 & 3.14 & 0.00 & 8.46 & 5.00 & TF-436 & 28.9 & 388.994 & 7014.893 \\
\hline & $04 / 28 / 87$ & $04 / 25 / 88$ & 51.9 & 156.6 & 375.66 & 382.18 & 6.52 & 1.00 & 8.39 & 10.00 & TF-600 & 20.7 & 449.635 & 7464.528 \\
\hline & $04 / 25 / 88$ & $10 / 24 / 88$ & 26.0 & 182.6 & 375.63 & 378.84 & 3.48 & 1.20 & 8.09 & 10.00 & TF-715 & 3.08 & 85.042 & 7549.569 \\
\hline & $10 / 24 / 88$ & $05 / 08 / 89$ & 28.0 & 210.6 & 375.46 & 376.79 & 1.16 & 0.30 & 7.55 & 4.00 & TF-799 & 27.2 & 423.750 & 7973.319 \\
\hline & 05/08/89 & $11 / 13 / 89$ & 27.0 & 237.6 & 375.48 & 377.82 & 2.37 & 0.30 & 7.47 & 8.00 & DW-11 & 3.16 & 55.970 & 8029.289 \\
\hline & $11 / 13 / 89$ & $11 / 19 / 90$ & 53.0 & 290.6 & 367.45 & 382.11 & 6.09 & 0.70 & 9.45 & 7.00 & DW-60 & 4.1 & 76.204 & 8105.492 \\
\hline & $11 / 19 / 90$ & $03 / 05 / 92$ & 67.3 & 357.9 & 201.07 & 208.86 & 7.79 & 2.77 & 8.07 & 0.00 & DW-74a & 7.745 & 96.990 & 8202.482 \\
\hline & $3 / 5 / 92$ & $04 / 26 / 93$ & 59.4 & 417.3 & 201.12 & 207.10 & 5.98 & 1.88 & 8.34 & 0.00 & DW-84 & 13.301 & 161.795 & 8364.278 \\
\hline & $4 / 26 / 93$ & $04 / 25 / 94$ & 52.0 & 469.3 & 172.49 & 176.73 & 4.80 & 0.70 & 8.82 & 0.00 & DW-103 & 19.180 & 198.049 & 8562.327 \\
\hline
\end{tabular}


Table 15 (contd.)

\begin{tabular}{|c|c|c|c|c|c|c|c|c|c|c|c|c|c|c|}
\hline $\begin{array}{l}\text { Exp. } \\
\text { No. }\end{array}$ & $\begin{array}{c}\text { Date } \\
\text { Started }\end{array}$ & $\begin{array}{c}\text { Date } \\
\text { Stopped/ } \\
\text { Sampled }\end{array}$ & $\begin{array}{l}\text { Sampling } \\
\text { Period } \\
\text { (weeks) }\end{array}$ & $\begin{array}{c}\text { Elapsed } \\
\text { Time } \\
\text { (weeks) }\end{array}$ & $\begin{array}{l}\text { Vessel } \\
\text { In (g) }\end{array}$ & $\begin{array}{l}\text { Vessel } \\
\text { Out }(g)\end{array}$ & $\begin{array}{l}\text { Vessel } \\
\text { Delta } \\
(\mathrm{g})\end{array}$ & $\begin{array}{l}\text { Portion } \\
\text { Removed } \\
\text { (mL) }\end{array}$ & $\begin{array}{l}\text { Acidified } \\
\text { Volume } \\
\text { (mL) }\end{array}$ & $\begin{array}{l}\text { DIW } \\
\text { Added } \\
\text { (mL) }\end{array}$ & $\begin{array}{l}\text { Sample } \\
\text { Number }\end{array}$ & $\begin{array}{l}\text { U Conc. } \\
\text { Reported } \\
(\mu \mathrm{g} / \mathrm{mL})\end{array}$ & $\begin{array}{c}\text { Uranium } \\
\text { Release } \\
(\mu \mathrm{g})\end{array}$ & $\begin{array}{c}\text { Total } \\
\text { Release } \\
(\mu \mathrm{g})\end{array}$ \\
\hline \multirow[t]{15}{*}{7} & $04 / 25 / 85$ & $07 / 25 / 85$ & 13.0 & 13.0 & 374.68 & 378.98 & 0.30 & 0.00 & 15.35 & 0.00 & TF-195 & 0.069 & 1.059 & 1.059 \\
\hline & $07 / 25 / 85$ & $10 / 24 / 85$ & 13.0 & 26.0 & 374.89 & 375.56 & 0.67 & 0.00 & 15.17 & 0.00 & TF-235 & 19.9 & 301.883 & 302.941 \\
\hline & $10 / 24 / 85$ & $01 / 23 / 86$ & 13.0 & 39.0 & 375.17 & ND & ND & 0.00 & 12.95 & 0.00 & TF-266 & 7.36 & 95.312 & 398.253 \\
\hline & $01 / 23 / 86$ & $04 / 24 / 86$ & 13.0 & 52.0 & 375.01 & 375.40 & 0.39 & 0.00 & 14.39 & 0.00 & TF-300 & 46.2 & 664.818 & 1063.070 \\
\hline & $04 / 24 / 86$ & $10 / 23 / 86$ & 26.0 & 78.0 & 375.19 & 375.91 & 0.72 & 0.00 & 9.77 & 0.00 & TF-362 & 110 & 1074.700 & 2137.770 \\
\hline & $10 / 23 / 86$ & $04 / 28 / 87$ & 26.7 & 104.7 & 375.06 & 375.58 & 0.52 & 0.00 & 5.86 & 10.00 & TF-437 & 14.2 & 225.212 & 2362.981 \\
\hline & $04 / 28 / 87$ & $11 / 16 / 87$ & 28.9 & 133.6 & 375.03 & 375.16 & 0.13 & 0.00 & 7.79 & 10.00 & TF-522 & 4.46 & 79.343 & 2442.324 \\
\hline & $11 / 16 / 87$ & $04 / 25 / 88$ & 23.0 & 156.6 & 375.16 & 375.80 & 0.64 & 0.00 & 10.53 & 10.00 & TF-601 & 5.5 & 112.915 & 2555.239 \\
\hline & $04 / 25 / 88$ & $10 / 24 / 88$ & 26.0 & 182.6 & 375.00 & 375.94 & 1.05 & 0.00 & 7.95 & 10.00 & TF-704 & 5.9 & 105.905 & 2661.143 \\
\hline & $10 / 24 / 88$ & 05/08/89 & 28.0 & 210.6 & 374.94 & 377.43 & 2.53 & 0.80 & 8.54 & 4.00 & TF-800 & 5.99 & 109.849 & 2770.992 \\
\hline & $05 / 08 / 89$ & $11 / 13 / 89$ & 27.0 & 237.6 & 374.62 & 375.23 & 0.61 & 0.10 & 9.82 & 5.00 & DW-12 & 0.673 & 11.929 & 2782.921 \\
\hline & $11 / 13 / 89$ & $11 / 19 / 90$ & 53.0 & 290.6 & 377.71 & 367.74 & 1.50 & 0.70 & 9.06 & 7.00 & DW-61 & 0.477 & 14.363 & 2797.285 \\
\hline & $11 / 19 / 90$ & $03 / 05 / 92$ & 67.3 & 357.9 & 200.62 & 202.90 & 2.28 & 0.80 & 9.06 & 0.00 & DW-75a & 3.0647 & 42.774 & 2840.059 \\
\hline & 03/05/92 & $04 / 26 / 93$ & 59.4 & 417.3 & 200.66 & 202.54 & 1.88 & 0.62 & 7.72 & 0.00 & DW-85 & 4.9322 & 56.812 & 2896.871 \\
\hline & $04 / 26 / 93$ & $04 / 25 / 94$ & 52.0 & 469.3 & 200.64 & 202.22 & 1.58 & 0.70 & 8.78 & 0.00 & DW-104 & 10.100 & 159.217 & 3056.088 \\
\hline \multirow[t]{7}{*}{8} & $04 / 25 / 85$ & $07 / 25 / 85$ & 13.0 & 13.0 & 374.76 & 375.11 & 0.35 & 0.00 & 18.01 & 0.00 & TF-196 & 0.048 & 0.875 & 2840.934 \\
\hline & $07 / 25 / 85$ & $10 / 24 / 85$ & 13.0 & 26.0 & 375.08 & 375.59 & 0.51 & 0.00 & 15.72 & 0.00 & TF-236 & 33.4 & 525.048 & 3365.981 \\
\hline & $10 / 24 / 85$ & $01 / 23 / 86$ & 13.0 & 39.0 & 375.66 & 376.00 & 0.34 & 0.00 & 14.09 & 0.00 & TF-267 & 17.5 & 246.575 & 3612.556 \\
\hline & $01 / 23 / 86$ & $04 / 24 / 86$ & 13.0 & 52.0 & 375.16 & 375.79 & 0.63 & 0.00 & 14.98 & 0.00 & TF-301 & 17.6 & 263.648 & 3876.203 \\
\hline & $04 / 24 / 86$ & $10 / 23 / 86$ & 26.0 & 78.0 & 375.35 & 376.13 & 0.78 & 0.00 & 15.41 & 0.00 & TF-363 & 386 & 5948.260 & 9824.463 \\
\hline & $10 / 23 / 86$ & $04 / 28 / 87$ & 26.7 & 104.7 & 375.32 & 375.69 & 0.37 & 0.00 & 5.61 & 10.00 & TF-438 & 135 & 2107.350 & 11931.81 \\
\hline & $04 / 28 / 87$ & $07 / 20 / 87$ & 11.9 & 116.6 & 375.39 & 375.90 & 0.51 & 0.00 & 9.28 & 5.00 & TE-457 & 723 & 10324.44 & 22256.25 \\
\hline \multicolumn{15}{|c|}{ Terminated on $7 / 20 / 87$} \\
\hline
\end{tabular}



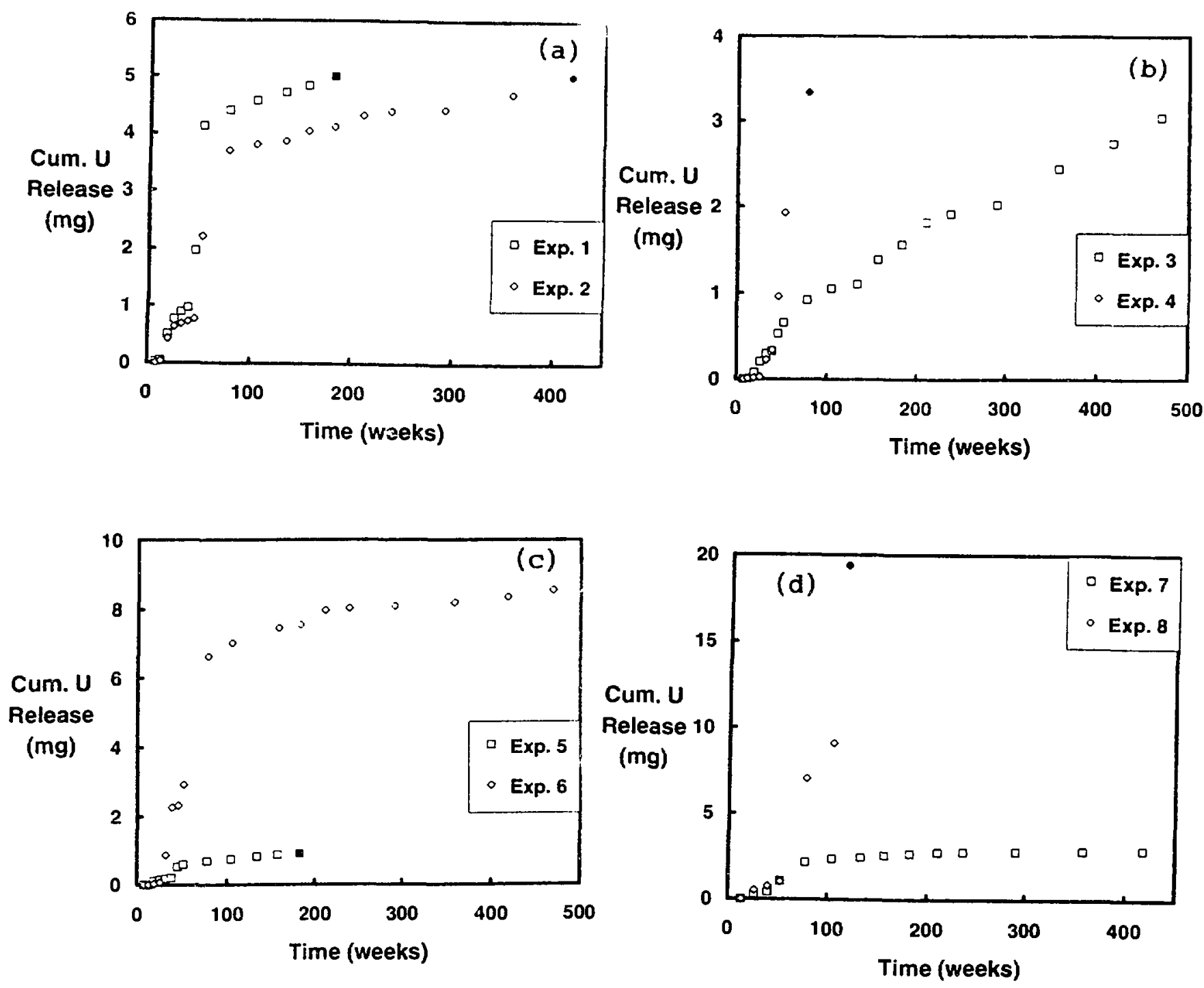

Fig. 13. Cumulative Uranium Release in Milligrams as Measured after a Ten-Minute Acid Strip of the Test Vessel Plus Contained Fluids. Blackened symbols represent tests that have been terminated. 
Table 16. Normalized Release Rate for $\mathrm{UO}_{2}$ Samples in Unsaturated Tests

\begin{tabular}{|c|c|c|c|c|c|c|c|c|c|c|c|}
\hline & $\begin{array}{c}\text { Pellet } \\
\text { Surface } \\
\text { Area } \\
\left(\mathrm{m}^{2}\right)\end{array}$ & $\begin{array}{l}\text { Normalized } \\
\text { Periodic } \\
\text { Release } \\
\text { (mg/m } 2 / \text { day) }\end{array}$ & $\begin{array}{l}\text { Sampling } \\
\text { Period } \\
\text { (weeks) }\end{array}$ & $\begin{array}{l}\text { Normalized } \\
\text { Cumulative } \\
\text { Release } \\
\left(\mathrm{mg} / \mathrm{m}^{2} / \text { day }\right)\end{array}$ & $\begin{array}{c}\text { Elapsed } \\
\text { Time } \\
\text { (weeks) }\end{array}$ & & $\begin{array}{c}\text { Pellet } \\
\text { Surface } \\
\text { Area } \\
\left(\mathrm{m}^{2}\right) \\
\end{array}$ & $\begin{array}{c}\text { Normalized } \\
\text { Periodic } \\
\text { Release } \\
\left.\text { (mg/m } / \mathrm{m}^{2} / \text { day }\right)\end{array}$ & $\begin{array}{l}\text { Sampling } \\
\text { Period } \\
\text { (weeks) }\end{array}$ & $\begin{array}{l}\text { Normalized } \\
\text { Cumulative } \\
\text { Release } \\
\left(\mathrm{mg} / \mathrm{m}^{2} / \text { day }\right)\end{array}$ & $\begin{array}{c}\text { Elapsed } \\
\text { Time } \\
\text { (weeks) }\end{array}$ \\
\hline \multirow[t]{14}{*}{ PMP8U-1 } & 0.00407 & 0.11515 & 8.0 & 0.11515 & 8.0 & PMP8U-3 & 0.0486 & 0.00010 & 8.0 & 0.00010 & 8.0 \\
\hline & & 0.15133 & 5.0 & 0.12907 & 13.0 & & & 0.00345 & 5.0 & 0.00139 & 13.0 \\
\hline & & 2.39978 & 6.6 & 0.89150 & 19.6 & & & 0.03190 & 6.6 & 0.01163 & 19.6 \\
\hline & & 1.43969 & 6.4 & 1.02704 & 26.0 & & & 0.05775 & 6.4 & 0.02304 & 26.0 \\
\hline & & 0.69075 & 6.6 & 0.95919 & 32.6 & & & 0.03974 & 6.6 & 0.02641 & 32.6 \\
\hline & & 0.40672 & 6.4 & 0.86812 & 39.0 & & & 0.01424 & 6.4 & 0.02440 & 39.0 \\
\hline & & 5.34723 & 6.6 & 1.51401 & 45.6 & & & 0.08706 & 6.6 & 0.03344 & 45.6 \\
\hline & & 11.79066 & 6.4 & 2.78448 & 52.0 & & & 0.05976 & 6.4 & 0.03669 & 52.0 \\
\hline & & 0.36943 & 26.0 & 1.97946 & 78.0 & & & 0.03005 & 26.0 & 0.03488 & 78.0 \\
\hline & & 0.22085 & 26.7 & 1.53081 & 104.7 & & & 0.01525 & 26.7 & 0.02957 & 104.7 \\
\hline & & 0.17635 & 28.9 & 1.23819 & 133.6 & & & 0.00518 & 28.9 & 0.02430 & 133.6 \\
\hline & & 0.18940 & 23.0 & 1.08413 & 156.6 & & & 0.03672 & 23.0 & 0.02613 & 156.6 \\
\hline & & 0.22096 & 26.0 & 0.96120 & 182.6 & & & 0.01940 & 26.0 & 0.02517 & 182.6 \\
\hline & & & & & & & & 0.02624 & 28.0 & 0.02531 & 210.6 \\
\hline \multirow[t]{18}{*}{ PMP8U-2 } & 0.00406 & 0.04848 & 8.0 & 0.04848 & 8.0 & & & 0.01064 & 27.0 & 0.02364 & 237.6 \\
\hline & & 0.18103 & 5.0 & 0.09946 & 13.0 & & & 0.00588 & 53.0 & 0.02040 & 290.6 \\
\hline & & 2.07823 & 6.6 & 0.76386 & 19.6 & & & 0.01852 & 67.4 & 0.02005 & 357.9 \\
\hline & & 1.10180 & 6.4 & 0.84742 & 26.0 & & & 0.01490 & 59.6 & 0.01932 & 417.3 \\
\hline & & 0.30067 & 6.6 & 0.73711 & 32.6 & & & 0.01683 & 52.0 & 0.01904 & 469.3 \\
\hline & & 0.20958 & 6.4 & 0.65016 & 39.0 & & & & & & \\
\hline & & 0.25122 & 6.6 & 0.59263 & 45.6 & PMP8U-4 & 0.0467 & 0.00103 & 8.0 & 0.09928 & 8.0 \\
\hline & & 7.91338 & 6.4 & 1.49767 & 52.0 & & & 0.00472 & 5.0 & 0.09339 & 80.3 \\
\hline & & 2.02146 & 26.0 & 1.67227 & 78.0 & & & 0.00428 & 6.6 & 0.08665 & 86.9 \\
\hline & & 0.13801 & 26.7 & 1.28085 & 104.7 & & & 0.00460 & 6.4 & 0.08100 & 93.3 \\
\hline & & 0.08484 & 28.9 & 1.02246 & 133.6 & & & 0.08988 & 6.6 & 0.08158 & 99.9 \\
\hline & & 0.26617 & 23.0 & 0.91136 & 156.6 & & & 0.05387 & 6.4 & 0.07990 & 106.3 \\
\hline & & 0.10003 & 26.0 & 0.79582 & 182.6 & & & 0.29037 & 6.6 & 0.09216 & 112.9 \\
\hline & & 0.24244 & 28.0 & 0.72224 & 210.6 & & & 0.46036 & 6.4 & 0.11200 & 119.3 \\
\hline & & 0.09331 & 27.0 & 0.65076 & 237.6 & & & 0.16478 & 26.0 & 0.12144 & 145.3 \\
\hline & & 0.02532 & 53.0 & 0.53668 & 290.6 & & & & & & \\
\hline & & 0.13910 & 67.4 & 0.46191 & 357.9 & & & & & & \\
\hline & & 0.19262 & 59.6 & 0.42358 & 417.3 & & & & & & \\
\hline
\end{tabular}


Table 16 contd.

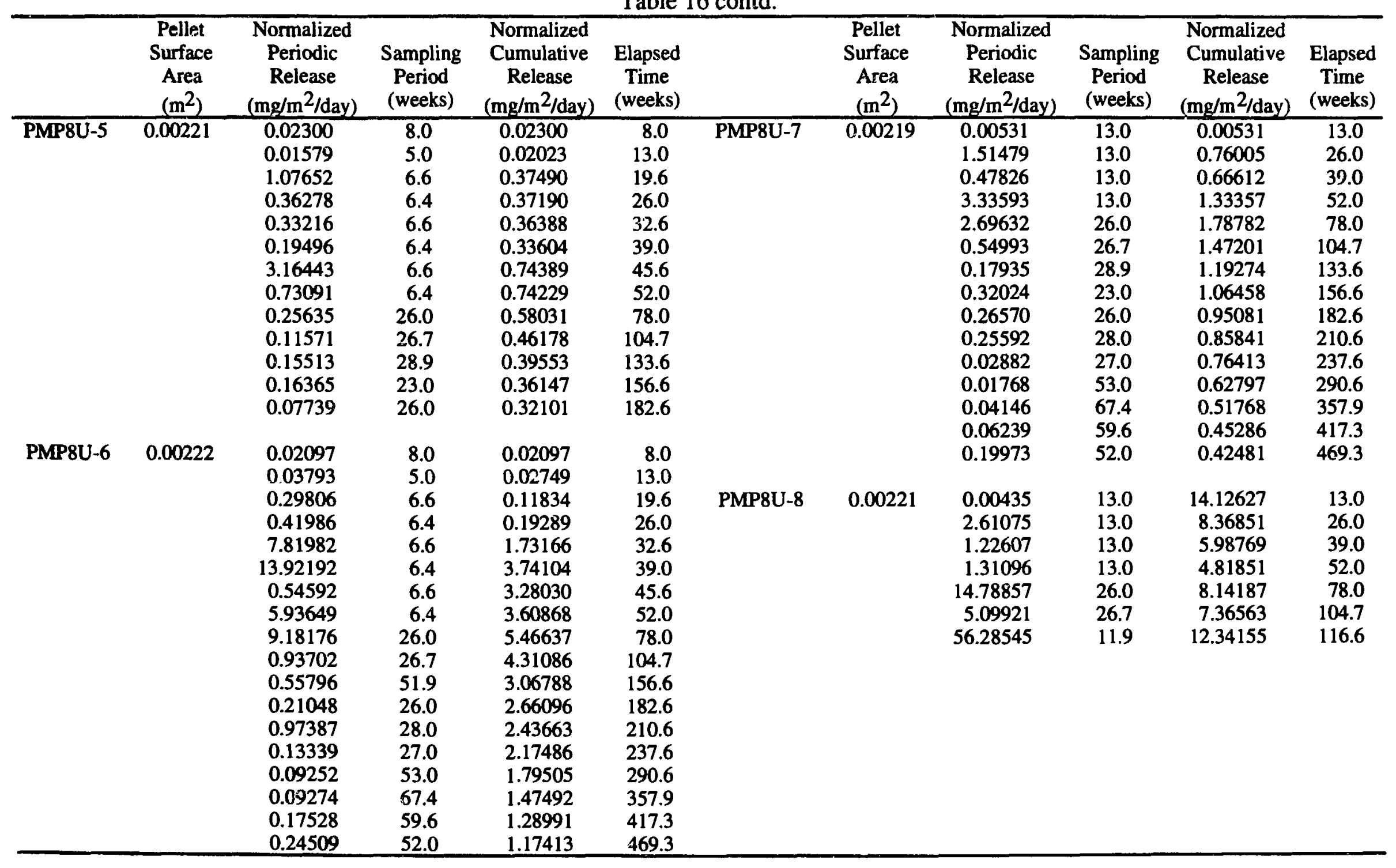


Size-fractioned uranium release trends have also been examined for a few samples (Fig. 14). A comparison of filtered and nonfiltered solution aliquots from the 8- and 9-year tests indicates that only 2 to $6 \%$ of the released uranium passed through a $5 \mathrm{~nm}$ filter, with the remaining fraction being released in particulate form or reprecipitating as secondary uranyl phases on the test vessel walls. The acid strip component represents the largest recovered uranium fraction from the tests $(80$ to $98 \%)$. The suspended fraction represents all uranium suspended in solution, less the fraction passing through the $5 \mathrm{~nm}$ filter. This suspended fraction represents from 1 to $15 \%$ of the total release, with the relatively high variability probably' resulting from the resuspension of particulate material during the vessel opening and sampling processes. Examinations of filtered residues from these tests reveal the presence of elongated uranium silicate grains (Fig. 15). These phases probably formed as crystalline alteration phases on the sample surface and became dislodged by dripping water during the biweekly leachant injection.

The results from solution cation analyses are presented in Fig. 16. Leachate concentrations of $\mathrm{Mg}, \mathrm{Ca}, \mathrm{K}$, and Si are depleted relative to the starting EJ-13 leachant (Figs. 16a to 16d). Magnesium is generally depleted to the greatest extent, with leachate concentrations typically reduced to $\sim 10 \%$ of the initial EJ-13 values. Calcium and potassium are generally depleted to $-30 \%$ of the original EJ-13 compositions, while silicon is depleted to a level that is within 50 to $60 \%$ of the original EJ-13 composition. Analytical results from the last several tes، periods have also revealed a gradual increase in calcium concentrations. Sodium concentrations are similar to those of the starting EJ-13 solution (Fig. 16e), a finding consistent with the absence of any discrete sodium uranyl phases on the $\mathrm{UO}_{2}$ pellet surfaces. Solution $\mathrm{pH}$ values are also noted to decrease for all samples relative to the initial 8.2 value for the EJ-13 leachant (Fig. 16f).

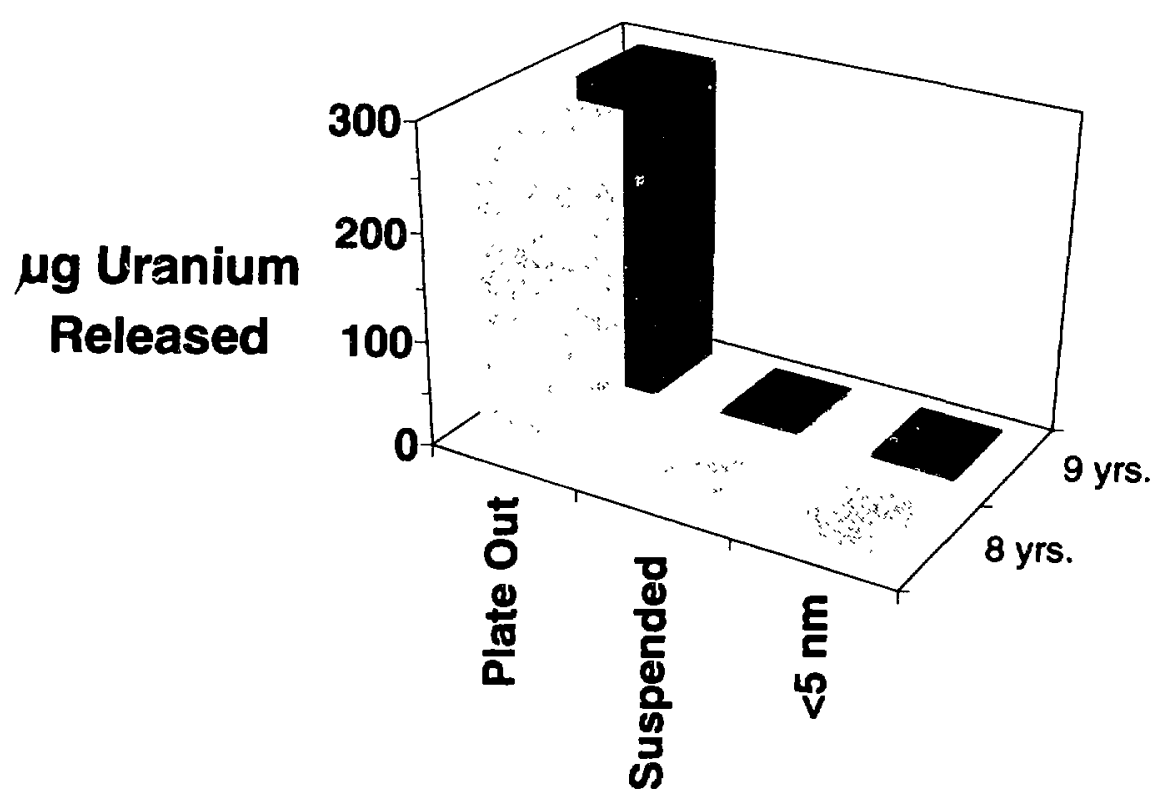

Fig. 14. Fractional Release of Uranium for Eight- and Nine-Year Solutions from Tesi Number PMP8U-3. Plate out represents release portion recovered after 10-min acid strip of test vessel less suspended and $<5 \mathrm{~nm}$ fractions, suspended fraction represents unfiltered leachate concentration minus the $<5 \mathrm{~nm}$ fraction, and $<5 \mathrm{~nm}$ represents fraction of uranium passing through $5 \mathrm{~nm}$ filter. 

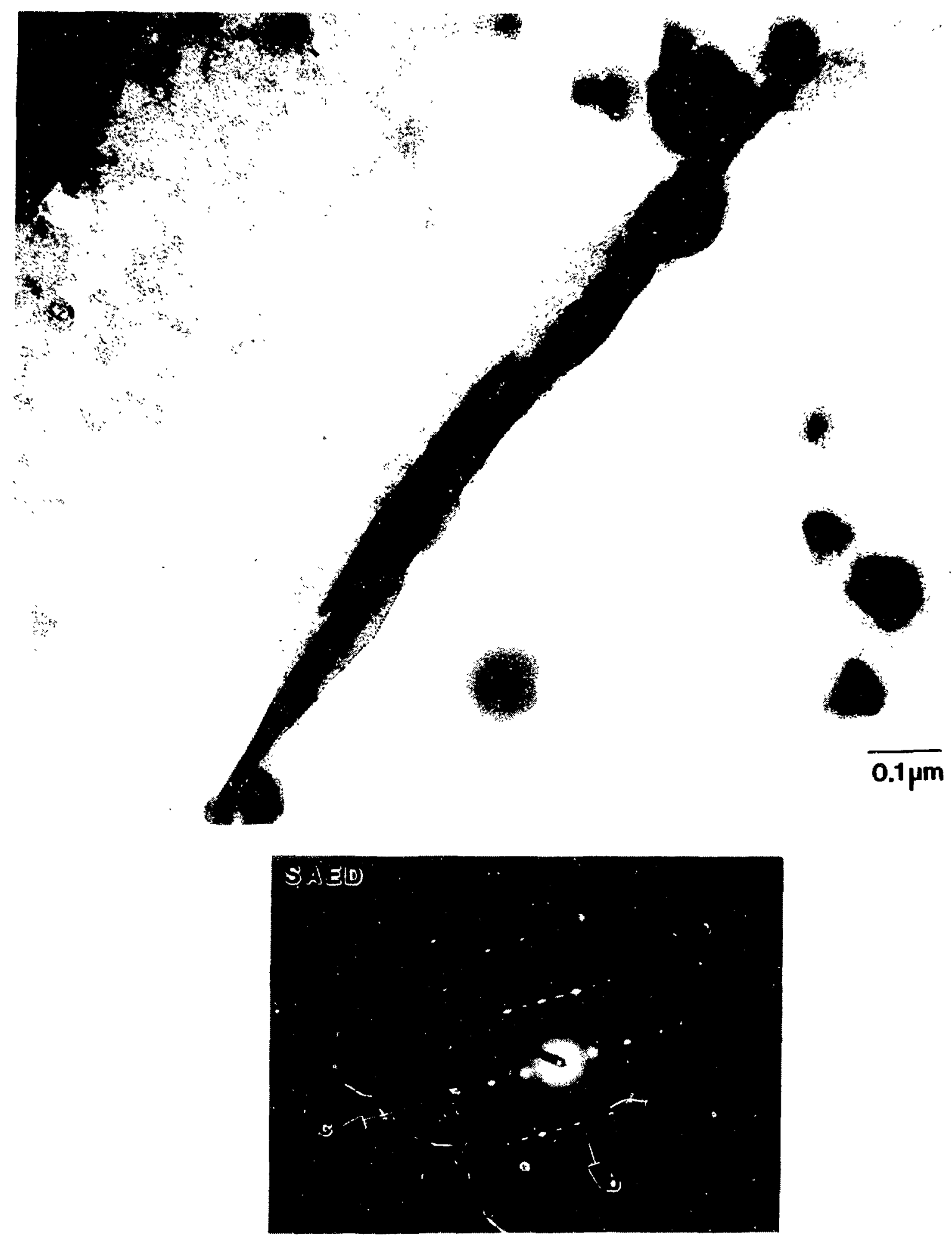

Fig. 15. Suspended Fraction in Solution from Unsaturated Tests with $\mathrm{UO}_{2}$ after Eight Years:

(a) AEM Photomicrograph of Rod-Shaped Uranium Silicate Colloid Particle and

(b) Selected Area Electron Diffraction Pattern from Uranium Silicate Crystal 

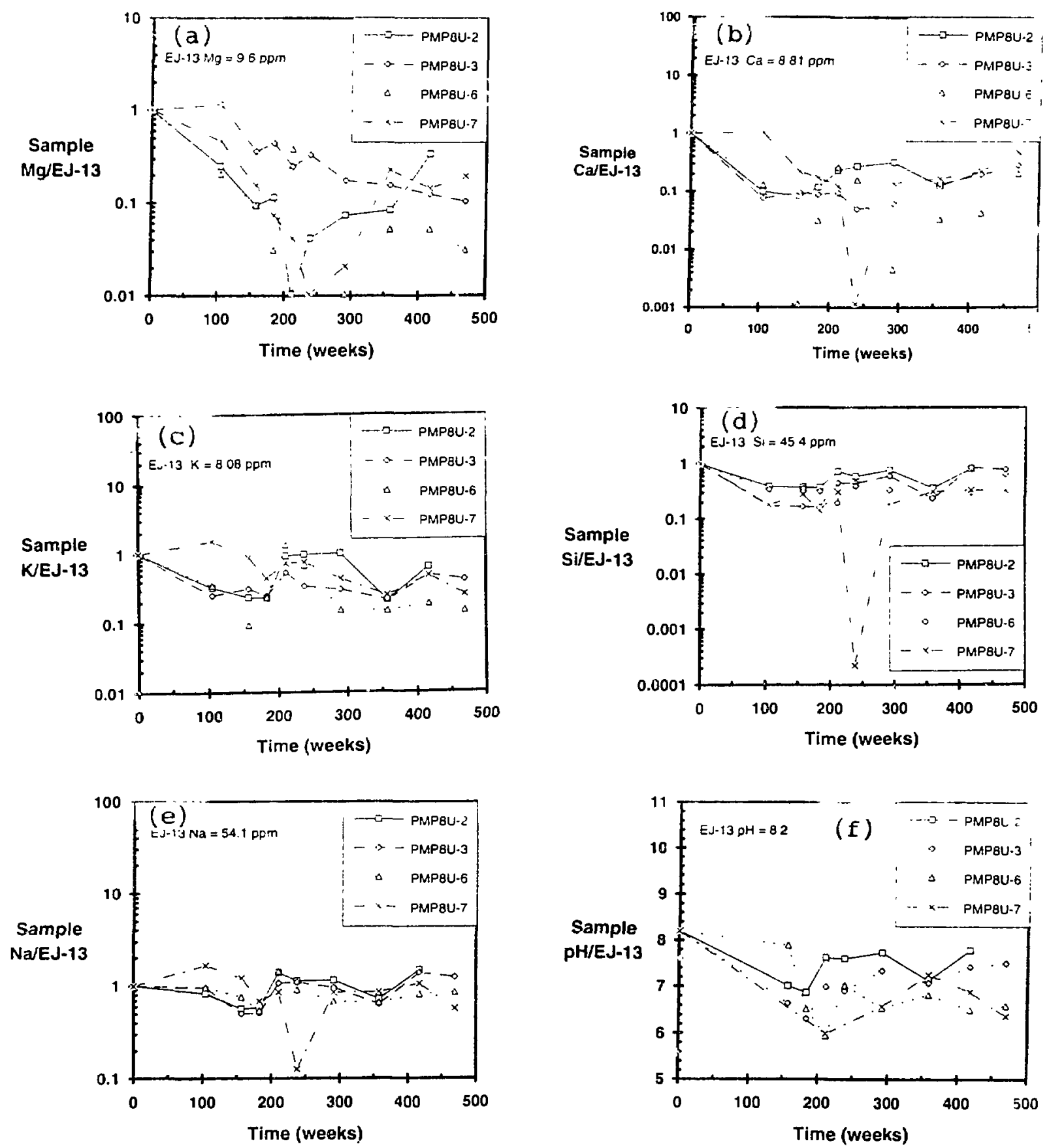

Fig. 16. Leachate Concentrations Normalized to the Concentration of the Starting EJ-13 Leachant in Unsaturated Tests with $\mathrm{UO}_{2}$ Samples: (a) Magnesium, (b) Calcium, (c) Potassium, (d) Silicon, (e) Sodium, and (f) Solution pH Values 
Detailed SEM/EDS analyses of the surfaces of samples terminated during the initial 1-2 year period, during which pulsed uranium release occurred, have revealed the presence of micron-sized fragments of uranium-rich material, apparently produced as corroded and dislodged $\mathrm{UO}_{2+x}$ granules were washed from the sample surface during the biweekly leachant injection. An examination of the altered $\mathrm{UO}_{2+x}$ pellet surfaces has also revealed highly corroded grain boundaries, with individual grains becoming detached from the samples with severe sample corrosion. Detailed photomicrographs of these samples and the reacted $\mathrm{UO}_{2+x}$ surface have been presented in previous ANL reports and by Wronkiewicz et al. [15]. A decrease in the abundance of loosened particulate material was observed during SEM examinations of the post-two-year samples. The SEM/EDS investigations also indicated that the $\mathrm{Mg}, \mathrm{Ca}, \mathrm{Si}$, and $\mathrm{K}$ depletions noted in the solution analyses are paralleled by the incorporation of these elements into uranyl oxide hydrate and uranyl silicate phases that formed on the $\mathrm{UO}_{2+x}$ pellet surfaces.

The top surface of a sample terminated after eight years was dominated by the uranyl alkaline silicate phase, boltwoodite (Fig. 17a) $\left[\mathrm{K}\left(\mathrm{H}_{3} \mathrm{O}\right) \mathrm{UO}_{2}\left(\mathrm{SiO}_{4}\right) \cdot \mathrm{nH}_{2} \mathrm{O}\right]$. Also present were dehydrated schoepite (Fig. 17b) [ $\left.\mathrm{UO}_{3} \cdot 0.8 \mathrm{H}_{2} \mathrm{O}\right]$, uranophane (Fig. 17b)

$\left[\mathrm{Ca}\left(\mathrm{UO}_{2}\right)_{2}\left(\mathrm{SiO}_{3}\right)_{2}(\mathrm{OH})_{2} \cdot 5 \mathrm{H}_{2} \mathrm{O}\right.$ ], soddyite (Fig. 17c) ${ }_{2}^{\mathrm{r}} \mathrm{J}_{6} \mathrm{Si}_{2} \mathrm{O}_{16} \cdot \mathrm{H}_{2} \mathrm{O}$, and hollow-shaped $\mathrm{Mg}-\mathrm{Al}-\mathrm{Si}$ tubes believed to be the clay-mineral palygorskite (attapulgite) (Fig. 17d). This tubeshaped phase had not been observed on any previous samples and helps to explain the "sink" for the magnesium in the EJ-13 leachant, which was strongly depleted in the solutions dripping from the $\mathrm{UO}_{2}$ samples (Fig. 16a). The bottom surface of the sample was characterized by the formation of schoepite (Fig. 18a) [ $\mathrm{UO}_{3} \cdot 2 \mathrm{H}_{2} \mathrm{O}$ ], dehydrated schoepite (Figs. 18b and 18c), and compregnacite (Figs. $18 \mathrm{c}$ and $18 \mathrm{~d}$ ) $\left[\mathrm{K}_{2} \mathrm{U}_{6} \mathrm{O}_{19} \cdot 10 \mathrm{H}_{2} \mathrm{O}\right]$.

Experimental results from these tests have been presented at several conferences the past year, including the 1993 Spent Nuclear Fuels Conference in Santa Fe, New Mexico; the 1993 Geological Society of America's annual meeting in Boston, Massachusetts; and the 1994 Spent Nuclear Fuels Conference in Montebello, Quebec.

\section{E. Discussion}

The decrease in released uranium after the 1-2 year period is thought to result from the formation of a dense surface mat of uranyl silicate phases, which significantly lessened the amount of released particulate material from the $\mathrm{UO}_{2}$ pellet surfaces. After 8-9 years, however, it still appears that uranium release is being dominated by particulate material release, despite the reduction in total uranium loss and the disappearance of micron-sized particulate material from the sample surfaces. With these later tests, it appears that the particulates are finer-grained than those of the 1-2 year samples.

The covering of secondary minerals also does not appear to act as a complete barrier for fluid access to the $\mathrm{UO}_{2+x}$ pellet surface. During SEM examinations of the samples, the granular $\mathrm{UO}_{2}$ surface could still be observed in many locations, even in regions where thick mats of alteration minerals have accumulated.

The SEM/EDS investigations also indicate that these cation components have been incorporated into distinct uranyl-bearing phases that formed on the $\mathrm{UO}_{2+x}$ pellet surfaces. Mineral trends indicate the following paragenetic sequence for the top $\mathrm{UO}_{2+\mathrm{x}}$ surfaces over the past eight years: uraninite $\rightarrow$ uranyl oxide hydrates $\rightarrow$ uranyl silicates $\rightarrow$ uranyl alkaline silicates. This trend is identical to the pattern of uraninite alteration observed in naturally occurring weathered uraninite deposits (Fig. 19) and indicates that the experimental conditions used in these tests replicated the $\mathrm{UO}_{2}$ corrosion process expected to occur in natural geologic systems. 


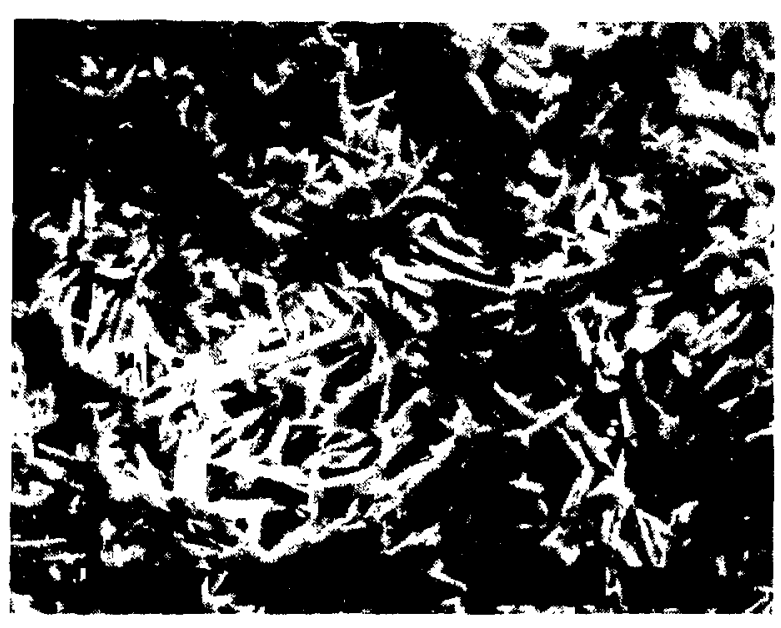

(a)

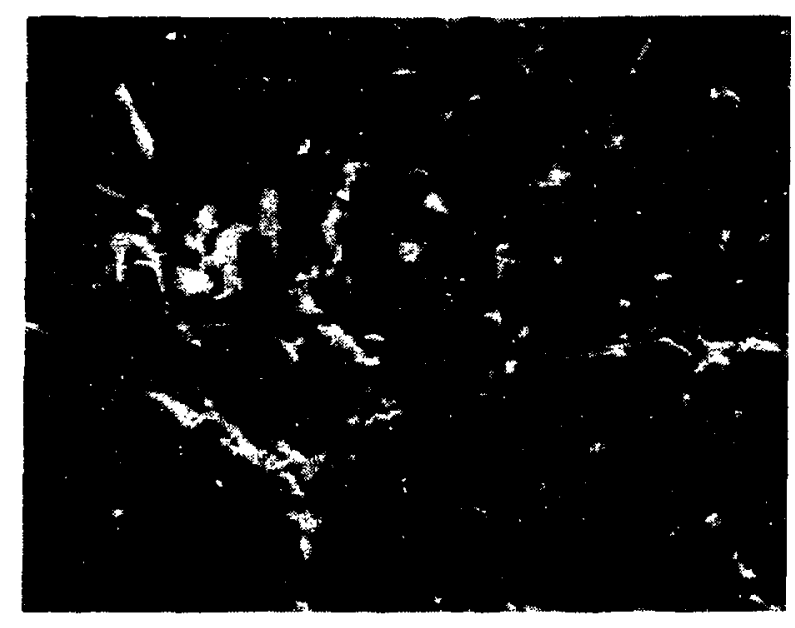

(c)

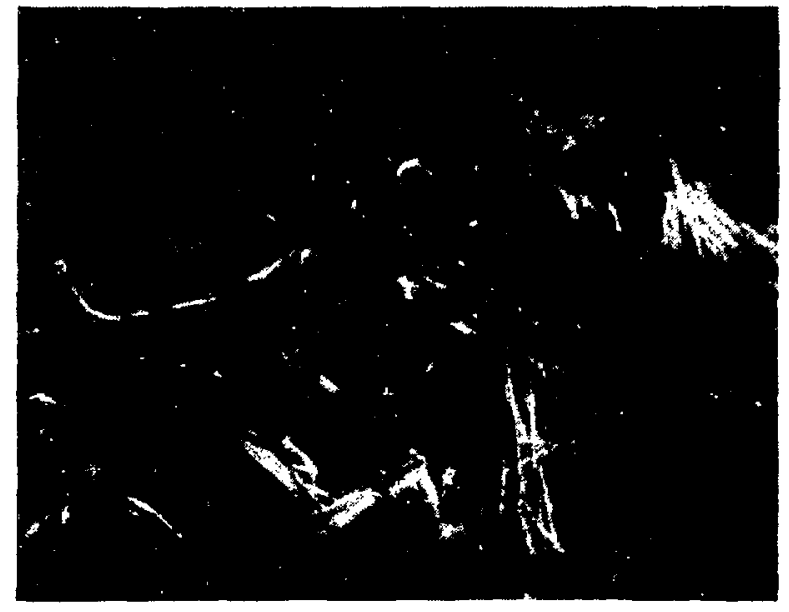

(b)

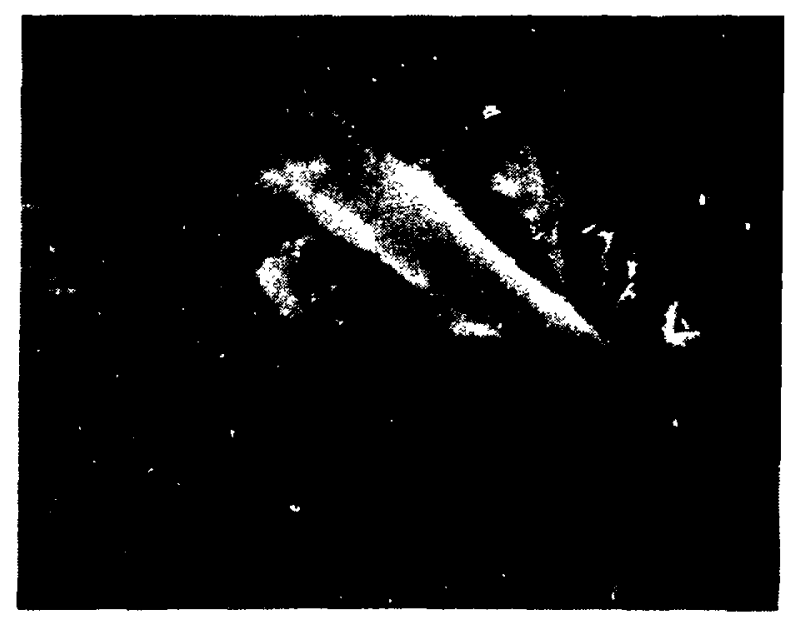

(d)

Fig.17. SEM Photomicrographs for the Top Surface of $\mathrm{UO}_{2}$ Pellet after Eight Years of Reaction: (a) Dense Mat of Boltwoodite Needles, (b) Uranophane Needles and Dehydrated Schoepite "Book-Shaped"-Hexagonal Crystals, (c) Bladed Soddyite Crystals, and (d) Palygorskite Tubes and Dehydrated Schoepite 


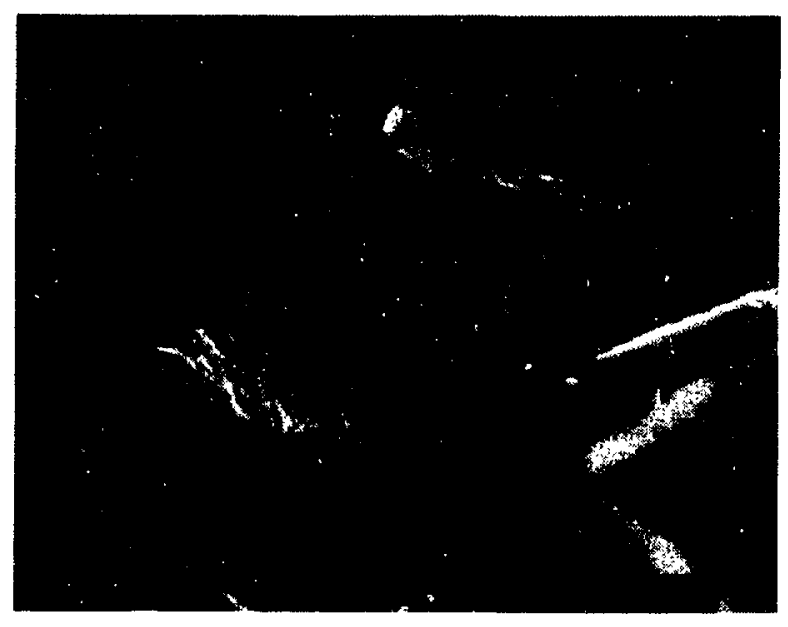

(a)

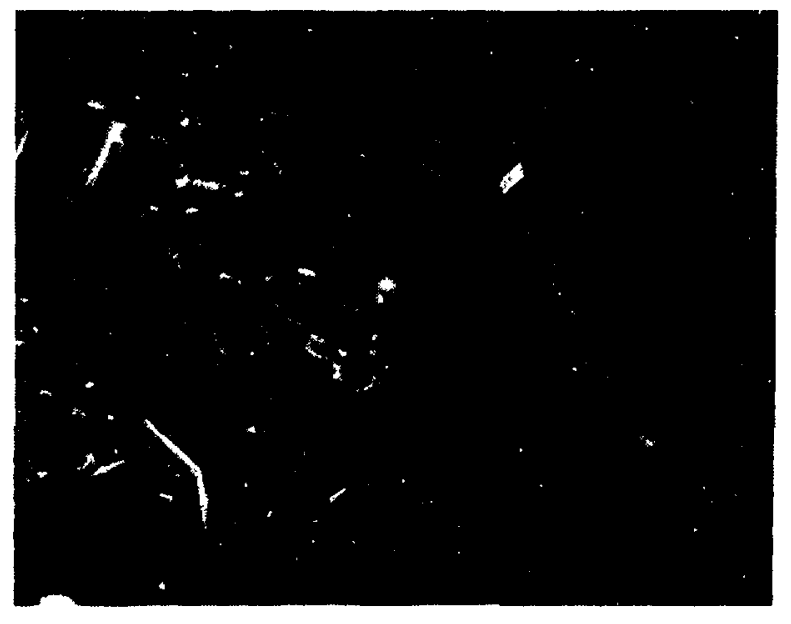

(c)

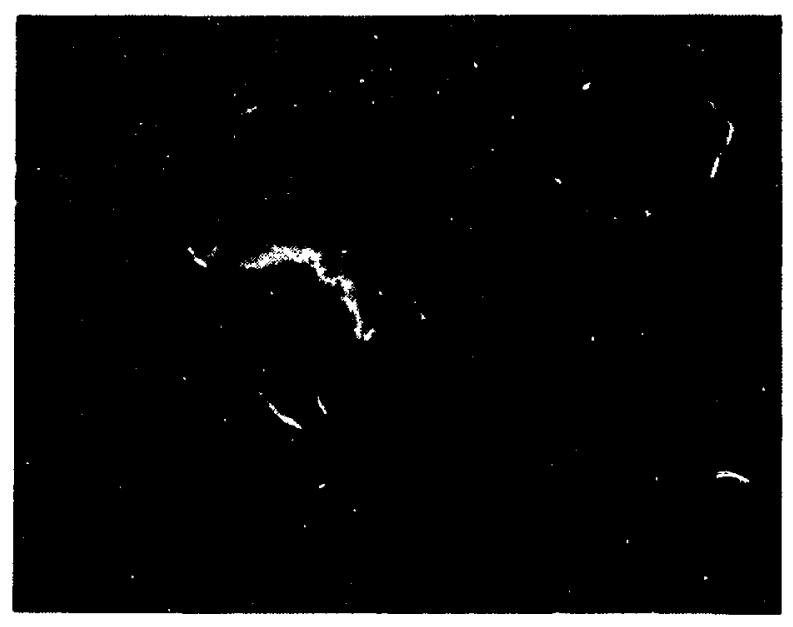

(b)

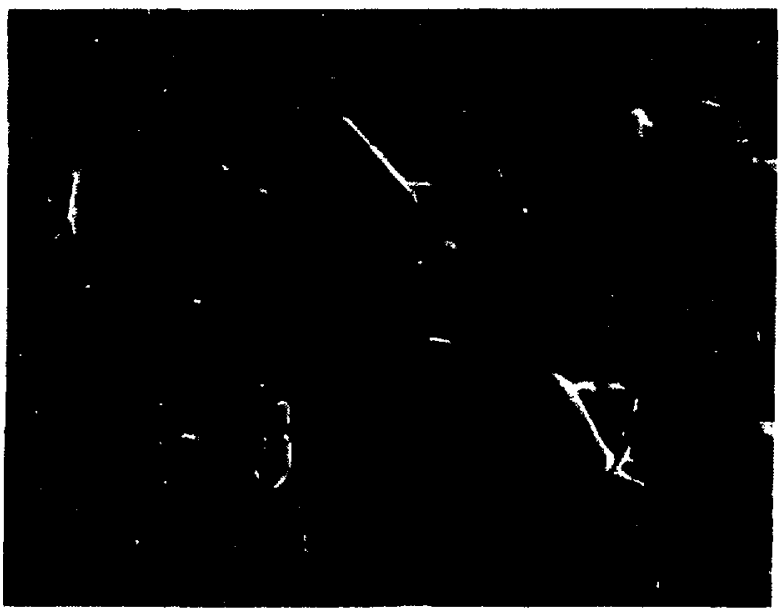

(d)

Fig. 18. SEM Photomicrographs for the Bottom Surface of $\mathrm{UO}_{2}$ Pellet after Eight Years of Reaction: (a) Schoepite Crystals Show: Evidence for Dissolution Pitting, (b) Dehydrated Schoepite "Book-Shaped"-Hexagonal Crystals, (c) Reacted UO Un $_{2+x}$ Surface Showing both Grain and Grain Boundary Dissolution as well as Dislodged Granules, and (d) Compreignacite Crystals 

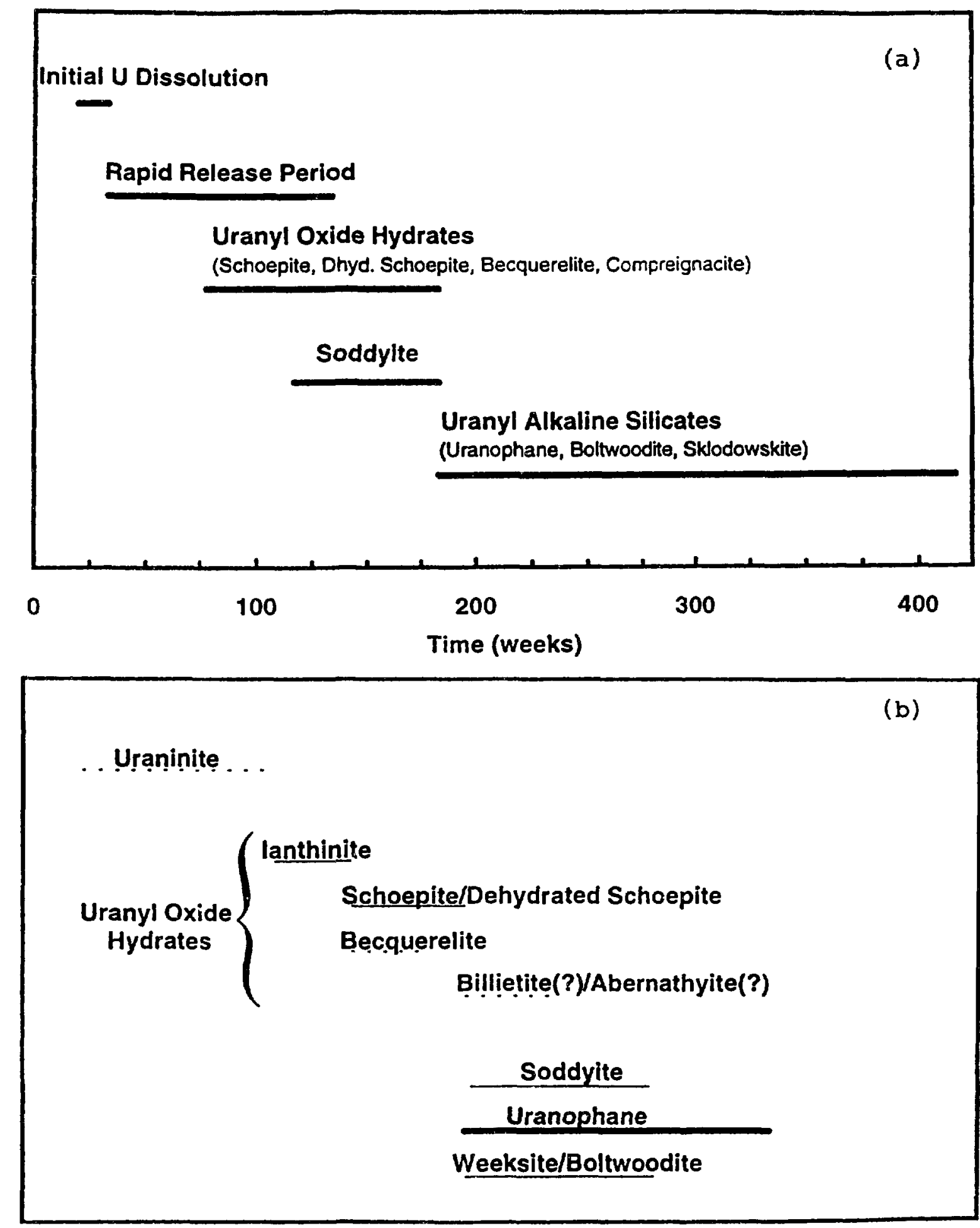

-a-n Time

Fig. 19. Paragenetic Sequence for Uranyl Minerals Formed under Oxidizing Conditions:

(a) Experimental Sequence Formed in Unsaturated Drip Tests with $\mathrm{UO}_{2}$ and (b) Natural Geologic Sequence Formed during the Alteration of Uraninite in the Nopal I, Mexico, Deposit [16] 
It would also be of interest to study in detail the reaction that is occurring at the grain boundaries, with emphasis on the depth into the pellet which the reaction has penetrated. To accomplish this would require a change in the Test Plan governing the work.

\section{F. Conclusions}

The following conclusions were derived from the study of $\mathrm{UO}_{2}$ reactions with dripping EJ-13 groundwater:

(1) During the first 1-? years, the pulsed release of uranium occurred mainly because of the spallation of $\mathrm{CO}_{2}$ granules from the sample surface. The spallation of $\mathrm{UO}_{2}$ granules, in turn, results from the rapid corrosion of intergrain boundary regions. This rapid corrosion of the intergrain boundaries probably results from energetically favorable lattice deformations produced during the press sintering of the $\mathrm{UO}_{2}$ pellets.

(2) After two years cf reaction, the uranium release rate subsided to the present rate of $\sim 0.1$ to $0.3 \mathrm{mg}^{\circ} \mathrm{m}^{-2} \cdot$ day $^{-1}$. The reduction of spalled material probably results from the formation of a cohesive net of alteration minerals on the sample surface that entrap the $\mathrm{UO}_{2}$ granules.

(3) At the rate of 0.1 to $0.3 \mathrm{mg}^{\bullet} \mathrm{m}^{-2} \bullet \mathrm{day}^{-1}$ observed in the longer term tests, $<6 \%$ of the released uranium will pass through a $5 \mathrm{~nm}$ filter.

(4) A distinct sequence of secondary alteration minerals formed on the reacted sample surfaces, starting with uranyl oxide hydrates, followed by uranyl silicates, and finally, uranyl alkali and alkaline earth silicates. This paragenetic sequence of alteration minerals is identical to that found in oxidized zones of naturally occurring uranium deposits. This similarity indicates that the unsaturated drip test method has accurately replicated alteration conditions expected in natural geologic systems, while accelerating the paragenetic sequence of alteration phases formed in natural systems into reasonably short time periods.

(5) The replication of a naturally occurring paragenetic sequence for uranium alteration minerals in these tests provides the first documented evidence for the bridging of short-term laboratory tests with natural analogue systems for uraninite minerals. The replication of naturally occurring geologic phenomenon in these tests will also provide public confidence in the experimental results that are obtained for spent nuclear fuel studies.

\section{G. Ongoing Work}

Three of the initial eight tests are continuing into their ninth year of operation. These samples will continue to be monitored for long-term reaction trends with respect to the release of uranium from the samples and the formation of secondary alteration products. Archived samples will also be cross-sectioned to examine grain boundary corrosion features, formation of alteration minerals within the grain boundaries, and depth of alteration into the samples, if guidance is received from the YMP to do so. 


\section{ACKNOWLEDGMENTS}

Acknowledgment is given to Jeffrey Emery and Joe Hoh for hot-cell support, Lohman Hafenrichter for the carbon analyses, Nancy Dietz for small-particle sample preparation, Delbert Bowers for the anion analyses, Meiling Gong for ICP-MS assistance, and Roberta Riel for manuscript preparation.

This task was performed under the guidance of the Yucca Mountain Site Characterization Project (YMP) and is part of activity D-20-43 in the YMP/Lawrence Livermore National Laboratory Spent Fuel Scientific Investigation Plan. The unsaturated spent fuel testing was initiated with internal Argonne National Laboratory funding. The work was supported by the U.S. Department of Energy, under contract W-31-109-ENG-38. 


\section{REFERENCES}

1. J. K. Bates and T. J. Gerding, Application of the NNWSI Unsaturated Test Method to Actinide Doped SRL 165 Type Glass, Argonne National Laboratory Report ANL-89/24 (1990).

2. J. K. Bates, J. P. Bradley, A. Teetsov, C. R. Bradley, and M. Bucholtz ten Brink, "Colloid Formation During Waste Form Reaction: Implication for Nuclear Waste Disposal," Science 256, 649-651 (1992).

3. G. D. Maupin, W. M. Bowen, and J. L. Daniel, Fabrication and Characterization of MCC Approved Testing Material-ATM-10 Glass, Pacific Northwest Laboratory Report PNL-5577-10 (1988).

4. A. B. Woodland, J. K. Bates, and T. J. Gerding, Parametric Effects on Glass Reaction in the Unsaturated Test Method, Argonne National Laboratory Report, ANL-91/36 (1991).

5. D. M. Strachan, B. P. McGrail, M. J. Apted, D. W. Engle, and P. W. Eslinger, Preliminary Assessment of the Controlled Release of Radionuclides from Waste Packages Containing Borosilicate Waste Glasses, Pacific Northwest Laboratory Report PNL-7591 (1990).

6. P. A. Finn, J. K. Bates, J. C. Hoh, J. W. Emery, L. D. Hafenrichter, E. C. Buck, and M. Gong, "Elements Present in Leach Solutions from Unsaturated Spent Fuel Tests," Mater. Res. Soc. Symp. Proc. $\underline{333}$, 399-407 (1994).

7. P. A. Finn, M. Gong, J. K. Bates, J. W. Emery, and J. C. Hoh, "The Effect of Fuel Type in Unsaturated Spent Fuel Test," Proc. Fifth Annual Int. Conf. on High Level Radioactive Waste Manage., Las Vegas, Nevada, pp. 1080-1087 (1994).

8. R. J. Guenther, D. E. Blahnik, T. K. Campbell, U. P. Jenquin, J. E. Mendel, L. E. Thomas, and C. K. Thornhill, Characterization of Spent Fuel Approved Testing Material - ATM-103, Pacific Northwest Laboratory Report PNL-5109-103 (1988).

9. R. J. Guenther, D. E. Blahnik, T. K. Campbell, U. P. Jenquin, J. E. Mendel, and C. K. Thornhill, Characterization of Spent Fuel Approved Testing Material - ATM-106, Pacific Northwest Laboratory Report PNL-5109-106 (1988).

10. J. K. Bates, J. P. Bradley, A. Teetsov, C. R. Bradley, and M. Bucholtz ten Brink, "Colloid Formation During Waste Form Reaction: Implication for Nuclear Waste Disposal," Science 256, 649-651 (1992).

11. R. S. Forsyth and L. O. Werme, Spent Fuel Corrosion and Dissolution, Swedish Nuclear Fuel and Waste Management Report SKB-91-60 (1991).

12. J. F. Kerrisk and R. J. Silva, "A Consistent Set of Thermodynamic Constants for Americium(III) Species with Hydroxyl and Carbonate," Proc. Workshop on Geochemical Modeling, CONF-8609134, pp. 167-175 (1986).

13. C. N. Wilson, Results from NNWSI Series 3 Spent Fuel Dissolution Tests, Pacific Northwest Laboratory Report PNL-7170 (1990). 
14. S. Stroes-Gascoyne, L. H. Johnson, P. A. Beeley, and D. M. Sellinger, "Dissolution of Used CANDU Fuel at Various Temperatures and Redox Conditions," Mater. Res. Soc. Symp. Proc. 50, 317-326 (1986).

15. D. J. Wronkiewicz, J. K. Bates, T. J. Gerding, E. Veleckis, and B. S. Tani, "Uranium Release and Secondary Phase Formation during Unsaturated Testing of $\mathrm{UO}_{2}$ at $90^{\circ} \mathrm{C}$," $\mathrm{J}$. Nucl. Mater. 190, 107-127 (1992).

16. B. W. Leslie, E. C. Pearcy, and J. D. Prikryl, "Oxidative Alteration of Uraninite at the Nopal I Deposit, Mexico: Possible Contaminant Transport and Source Term Constraints for the Proposed Repository at Yucca Mountain," Mater. Res. Soc. Symp. Proc. 294, 505-512 (1993). 
Distribution for ANL-94/42

Internal:
J. K. Bates (35)
J. Fortner
J. J. Laidler
E. C. Buck
J. E. Harmon
C. C. McPheeters
J. C. Cunnane
J. E. Helt
S. F. Wolf
J. W. Emery
J. C. Hoh
P. A. Finn
T. R. Johnson
D. J. Wronkiewicz TIS Files

\section{External:}

DOE-OSTI (2)

ANL-E Library (2)

ANL-W Library

Manager, Chicago Operations Office, DOE

A. Bindokas, DOE-CH

J. Haugen, DOE-CH

Chemical Technology Division Review Committee Members:

E. R. Beaver, Monsanto Company, St. Louis, MO

D. L. Douglas, Consultant, Bloomington, $\mathrm{MN}$

R. K. Genung, Oak Ridge National Laboratory, Oak Ridge, TN

J. G. Kay, Drexel University, Philadelphia, PA

G. R. St. Pierre, Ohio State University, Columbus, $\mathrm{OH}$

J. Stringer, Electric Power Research Institute, Palo Alto, CA

J. B. Wagner, Arizona State University, Tempe, AZ

T. Ahn, U. S. Nuclear Regulatory Commission, Washington, DC

D. H. Alexander, USDOE, Civilian Radioactive Waste Management, Washington, DC

J. Allison, USDOE, Office of Waste Operations, Germantown, MD

S. Bates, Idaho Falls, ID

H. Benton, B\&W Fuel Company, Las Vegas, NV

A. Berusch, USDOE, Office of Civilian Radioactive Waste Management, Washington, DC

N. E. Bibler, Westinghouse Savannah River Company, Aiken, SC

J. M. Boak, USDOE, Yucca Mountain Site, Las Vegas, NV

K. Boomer, Westinghouse Hanford Company, Richland, WA

W. Bourcier, Lawrence Livermore National Laboratory, Livermore, CA

E. Bramlitt, Defense Nuclear Agency, Kirtland Air Force Base, Kirtland, NM

A. Brandstetter, Science Applications, International Corporation, Las Vegas, NV

N. R. Brown, USDOE, Richland Operations Office, Richland, WA

J. Bucher, Lawrence Berkeley Laboratory, Berkeley, CA

J. Canepa, Los Alamos National Laboratory, Los Alamos, NM

K. A. Chacey, USDOE, Office of Waste Management, Germantown, MD

D. Chestnut, Lawrence Livermore National Laboratory, Livermore, CA

G. R. Choppin, Florida State University, Tallahassee, FL

S. Clark, University of Georgia, Savannah River Ecology Laboratory, Aiken, SC 
P. Cloke, Science Applications International Corp., Las Vegas, NV

M. O. Cloninger, Mac Technical Services, Inc., Richland, WA

D. Codell, U. S. Nuclear Regulatory Commission, Washington, DC

G. Colten-Bradley, U. S. Nuclear Regulatory Commission, Rockville, MD

C. Colter, Los Alamos National Laboratory, Los Alamos, NM

S. Coplan, U. S. Nuclear Regulatory Commission, Washington, DC

S. P. Cowan, USDOE, Office of Waste Management, Germantown, MD

J. Davidson, U. S. Environmental Protection Agency, Washington, DC

J. Docka, Roy F. Weston, Inc., Washington, DC

R. Dresser, Roy F. Weston, Inc., Washington, DC

R. S. Dyer, Yucca Mountain Project Office, Las Vegas, NV

R. E. Erickson, USDOE, Office of Waste Operations, Germantown, MD

E. Essington, Los Alamos National Laboratory, Los Alamos, NM

F. M. Estes, Idaho State University, Pocatello, ID

R. C. Ewing, Department of Geology, University of New Mexico, Albuquerque, NM

D. Farr, Los Alamos National Laboratory, Los Alamos, NM

R. Fish, B\&W Fuel Company, Las Vegas, NV

J. Gauthier, Sandia National Laboratories, Albuquerque, NM

F. Gelbard, Sandia National Laboratories, Albuquerque, NM

C. P. Gertz, USDOE, Yucca Mountain Project Office, Las Vegas, NV

S. E. Gomberg, USDOE, Office of Civilian Radioactive Waste Management, Washington, DC

W. Gray, Battelle Pacific Northwest Laboratory, Richland, WA

P. W. Hart, USDOE, Office of Technology Development, Germantown, MD

J. Hennessey, USDOE, Office of Waste Operations, Germantown, MD

D. Hobart, LANL-TTSO/USDOE Headquarters, Germantown, MD

J. Hunt, University of California, Berkeley, Berkeley, CA

D. Hutchins, Martin Marietta Systems, Inc., Oak Ridge, TN

C. Interrante, U. S. Nuclear Regulatory Commission, Washington, DC

C. Jantzen, Westinghouse Savannah River Company, Aiken, SC

L. J. Jardine, Lawrence Livermore National Laboratory, Livermore, CA

P. Kearl, Oak Ridge National Laboratory, Grand Junction, CO

J. Keith, Daniel B. Stephens \& Associates, Albuquerque, NM

J. Kerrisk, Los Alamos National Laboratory, Los Alamos, NM

W. S. Ketola, USDOE, West Valley Project Office, West Valley, NY

D. A. Knecht, Lockheed Idaho Technology Company, Idaho Falls, ID

W. L. Kuhn, Battelle Pacific Northwest Laboratory, Richland, WA

K. S. Kung, Los Alamos National Laboratory, Los Alamos, NM

J. H. Lee, Intera, Las Vegas, NV

W. Lee, Environmental Evaluation Group, Albuquerque, NM

W. W. Lee, University of California, Berkeley, CA

J. C. Lehr, USDOE, Office of Environmental Restoration, Germantown, MD

H. Leider, Lawrence Livermore National Laboratory, Livermore, CA

R. A. Lemons, Los Alamos National Laboratory, Los Alamos, NM

S. Levy, Los Alamos National Laboratory, Los Alamos, NM

D. Livingston, USDOE, Yucca Mountain Site, Las Vegas, NV

R. Lopez, Los Alamos National Laboratory, Los Alamos, NM 
J. J. Lorenz, USDOE, Yucca Mountain Site, Las Vegas, NV

R. Luce, Nuclear Waste Technical Review Board, Arlington, VA

W. Lutze, University of New Mexico, Albuqueque, NM

H. Manaktala, Southwest Research Institute, San Antonio, TX

S. Martin, Lawrence Livermore National Laboratory, Livermore, CA

J. M. Matuszek, JMM Consulting, Del Mar, NY

J. McCarthy, Oak Ridge National Laboratory, Oak Ridge, TN

L. McDowell-Boyer, Oak Ridge National Laboratory, Grand Junction, CO

T. W. McIntosh, USDOE, Office of Waste Management, Germantown, MD

J. Meldrum, University of Nevada - Las Vegas, Las Vegas, NV

A. Mitchell, Los Alamos National Laboratory, Los Alamos, NM

R. Morissette, Science Applications International Corp., Las Vegas, NV

D. Morris, Los Alamos National Laboratory, Los Alamos, NM

P. K. Nair, Southwest Research Institute, San Antonio, TX

S. Nelson, Las Vegas, NV

B. Newman, Los Alamos National Laboratory, Los Alamos, NM

C. Novak, Sandia National Laboratories, Albuquerque, NM

E. Nuttall, University of New Mexico, Albuquerque, NM

W. O'Connell, Lawrence Livermore National Laboratory, Livermore, CA

G. C. S. Ordaz, USDOE, Office of Technology Development, Germantown, MD

C. Palmer, Lawrence Livermore National Laboratory, Livermore, CA

R. Palmer, West Valley Nuclear Services, West Valley, NY

H. Papenguth, Sandia National Laboratories, Albuquerque, NM

U-Sun Park, Science Applications International Corp., Las Vegas, NV

W. D. Pearson, Westinghouse Savannah River Company, Aiken, SC

C. Peterson, U. S. Nuclear Regulatory Commission, Washington, DC

T. H. Pigford, University of California, Berkeley, CA

M. J. Plodinec, Westinghouse Savannah River Company, Aiken, SC

W. Polzer, Los Alamos National Laboratory, Los Alamos, NM

W. G. Ramsey, Westinghouse Savannah River Company, Aiken, SC

P. Reimus, Los Alamos National Laboratory, Los Alamos, NM

B. Robinson, Los Alamos National Laboratory, Los Alamos, NM

P. Rogers, Los Alamos National Laboratory, Los Alamos, NM

R. Rundberg, Los Alamos National Laboratory, Los Alamos, NM

C. G. Russomanno, USDOE, Civilian Radioactive Waste Management, Washington, DC

J. Ryan, University of Colorado, Boulder, $\mathrm{CO}$

R. Schulze, Los Alamos National Laboratory, Los Alamos, NM

W. C. Schutte, USDOE, Office of Technology Development, Germantown, MD

R. Sherman, Los Alamos National Laboratory, Los Alamos, NM

M. Siegel, Sandia National Laboratories, Albuquerque, NM

M. Silva, Environmental Evaluation Group, Albuquerque, NM

R. Silva, Lawrence Livermore National Laboratory, Livermore, CA

A. Simmons, USDOE, Las Vegas, NV

E. Springer, Los Alamos National Laboratory, Los Alamos, NM

J. Sproull, Westinghouse Savannah River Company, Aiken, SC

D. Stahl, M\&O/B\&W Fuel Company, Las Vegas, NV 
W. Steinkampf, U.S. Geological Survey, Lakewood, CO

L. Stetzenbach, University of Nevada - Las Vegas, Las Vegas, NV

R. B. Stout, Lawrence Livermore National Laboratory, Livermore, CA

D. Strachan, Battelle Pacific Northwest Laboratories, Richland, WA

M. Tomozawa, Rensselaer Polytechnic Institute, Troy, NY

I. Triay, Los Alamos National Laboratory, Los Alamos, NM

V. Trice, USDOE, Office of Waste Management, Germantown, MD

D. Turner, Southwest Research Institute, San Antonio, TN

B. Viani, Lawrence Livermore National Laboratory, Livermore, CA

J. Wan, New Mexico Tech, Socorro, NM

L. Wang, University of New Mexico, Albuquerque, NM

R. Weiner, Environmental Evaluation Group, Albuquerque, NM

M. Whitbeck, Desert Research Institute, University of Nevada, Reno, NV

C. N. Wilson, Westinghouse Hanford Company, Richland, WA

J. Wilson, New Mexico Tech, Socorro, NM

M. Wilson, Sandia National Laboratories, Albuquerque, NM

A. Wistrom, Los Alamos National Laboratory, Los Alamos, NM

J. H. Wolfram, Biotechnology-INTEL, Montana State University, Bozeman, MT

K. Wolfsberg, Los Alamos National Laboratory, Los Alamos, NM

A. Wollerman, Science Applications International Corp., Germantown, MD

A. Yang, U.S. Geological Survey, Denver, CO

M. P. Gardiner, Harweli Laboratory, Didcot, Oxon, UNITED KINGDOM

B. Grambow, Kernforschungszentrum Karlsruhe, GmbH, GERMANY

J. Kim, Kernforschungszentrum Karlsruhe, GERMANY

H. Nitsche, Forschungszentrum Rossendorf e.V., Institut fur Radiochemie, GERMANY

T. Payne, Australian Nuclear Science and Technology Organization, AUSTRALIA

P. Van Isegham, Boerecamp, BELGIUM

E. Vernaz, Centre d'Etudes Nucleares de la Valle du Rhone, Marcoule, FRANCE

P. Vilks, Atomic Energy of Canada, Whiteshell Laboratories, Pinawa, Manitoba, CANADA

L. Werme, Svensk Karnbranslehantering AB, Stockholm, SWEDEN 